\title{
Report Title: Microporous Metal Organic Materials for Hydrogen Storage
}

\author{
Type of Report: Final Scientific Report
}

Reporting Period: Start Date: June 24, 2005

End Date: November 23, 2008

\section{Principal Authors: S.G. Sankar, Jing Li and Karl Johnson}

Date Report was Issued: January 2009

DOE Award Number: DE-FC26-05NT42446

Names and Addresses of Submitting Organizations:

Advanced Materials Corporation

850 Poplar Street, Pittsburgh, PA 15220

Contact: S.G. Sankar

E-mail: sankar@advanced-material.com

Tel: (412) $9219600 \times 2223$

Fax: (412) 9211790

Sub-Contract Participants:

Rutgers - The State University of New Jersey

Contact: Jing Li

E-mail: jingli@rutchem.rutgers.edu

Tel: (732) 4453758

And

The University of Pittsburgh

Contact: Karl Johnson

E-mail: karlj@puccini.che.pitt.edu

Tel: (412) 6245644 


\section{DISCLAIMER}

This report was prepared as an account of work sponsored by an agency of the United States Government. Neither the United States Government nor any agency thereof, nor any of their employees, makes any warranty, express or implied, or assumes any legal liability or responsibility for the accuracy, completeness or usefulness of any information, apparatus, product, or process disclosed, or represents that its use would not infringe privately owned rights. Reference herein to any specific commercial product, process, or service by trade name, trademark, manufacturer, or otherwise does not necessarily constitute or imply its endorsement, recommendation, or favoring by the United States Government or any agency thereof. The views and opinions of authors expressed herein do not necessarily state or reflect those of the United States Government or any agency thereof. 


\section{ABSTRACT}

We have examined a number of Metal Organic Framework Materials for their potential in hydrogen storage applications. Results obtained in this study may, in general, be summarized as follows:

1. We have identified a new family of porous metal organic framework materials with the compositions $\mathrm{M}$ (bdc) (ted) $0.5,\{\mathrm{M}=\mathrm{Zn}$ or $\mathrm{Co}$, bdc= biphenyl dicarboxylate and ted= triethylene diamine $\}$ that adsorb large quantities of hydrogen $(\sim 4.6 \mathrm{wt} \%)$ at $77 \mathrm{~K}$ and a hydrogen pressure of $50 \mathrm{~atm}$. The modeling performed on these materials agree reasonably well with the experimental results.

2. In some instances, such as in $\mathrm{Y}_{2}(\mathrm{sdba})_{3}$, even though the modeling predicted the possibility of hydrogen adsorption (although only small quantities, $\sim 1.2 \mathrm{wt} \%, 77 \mathrm{~K}, 50 \mathrm{~atm}$. hydrogen), our experiments indicate that the sample does not adsorb any hydrogen. This may be related to the fact that the pores are extremely small or may be attributed to the lack of proper activation process.

3. Some samples such as $\mathrm{Zn}$ (tbip) (tbip= 5-tert butyl isophthalate) exhibit hysteresis characteristics in hydrogen sorption between adsorption and desorption runs. Modeling studies on this sample show good agreement with the desorption behavior. It is necessary to conduct additional studies to fully understand this behavior.

4. Molecular simulations have demonstrated the need to enhance the solid-fluid potential of interaction in order to achieve much higher adsorption amounts at room temperature. We speculate that this may be accomplished through incorporation of light transition metals, such as titanium and scandium, into the metal organic framework materials. 


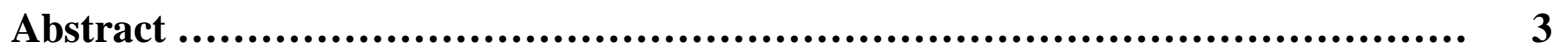

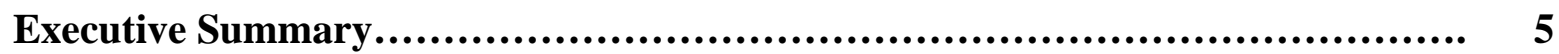

I. Synthesis, Sample Characterization and Low Pressure Adsorption Studies ........ 6

II. Gas Sorption Properties of the Microporous MOFs............................ 25

III. Gas Sorption Measurements at High Pressures................................ 28

IV. Molecular Modeling Results .............................................. 29

V. Conference Presentations, Invited Talks and Publications ...................... 90 


\section{EXECUTIVE SUMMARY}

Recent research work has shown that Metal Organic Frameworks (MOFs) offer a potential for large hydrogen storage, especially at cryogenic temperatures. The objective of the research undertaken is to synthesize new compositions of microporous MOFs, examine their storage capacities at liquid nitrogen temperature and at room temperature and to employ molecular modeling to understand the characteristics of the isotherms. Through a combination of these approaches, we proposed to enhance the basic understanding of these materials that would lead to the synthesis of new and improved MOFs. Advanced Materials Corporation (AMC) has teamed up with Rutgers University and the University of Pittsburgh to conduct this research. During this contract, Rutgers University has synthesized nearly forty five new crystal structures and characterized them thoroughly employing powder x-ray diffraction, thermogravimetry and low-temperature, low-pressure hydrogen adsorption measurements. A few of these compositions that showed a reasonable amount of hydrogen adsorption ( $\sim 1 \mathrm{wt} \%$ or greater) were examined by Advanced Materials Corporation employing a Pressure-Composition Isotherm measurement instrument at pressures up to $\sim 50$ atmospheres of hydrogen. For base line studies, we have synthesized and examined the properties of MOF-5 and HKUST-1, whose properties are widely reported in the literature. The University of Pittsburgh group has conducted molecular modeling studies. In the following, we describe our work performed during the contract period.

Results obtained during this period may, in general, be summarized as follows:

1. We have identified a new family of porous metal organic framework materials with the compositions $\mathrm{M}$ (bdc) (ted) $)_{0.5},\{\mathrm{M}=\mathrm{Zn}$ or $\mathrm{Co}$, bdc= biphenyl dicarboxylate and ted= triethylene diamine $\}$ that adsorb large quantities of hydrogen $(\sim 4.6 \mathrm{wt} \%)$ at $77 \mathrm{~K}$ and a hydrogen pressure of $50 \mathrm{~atm}$. The modeling performed on these materials agree reasonably well with the experimental results.

2. In some instances, such as in $\mathrm{Y}_{2}(\mathrm{sdba})_{3}$, even though the modeling predicted the possibility of hydrogen adsorption (although only small quantities, $\sim 1.2 \mathrm{wt} \%, 77 \mathrm{~K}, 50 \mathrm{~atm}$. hydrogen), our experiments indicate that the sample does not adsorb any hydrogen. This may be related to the fact that the pores are extremely small or may be attributed to the lack of proper activation process.

3. Some samples such as $\mathrm{Zn}$ (tbip) (tbip= 5-tert butyl isophthalate) exhibit hysteresis characteristics in hydrogen sorption between adsorption and desorption runs. Modeling studies on this sample show good agreement with the desorption behavior. It is necessary to conduct additional studies to fully understand this behavior.

4. Molecular simulations have demonstrated the need to enhance the solid-fluid potential of interaction in order to achieve much higher adsorption amounts at room temperature. We speculate that this may be accomplished through incorporation of light transition metals, such as titanium and scandium, into the metal organic framework materials. 


\section{SYNTHESIS, SAMPLE CHARACTERIZATION AND LOW PRESSURE ADSORPTION STUDIES}

The main focus of the Rutgers team has been on the design, synthesize, and structurally characterize new metal organic frameworks that are lightweight, thermally stable and highly porous. They are promising candidates for use as hydrogen storage media because of the following advantageous features: (a) The building units (metals and ligands) of these microporous MOFs can be controlled and tuned so that the sizes/dimensions of the pores are optimum for hydrogen adsorption. (b) The crystal structures of the MMOFs can be tailored to have metals with unsaturated coordination or hydrogen bonds that will lead to a stronger interaction between the host and hydrogen and (c) the MMOFs can be synthesized via simple and cost effective routes with high purity and in large quantities.

During this contract period, the Rutgers team has performed the design and synthesis, as well as structure and pore characterization, of new microporous metal-organic frameworks (MMOFs) as promising hydrogen storage materials. Forty-five new crystal structures were discovered in the duration of this project, among which twenty-six are microporous. Typical hydrothermal and/or solvothermal synthetic methods were employed in the single crystal growth and pure-phase bulk sample prepraration of the MOFs that are reported herein. Other than the X-ray diffraction studies for determining the structures of these MMOFs, thermogravimetric analysis and gas sorption (argon and hydrogen) studies were also employed to fully characterize the properties and behaviour of these materials.

Starting from the second year of the project, we initiated organic syntheses of ligands with predesigned structures and chemical functionalities in order to further diversify the possibility of the combination of the organic and inorganic components of MOFs and enhance the opportunity of discovering new MOF materials.

During the performance of this research, a few intersting non-porous metal-organic frameworks were also discovered. Their single crystal growth and bulk sample preparation were also carried out hydro/solvothermally in solvents such as water and dimethylformamide at elevated temperatures from $100{ }^{\circ} \mathrm{C}$ to $150^{\circ} \mathrm{C}$. Due to their limited relevance to this project, only the single crystal strcutural data are included in Table 1, together with those of the porous MOFs.

Syntheses of new organic ligands, and the syntheses, structures, and hydrogen sorption properties of the MMOFs are reported in detail below:

\section{A. Syntheses of new organic ligands}

\section{(1) 4,4'-Azopyridine (APy)}

A solution of 4-aminopyridine $(4.24 \mathrm{~g}, 98 \%, 44.1 \mathrm{mmol})$ in water $(80 \mathrm{~mL})$ was added dropwise into a two-neck round bottom flask containing commercial bleach (Clorox ${ }^{\circledR}, 5.5 \mathrm{wt} \% \mathrm{NaClO}$, being chilled in ice-water bath and magnetically stirred) over a period of $1 \mathrm{hr}$. The mixture was stirred for another $30 \mathrm{~min}$ before the orange-colored precipitate was filtered and the filtrate extracted with diethyl ether $(200 \mathrm{~mL} \times 3)$. The precipitate was then re-dissolved in diethyl ether and combined with the diethyl ether extracts. The ether solution was then washed with brine (saturated, $300 \mathrm{~mL}$ ) and dried over anhydrous sodium sulfate for $20 \mathrm{~min}$. The solvent was, 
thereafter, evaporated on a rotary evaporator to afford the orange-red, crude product. After purification by flash chromatography (silica gel, 230-400 mesh, dichloromethane/methanol = 96/4 as eluent), the pure product was obtained as an orange-colored, crystalline solid (needles, $2.61 \mathrm{~g}, 64 \%$ yield based on 4-aminopyridine). ${ }^{1} \mathrm{H}$ NMR $\left(200 \mathrm{MHz}, \mathrm{CDCl}_{3}\right): 7.75(\mathrm{~d}, 4 \mathrm{H}, J=6.2$ $\mathrm{Hz}), 8.88$ (d, $6 \mathrm{H}, J=6.2 \mathrm{~Hz}) .{ }^{13} \mathrm{C} \mathrm{NMR}\left(50 \mathrm{MHz}, \mathrm{CDCl}_{3}\right): 116.5,151.9,156.8$.

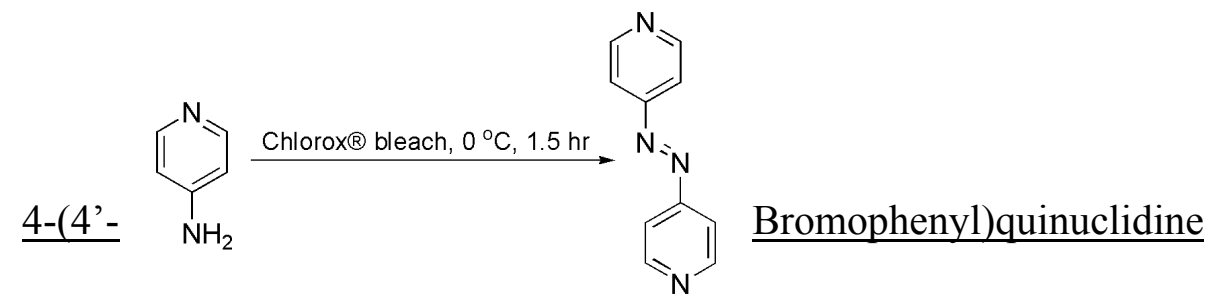

Under a nitrogen atmosphere, bromine $(3.75 \mathrm{~mL}, 99.5 \%, 72.7 \mathrm{mmol})$ was injected into an acetic acid solution (glacial, $24 \mathrm{~mL}$ ) of 4-phenylquinuclidine $(0.69 \mathrm{~g}, 98 \%, 3.6 \mathrm{mmol})$. The mixture was then heated to reflux for $3 \mathrm{hrs}$. The mixture was cooled to room temperature and then poured into saturated $\mathrm{NaOH}$ solution in water (chilled in ice water bath) slowly and with stirring. The light yellow precipitate was filtered and washed copiously with water. After purification by flash chromatography (silica gel, 230-400 mesh, dichloromethane /methanol/concentrated ammonium hydroxide $=90 / 9 / 1$ as eluent), the beige-colored pure product 4-(4'-bromophenyl)quinuclidine was obtained by evaporating the solvent in vacuo (0.685 g after being dried under vacuum, $71 \%$ based on 4-phenylquinuclidine). Melting point (in sealed capillary tube, uncorrected): 400-401 ${ }^{\circ} \mathrm{C}$. ${ }^{1} \mathrm{H}$ NMR (200 MHz, methanol-d): 1.85 (t, 6H, $\left.J=7.8 \mathrm{~Hz}\right), 3.04$ (t, 6H, $J=7.8 \mathrm{~Hz}$ ), 4.22-7.46 $(\mathrm{dd}, 4 \mathrm{H}, J=8.6 \mathrm{~Hz}) .{ }^{13} \mathrm{C}$ NMR $(50 \mathrm{MHz}$, methanol-d): 32.4, 33.0, 48.7, 120.9, 128.8, 132.4, 148.6.

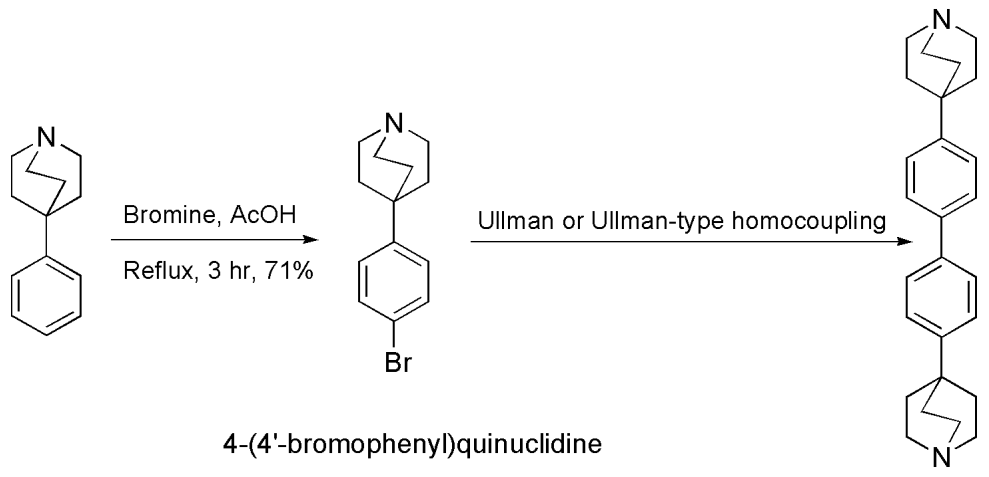

\section{(3) $\underline{4,4}$ '-Azodibenzoic acid ( ${ }_{2} \underline{\text { ADBA })}$}

At $80{ }^{\circ} \mathrm{C}$, an aqueous solution of D-glucose monohydrate $(27.60 \mathrm{~g}, 99 \%, 0.15 \mathrm{~mol})$ in water (45 $\mathrm{mL}$ ) was added drop-wise into a stirred solution of 4-nitrobenzoic acid $(3.50 \mathrm{~g}, 99 \%, 0.02 \mathrm{~mol})$ and sodium hydroxide $(6.0 \mathrm{~g}, 0.15 \mathrm{~mol})$ in water $(50 \mathrm{~mL})$. When the addition was complete, the mixture was cooled to room temperature and air was bubbled through it overnight. The orangecolored precipitate was filtered and rinsed with water. The solid was, thereafter, dissolved in hot water $(150 \mathrm{~mL})$. Upon addition of glacial acetic acid, light pinkish precipitate was formed, which was filtered and rinsed with cold water to afford the product $(2.34 \mathrm{~g}$ after being dried under vacuum, $82 \%$ yield based on 4-nitrobenzoic acid). ${ }^{1} \mathrm{H}$ NMR (200 MHz, DMSO- $\left.d_{6}\right): 8.02$ (d, 4H, $J=8.6 \mathrm{~Hz}), 8.18(\mathrm{~d}, 4 \mathrm{H}, J=8.6 \mathrm{~Hz}) .{ }^{13} \mathrm{C}$ NMR (50 MHz, DMSO-d 6 ): 123.5, 131.4, 134.1, 154.8 , 
167.3. FT-IR ( $\left.v \mathrm{~cm}^{-1}\right): 3300-2400,1686,1425,1293$. Melting point was not obtained because the compound decomposed at around $350{ }^{\circ} \mathrm{C}$ (in sealed capillary tube) before melting.

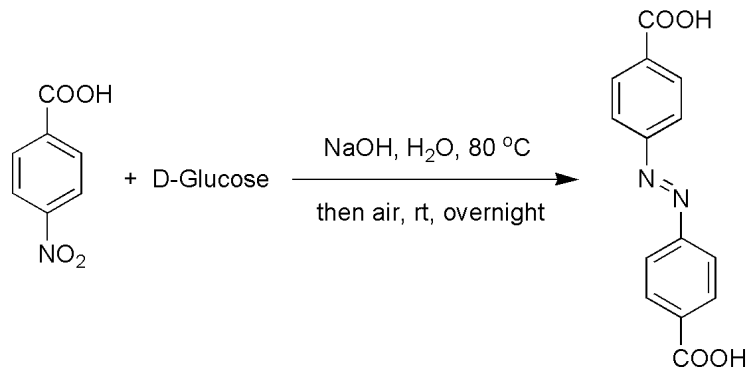

(4) $\underline{N, N}$ '-phenylenebis(salicylideneimine)dicarboxylic acid ( $\underline{H}_{4} \underline{\text { SPDC) }}$

To a magnetically stirred ethanol $(10 \mathrm{~mL})$ solution of ortho-phenylenediamine $(0.11 \mathrm{~g}, 98 \%, 1.0$ $\mathrm{mmol})$ at $50{ }^{\circ} \mathrm{C}$ was added 3-formyl-4-hydroxybenzoic acid $(0.35 \mathrm{~g}, 97 \%, 2.0 \mathrm{mmol})$ in ethanol $(30 \mathrm{~mL})$ drop-wise in about $10 \mathrm{~min}$. After being stirred for another $30 \mathrm{~min}$, the orange yellow precipitate was filtered, washed with cold ethanol and dried under vacuum to afford the product as a crystalline, orange-yellow solid $(0.27 \mathrm{~g}, 67 \%$ based on $o$-phenylenediamine). Melting point: 294-295 ${ }^{\circ} \mathrm{C} \mathrm{w} /$ decomposition. ${ }^{1} \mathrm{H}$ NMR (200 MHz, DMSO-d $)$ ) 7.05 (d, 2H, $\left.J=9.0 \mathrm{~Hz}\right), 7.42-$ $7.56(\mathrm{~m}, 4 \mathrm{H}), 7.97(\mathrm{dd}, 2 \mathrm{H}, J=2.0 \mathrm{~Hz}), 8.35(\mathrm{~d}, 2 \mathrm{H}, J=2.0 \mathrm{~Hz}), 9.08(\mathrm{~s}, 2 \mathrm{H})$. FT-IR $\left(\mathrm{v}, \mathrm{cm}^{-1}\right)$ : 3200-2500, 1695, 1609, 1511, 1271, 1232.

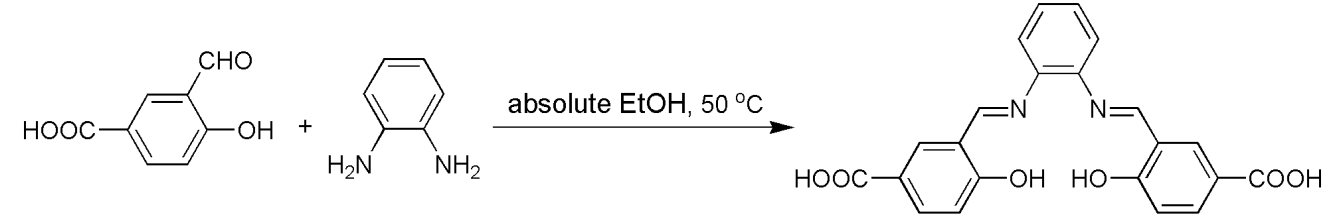

\section{(5) $\underline{\mathrm{H}}_{2} \underline{\mathrm{SPDC}-\mathrm{Pd}}$}

Into a magnetically stirred DMF $(\mathrm{mL})$ solution of $\mathrm{H}_{4} \mathrm{SPDC}(\mathrm{g}, \mathrm{mmol})$ was added slowly a DMF $(\mathrm{mL})$ solution of palladium(II) acetate $(\mathrm{g}, \mathrm{mmol})$. The mixture was then heated at $60{ }^{\circ} \mathrm{C}$ for 24 hours before the brownish yellow crystalline precipitate ( $\mathrm{g}$, \% yield based on $\mathrm{H}_{4} \mathrm{SPDC}$ ) was filtered, rinsed with cold DMF and dried in air.

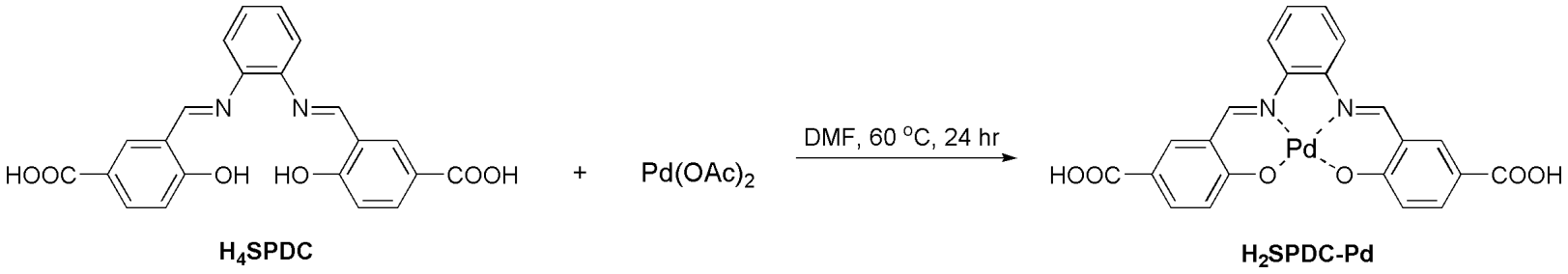

\section{(6) Triethylenediamine dioxide (TEDDO)}

Into a solution of triethylenediamine (TED, 97\%, 11.3g, $97.7 \mathrm{mmol}$ ) in water (distilled, $100 \mathrm{~mL}$ ) was added slowly hydrogen peroxide $(35 \%, 70 \mathrm{~mL}, 818 \mathrm{mmol})$. The mixture was then heated at $80{ }^{\circ} \mathrm{C}$ for $20 \mathrm{hrs}$. After removing water on a rotary evaporator, the colorless crystalline solid was recrystallized in ethanol $(95 \%, 300 \mathrm{~mL})$. The product thus obtained $(15.6 \mathrm{~g}, 89 \%$ yield based on TED) was essentially pure. ${ }^{1} \mathrm{H}$ NMR (400 MHz, $\left.\mathrm{D}_{2} \mathrm{O}\right): 3.98(\mathrm{~s}, 6 \mathrm{H}) .{ }^{13} \mathrm{CNMR}\left(100 \mathrm{MHz}, \mathrm{D}_{2} \mathrm{O}\right)$ : 
61.1. Thermogravimetric analysis of the as-made sample indicates that there are possibly two cocrystallized water molecules per TEDDO molecule.

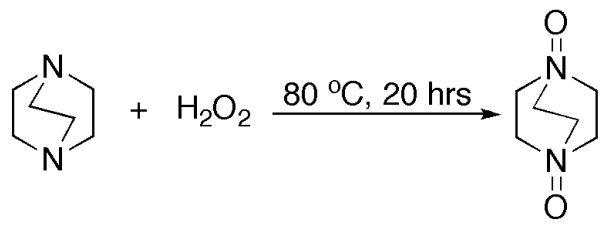

\section{B. Syntheses and structures of the microporous MOFs}

(1) $\left.\left[\mathrm{Co}_{3} \underline{(b p d c}\right)_{3}(\mathrm{bpy})\right] \cdot 4 \mathrm{DMF} \cdot \mathrm{H}_{2} \underline{\mathrm{O}}$

\section{Synthesis:}

Crystal samples of $\left[\mathrm{Co}_{3}(\mathrm{bpdc})_{3}(\mathrm{bpy})\right] \cdot 4 \mathrm{DMF} \cdot \mathrm{H}_{2} \mathrm{O}\left(\mathrm{bpdc}=\right.$ biphenyldicarboxilate, bpy $=4,4^{\prime}-$ bipyridine) or RPM1-Co were prepared by solvothermal reactions of $\mathrm{Co}\left(\mathrm{NO}_{3}\right)_{2}$ with bpy and bpdc in DMF. Reactions were carried out at $150^{\circ} \mathrm{C}$ for three days. A total amount of $590 \mathrm{mg}$ of samples were synthesized. Powder X-ray diffraction (PXRD) analysis of the product gave excellent agreement with the calculated PXRD pattern produced by single crystal data.

\section{Crystal Structure:}

The structure contains two crystallographically independent cobalt centers. The octahedrally coordinated Col is located on the 2-fold rotation axis and is connected to two adjacent $\mathrm{Co} 2$ centers with distorted trigonal bipyramidal geometry, through six bpdc ligands. Each of the two Co1-Co2 pairs is connected by three carboxylate groups via two $\mu 2$ and one $\mu 3$ bonding modes. The $\mathrm{Co} 3$ unit, acting as a node, is connected to six adjacent nodes via six bpdc to form a two-dimensional layer parallel to the ab (xy) plane. The remaining coordination sites of the two $\mathrm{Co} 2$ in each building block are occupied by nitrogen atoms of bpy ligand acting as pillars, which bind the adjacent 2D layers to generate a pillared 3D framework. Such a pillared 3D structure composed of "double" metal-carboxylate layers is rare. Two of these pillared 3D motifs, identical in structure, interpenetrate to

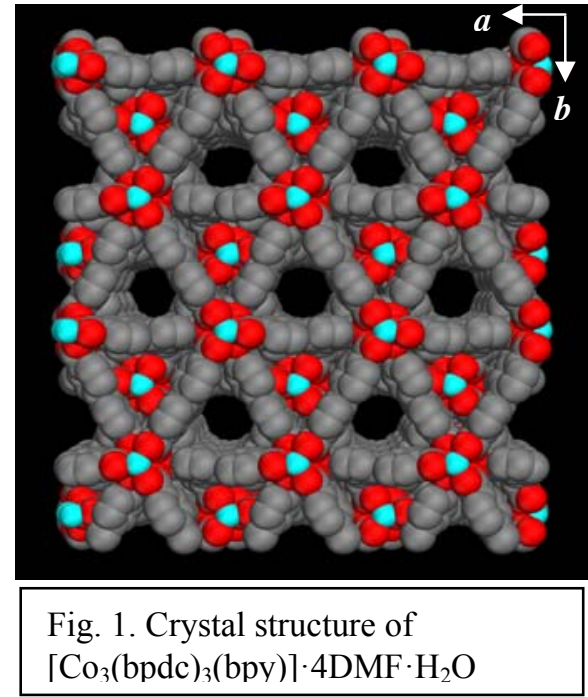
yield a new type of catenated network consisting of large open 1D channels. All aromatic rings self-assemble to line up approximately with their planes parallel to the z-axis, acting as sidewalls of the channels. The free space accommodates four DMF and one $\mathrm{H}_{2} \mathrm{O}$ molecule per formula unit. As illustrated in Fig 1, these channels contain large diameter supercages (approximately 11 $\times 11 \times 5 \AA$ in dimension based on van der Waals radius of carbon) and smaller windows (triangular in shape with an effective maximum dimension of about $8 \AA$ ). 


\section{(2) $[\mathrm{Co}(\mathrm{bpdc})(\mathrm{bpy})] \cdot 0.5 \mathrm{DMF}$}

\section{Synthesis:}

$[\mathrm{Co}(\mathrm{bpdc})(\mathrm{bpy})] \cdot 0.5 \mathrm{DMF}$ (bpy $=4,4^{\prime}$-bipyridine, bpdc $=$ biphenyldicarboxylate, $\mathrm{DMF}=$ dimethylformamide) were synthesized using DMF as solvent. In a typical reaction, $\mathrm{Co}\left(\mathrm{NO}_{3}\right)_{2} \cdot 6 \mathrm{H}_{2} \mathrm{O}(0.087 \mathrm{~g}, 0.3 \mathrm{mmol}), \mathrm{H} 2 \mathrm{bpdc}(97 \%, 0.072 \mathrm{~g}, 0.3 \mathrm{mmol})$ and 4,4'-bpy $(98 \%$, $0.128 \mathrm{~g}, 0.8 \mathrm{mmol}$ ) were loaded in a Parr reactor and the reaction was carried out at $150^{\circ} \mathrm{C}$ for $5-8$ days. Shiny pink solid ( $\sim 140 \mathrm{mg})$ was obtained after the reaction mixture was isolated and dried. A total number of six successful reactions yielded $\sim 513 \mathrm{mg}$ of pure samples.

\section{Crystal Structure:}

$[\mathrm{Co}(\mathrm{bpdc})(\mathrm{bpy})] \cdot 0.5 \mathrm{DMF}$ is a three-dimensional network containing rectangular-shaped $1 \mathrm{D}$ open channels along the a-axis (window size: $\sim 5.6 \times 3.0 \AA$ ). Fig. 2 shows the crystal structure of $[\mathrm{Co}(\mathrm{bpdc})(\mathrm{bpy})] \cdot 0.5 \mathrm{DMF}$. It can be considered built upon a $2 \mathrm{D}$ network based on $\mathrm{Co}_{2}(\mathrm{bpdc})_{4}(\mathrm{py})_{4}$ building block. Each Co of the $\mathrm{Co} 2$ pair in the building block is fourfold coordinated to oxygen atoms through chelating and $\mu 2$ bridging carboxylate ions of bpdc, forming a 2D lattice with quadrilateral shaped grids. Two such identical 2D nets interpenetrate to form a layer. The metals in the adjacent layers are further connected via the exo-bidentate ligand $4,4^{\prime}$ 'bpy at the apical positions resulting in a $3 \mathrm{D}$ porous framework structure.

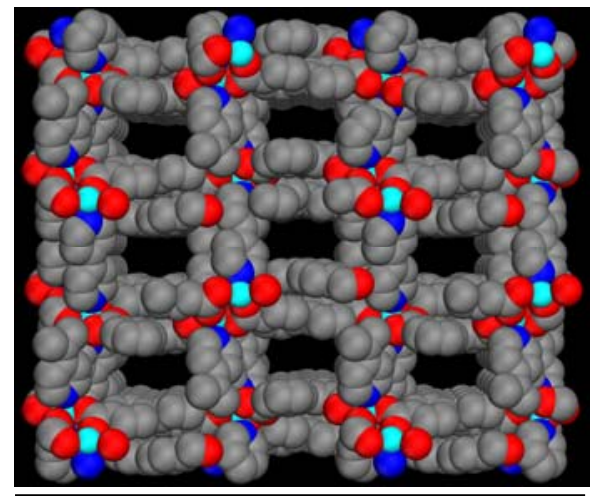

Fig. 2. [Co(bpdc)(bpy)] $0.5 \mathrm{DMF}$

\section{(3) $\left[\mathrm{CO}_{3}(\mathrm{hfipbb})_{2}\left(\mathrm{CHO}_{2}\right)_{2}(\mathrm{dppa})\left(\mathrm{H}_{2} \mathrm{O}\right)_{2}\right] \cdot 2 \mathrm{DMF} \cdot \mathrm{PhBr}_{2}$}

Synthesis:

Single crystals of $\left[\mathrm{Co}_{3}(\mathrm{hfipbb})_{2}\left(\mathrm{CHO}_{2}\right)_{2}(\mathrm{dppa})\left(\mathrm{H}_{2} \mathrm{O}\right)_{2}\right] \cdot 2 \mathrm{DMF} \cdot \mathrm{PhBr}_{2}(\mathrm{dppa}=1,3-\mathrm{di}(4-$ pyridyl)propane, $\mathrm{H} 2 \mathrm{hfipbb}=4$, 4'-(hexafluoroisopropylidene) bis(benzoic acid), $\mathrm{phBr}_{2}=$ dibromobenzene) were grown in a mixed solution of equal volume of dibromobenzene and dimethylformamide. $\mathrm{Co}\left(\mathrm{NO}_{3}\right)_{2} \cdot 6 \mathrm{H}_{2} \mathrm{O}(0.029 \mathrm{~g}, 0.1 \mathrm{mmol}), \mathrm{H}_{2} \mathrm{hfipbb}(0.039 \mathrm{~g}, 0.1 \mathrm{mmol})$ and $1,3-$ di(4-pyridyl)propane $(0.02 \mathrm{~g}, 0.1 \mathrm{mmol})$ were loaded in a Parr reactor and the reaction was carried out in a $2 \mathrm{ml}$ of solvents at $110^{\circ} \mathrm{C}$ for 2 days. Red cubic crystals $(\sim 60.6 \mathrm{mg})$ was obtained after the reaction mixture was isolated and dried.

\section{Crystal Structure:}

The 3D structure of this compound consists of two crystallographically independent $\mathrm{Co}$ sites. Each octahedrally coordinated cobalt(II) connects to the two neighboring square pyramidal cobalt(II) centers via four carboxylic groups from hfibpp and two $\mu^{2}$ oxygen from one of carboxylic group of formic acid. Each Co3 cluster is connected by the other carboxylic groups of formic acid to generate a cobalt chain. The chains are interconnected by

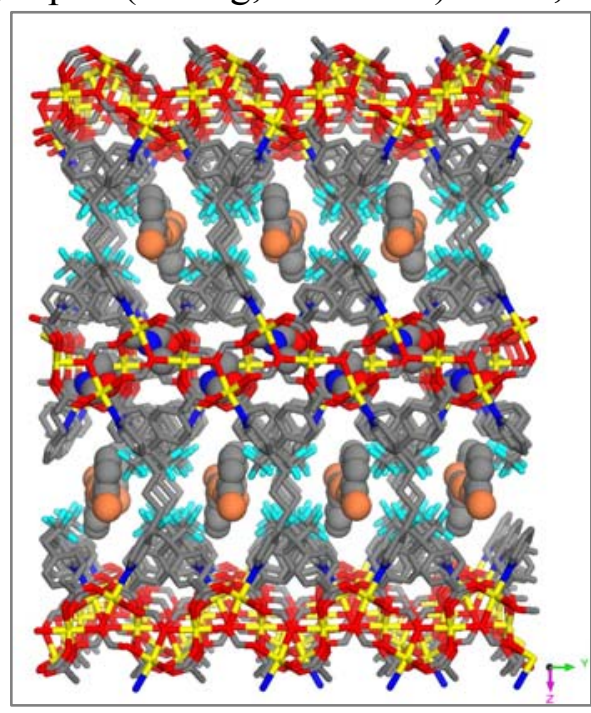

Fig. 3. $\mathrm{Co}_{3}(\text { hfipbb })_{2}$ Structure. 
hfipbb to form a layer. The adjacent layers are further connected by dppa to form a 3D porous framework (Fig. 3).

\section{(4) $\left[\mathrm{Cu}_{4}(\text { ipa })_{4}\left({ }(\mathrm{bpe})_{3}\left(\mathrm{H}_{2} \underline{\mathrm{O}}\right)\right] \cdot 1.7 \mathrm{H}_{2} \underline{\mathrm{O}}\right.$}

\section{Synthesis:}

Single crystals of $\left[\mathrm{Cu}_{4}(\mathrm{ipa})_{4}(\mathrm{bpe})_{3}\left(\mathrm{H}_{2} \mathrm{O}\right)\right] \cdot 1.7 \mathrm{H}_{2} \mathrm{O}$ (ipa $=$ isophthalic acid, bpe $=1$,2-bis $(4-$ pyridyl)-trans-ethane) were generated in hydrothermal reactions of $\mathrm{Cu}\left(\mathrm{NO}_{3}\right)_{2}(0.3 \mathrm{mmol})$, ipa $(0.1 \mathrm{mmol})$ and bpe $(0.1 \mathrm{mmol})$ carried out at $100^{\circ} \mathrm{C}$ for one day. The crystals were collected after a similar isolation and drying procedure as described above.

\section{Crystal Structure:}

The crystal structure of $\left[\mathrm{Cu}_{4}(\mathrm{ipa})_{4}(\mathrm{bpe})_{3}\left(\mathrm{H}_{2} \mathrm{O}\right)\right] \cdot 1.7 \mathrm{H}_{2} \mathrm{O}$ is a very complex one. It is a $3 \mathrm{D}$ framework with one dimensional channels. There are three crystallographically independent $\mathrm{Cu}$ sites, with square planar, tetrahedral, and octahedral geometry. A view of the structure is shown in

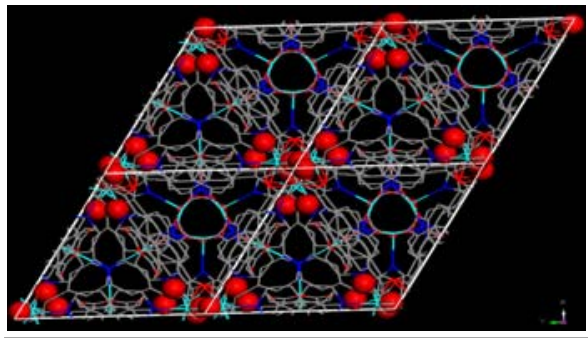

Fig. 4. Structure of $\left[\mathrm{Cu}_{4}(\text { bpe })_{3}(\text { pbaa })_{4}\left(\mathrm{H}_{2} \mathrm{O}\right)\right] \cdot 1.7 \mathrm{H}_{2} \mathrm{O}$ Fig. 4.

\section{(5) $[\mathrm{Mg}(\mathrm{bpdc})(\mathrm{DMF})] \cdot \mathrm{nDMF}$}

\section{Synthesis:}

Light metal containing MMOF $[\mathrm{Mg}(\mathrm{bpdc})(\mathrm{DMF})] \cdot \mathrm{nDMF}(\mathrm{bpdc}=$ bisphenyldicarboxylic acid); $\mathrm{DMF}=\mathrm{N}, \mathrm{N}$-Dimethylformide) was synthesized by solvothermal reactions at elevated temperature and pressure. Reactions of $\mathrm{Mg}\left(\mathrm{NO}_{3}\right)_{2} \cdot 9 \mathrm{H}_{2} \mathrm{O}$, and bpdc in DMF yielded pure polycrystalline/crystalline samples.

\section{Crystal Structure:}

As shown in Figure 5, the 3D porous structure is formed by tri-magnesium clusters connected by carboxylate ligands bpdc. There are two independent octahedral magnetism coordination environments in the tri-metal cluster in which the central $\mathrm{Mg}$ is coordinated to six oxygen atoms from six different bpdc ligands and the other two $\mathrm{Mg}$ metals are coordinated to four oxygen atoms from two bpdc and two oxygens from DMF molecules, respectively. Every trimegnetism cluster is connected to six identical tri-metal clusters to generate a $3 \mathrm{D}$ porous framework. The channels in the porous framework encapsulate $12 \mathrm{DMF}$ guest molecules

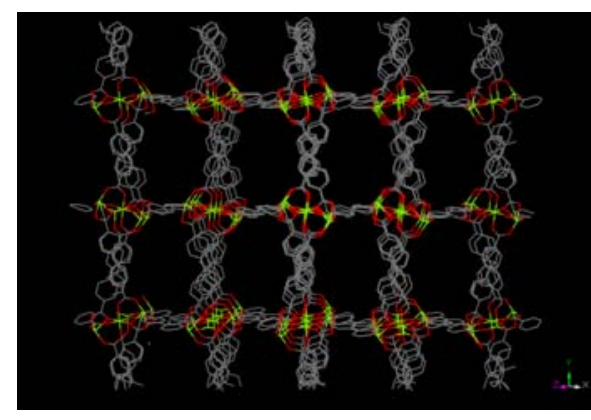

Fig. 5. Crystal structure of $[\mathrm{Mg}(\mathrm{bpdc})(\mathrm{DMF})] \cdot \mathrm{nDMF}$ per unit cell. 
(6) $\left[\mathrm{Y}_{2} \underline{2}(\mathrm{sdba})_{3} \underline{\mathrm{H}_{2}} \underline{\underline{\mathrm{O}})_{2}}\right]$

Synthesis:

Small, transparent rod-like crystals of $\left[\mathrm{Y}_{2}(\mathrm{sdba})_{3}\left(\mathrm{H}_{2} \mathrm{O}\right)_{2}\right] \cdot 0.616 \mathrm{EtOH} \cdot 0.125 \mathrm{H}_{2} \mathrm{O}$ were grown under solvothermal conditions using water and a small amount of ethanol as solvents. Typical reactions were carried out at $150^{\circ} \mathrm{C}$ for one day. The product was isolated and dried.

\section{Crystal Structure:}

The 3D porous framework is formed by the lightest rare earth metal yttrium and a dicarboxylic acid. The coordination geometry of each $\mathrm{Y}(\mathrm{III})$ is a distorted octahedron. The Y(III) atoms are connected alternately by four and two carboxylate groups, giving rise to a yttrium chain. Each chain is further bridged by six adjacent sdba ligand to form a 3D porous framework (Fig. 6) with cages filled with ethanol and water.

(7) $\left[\mathrm{Zn}(\mathrm{bdc})(\mathrm{ted})_{0.5}\right] \cdot 2 \mathrm{DMF}$

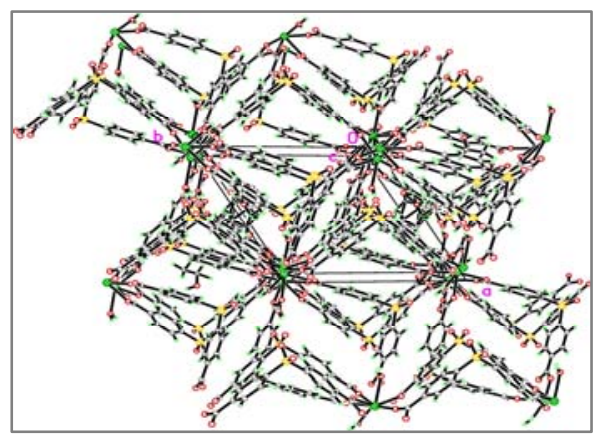

Fig. 6. $\mathrm{Y}_{2}(\mathrm{sdba})_{3}\left(\mathrm{H}_{2} \mathrm{O}\right)_{2}$ Structure

Synthesis:

A mixture of zinc (II) nitrate trihydrate, $\mathrm{H}_{2}$ bdc, ted (ted = triethylenediamine) and $150 \mathrm{ml}$ DMF was transferred to a vessel, sealed and heated at $393 \mathrm{~K}$ overnight. Colorless cubic crystals were formed. The product was isolated after washed by DMF. The TG curves showed $\sim 30-33 \%$ weight loss after the as-made samples were heated to $150-160^{\circ} \mathrm{C}$. Porous $\left[\mathrm{Zn}(\mathrm{bdc})(\mathrm{ted})_{0.5}\right]$ was formed after sample was heated at $150^{\circ} \mathrm{C}$ under $\mathrm{N}_{2}$ for 30 mins. PXRD shows the structure remains intact after removal of guest molecules. TGA data also shows that the sample is suitable for gas sorption studies.

\section{Crystal Structure:}

The $\left[\mathrm{Zn}(\mathrm{bdc})(\mathrm{ted})_{0.5}\right]$ structure is a $3 \mathrm{D}$ microporous MOF framework that can be described as [Zn(bdc)] layers linked by ted pillars. Within each layer the $\mathrm{Zn}(\mathrm{II})_{2}$ paddle-wheel units are interconnected by the bdc ligands

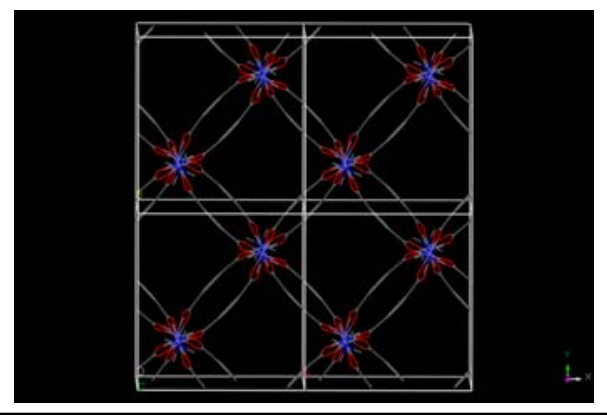

Fig. 7. $\left[\mathrm{Zn}(\mathrm{bdc})(\mathrm{ted})_{0.5}\right] \cdot 2 \mathrm{DMF} \cdot 0.05 \mathrm{H}_{2} \mathrm{O}$. (Fig. 7).

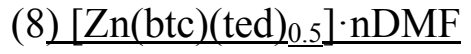

Synthesis:

$\left[\mathrm{Zn}(\mathrm{btc})(\mathrm{ted})_{0.5}\right] \cdot \mathrm{nDMF}$ (btc $=$ benzene-tricarboxylic acid, ted $=$ triethylenediamine) was synthesized by solvothermal reaction of zinc (II) nitrate tetrahydrate, $\mathrm{H}_{2}$ bdc, ted in DMF in a Parr vessel. The mixture was heated at $428 \mathrm{~K}$ for overnight. Colorless cubic crystals were washed and collected after the reaction was complete. 


\section{Crystal Structure:}

The $\left[\mathrm{Zn}(\mathrm{bdc})(\mathrm{ted})_{0.5}\right]$ structure is a 3D microporous MOF framework that can be described as [Zn(bdc)] layers linked by ted pillars. Within each layer the $\mathrm{Zn}(\mathrm{II})_{2}$ paddle-wheel units are interconnected by the bdc ligands (Fig. 8).

\section{(9) $[\mathrm{Zn}(\mathrm{bpdc})(\mathrm{bpe})] \cdot \mathrm{DMF}$}

Synthesis:

Pale yellow salt-like crystals of [ $\mathrm{Zn}(\mathrm{bpdc})(\mathrm{bpe})] \cdot \mathrm{DMF}$ were grown via solvothermal reactions in N,Ndimethylformamide (DMF) using zinc salt and 4,4'biphenyldicarboxylic acid (bpdc) and 1,2-bis(4pyridyl)ethane (bpe) as ligands. About $500 \mathrm{mg}$ of samples were isolated from a total number of 10 reactions. All reactions were carried out at $80^{\circ} \mathrm{C}$ for 3 days. Powder X-ray analysis was performed on all samples.

\section{Crystal Structure:}

In this structure, each zinc metal is bound to two oxygen atoms from the two bpdc and two nitrogen atoms from two bpe ligands to generate tetrahedral building block. All building blocks are connected leading to a 3D-diamondoid

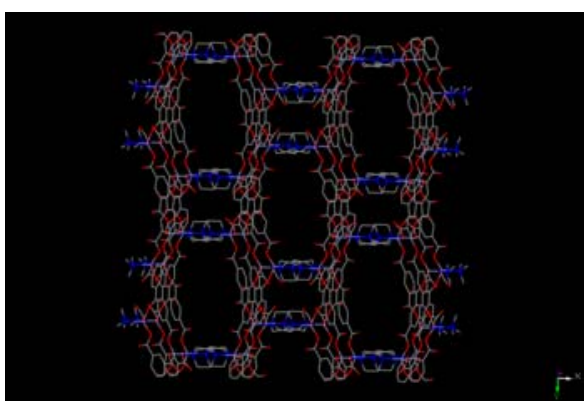

Fig. 8. $\mathrm{Zn}(\mathrm{BTC})(\mathrm{TED})_{0.5} \cdot \mathrm{nDMF}$.

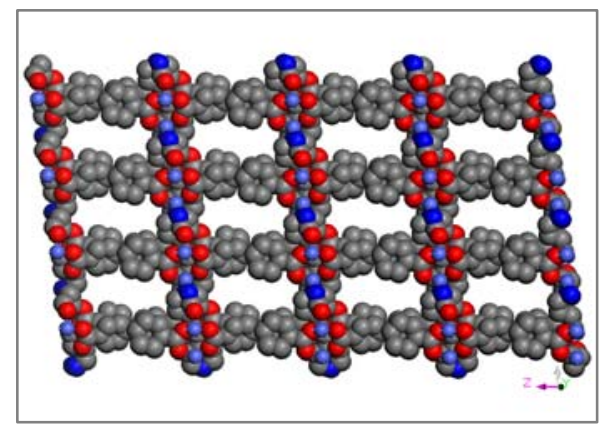

Fig. 9. $[\mathrm{Zn}(\mathrm{bpdc})(\mathrm{bpe})] \cdot \mathrm{DMF}$ network. Five of the identical 3D networks are interwoven to form the overall 3D structure comprised of 1D channels (Fig. 9). DMF molecules fill in the channels.

(10) $\left[\mathrm{Zn}(\mathrm{bpdc})(\text { ted })_{0.5}\right] \cdot \mathrm{nDMF}$

\section{Synthesis:}

The compound was synthesized by mixing zinc (II) nitrate trihydrate, biphenyldicarboxylic acid $\left(\mathrm{H}_{2} \mathrm{bpdc}\right)$ and triethylenediamine (ted) in dimethylformamide (DMF) and heated at $120^{\circ} \mathrm{C}$ for 2 days. The product was washed in DMF $(10 \mathrm{ml} \times 2)$ and colorless cubic crystals were isolated and collected.

\section{Crystal Structure:}

The $\left[\mathrm{Zn}(\mathrm{bpdc})(\mathrm{ted})_{0.5}\right]$ structure is a $3 \mathrm{D}$ microporous MOF framework that can be described as [ $\mathrm{Zn}(\mathrm{bpdc})]$ layers linked by ted pillars. Within each layer the $\mathrm{Zn}(\mathrm{II})_{2}$ paddle-wheel units are interconnected by the bpdc ligands (Fig. 10).

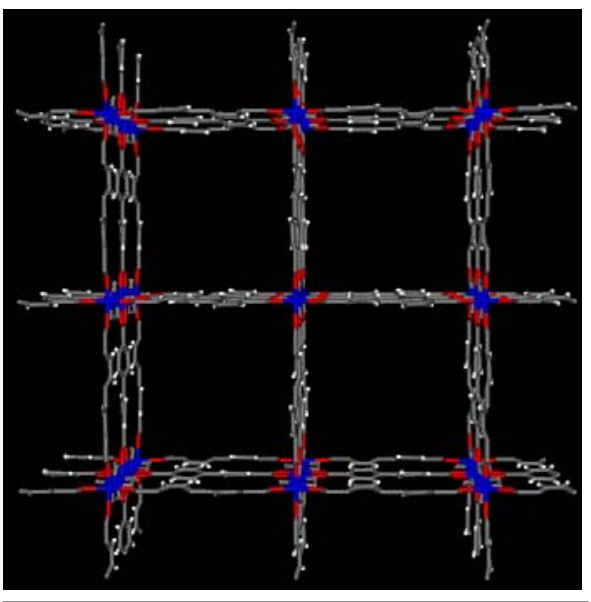

Fig. 10. $\left[\mathrm{Zn}(\mathrm{bpdc})(\mathrm{ted})_{0.5}\right] \cdot \mathrm{nDMF}$. 


\section{(11) $\left[\mathrm{Zn}_{4} \underline{\left.\mathrm{O}(\mathrm{bdc})_{3}\right]}\right] \cdot 3 \mathrm{DMF} \cdot 2 \mathrm{H}_{2} \underline{\mathrm{O}}$}

The known compound of $\left[\mathrm{Zn}_{4} \mathrm{O}(\mathrm{bdc})_{3}\right] \cdot 3 \mathrm{DMF} \cdot 2 \mathrm{H}_{2} \mathrm{O}$ (bdc $=$ benzenedicarboxylate, $\mathrm{DMF}=$ dimethylformamide) was reproduced for high pressure sorption experiments. The reactions were carried out in DMF at $100^{\circ} \mathrm{C}$. $\mathrm{Zn}\left(\mathrm{NO}_{3}\right)_{2} \cdot 6 \mathrm{H}_{2} \mathrm{O}(0.94 \mathrm{~g})$ and $\mathrm{H}_{2}$ bdc or benzenedicarboxylic acid $(0.17 \mathrm{~g})$ were mixed and reacted in a reaction container for 20 hours. Cubic colorless crystals were isolated after the reaction. A total amount of $\sim 500 \mathrm{mg}$ of pure samples were prepared.

\section{Crystal Structure and Data:}

This structure has been reported earlier by Li, H.L.; Eddaoudi, M.; O'keeffe, M.; Yaghi, O.M. Nature, 1999, 402, 276.

\section{(12) [Zn(tbip)]}

Synthesis:

Pure crystalline samples of Zn(tbip) (tbip = 5-tert-butyl isophthalate) were prepared by hydrothermal reactions of $\mathrm{Zn}\left(\mathrm{NO}_{3}\right)_{2}$ and $\mathrm{H}_{2}$ tbip in water and ethanol. All reactions were carried out at $180^{\circ} \mathrm{C}$ for two days. A total number of 18 reactions yielded $500 \mathrm{mg}$ of pure samples, as identified by PXRD analysis.

\section{Crystal Structure:}

In this structure, tetrahedral zinc centers are linked by tbip ligands to generate a three-dimensional framework. ${ }^{2}$ Each $\mathrm{Zn}^{2+}$ cation occupies a 2 -fold rotation symmetry position. All adjacent zinc nodes are bridged, along the $c$ axis, by two

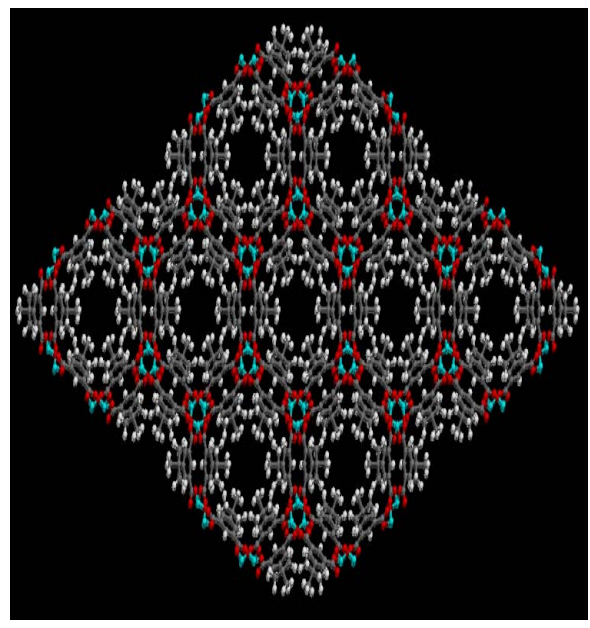

Fig. 11. Crystal structure of $\mathrm{Zn}(\mathrm{tbip})$. carboxylic groups to form a $3_{1}$ helical chain with a pitch of $7.977 \AA$ along the crystallographic $c$ axis (screw axis). The shortest zinc-zinc intrachain distance is $3.38 \AA$. Each chain connects to three identical neighboring chains through tbip giving rise to two interchain distances $(10.825$ and $7.212 \AA$ ). This results in a 3D structure containing close-packed 1D open channels (or microtubes) along the $c$ direction (Fig. 11).

\section{(13) $\left[\mathrm{Zn}_{3}\left(\mathrm{bpdc}_{3}(\mathrm{DMF})_{2}\right] \cdot 4 \mathrm{DMF}\right.$}

\section{Synthesis:}

The compound was synthesized by mixing zinc (II) nitrate hexahydrate, biphenyldicarboxylic acid $\left(\mathrm{H}_{2} \mathrm{bpdc}\right)$ in dimethylformamide (DMF) and heated at $100^{\circ} \mathrm{C}$ for one day. The colorless prism crystals were isolated and collected.

\section{Crystal Structure:}

The $\left[\mathrm{Zn}_{3}(\mathrm{bpdc})_{3}(\mathrm{DMF})_{2}\right] \cdot 4 \mathrm{DMF}$ structure is a $2 \mathrm{D}$ metal organic framework that can be described as trinuclear zinc

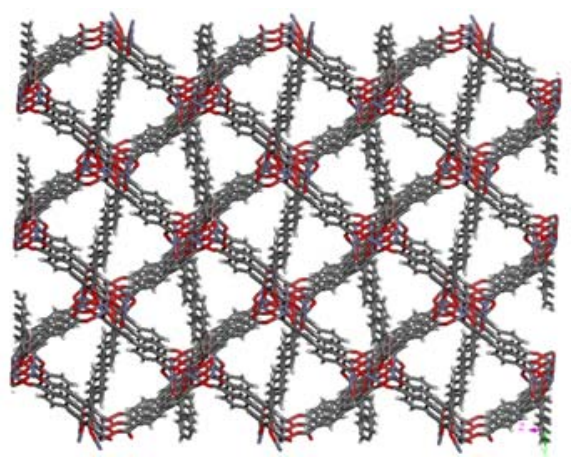

Fig. 12. $\left[\mathrm{Zn}_{3}(\mathrm{bpdc})_{3}(\mathrm{DMF})_{2}\right] \cdot 4 \mathrm{DMF}$. cluster linked to six adjacent clusters by carboxylic acid bpdc to form a double- layer twodimensional network. There are four guest and two terminal DMF molecules per unit formular (see Fig. 12). 
(14) $\left[\mathrm{Cu}(\mathrm{bdc})(\text { ted })_{0.5}\right] \cdot 2 \mathrm{DMF}$

Synthesis:

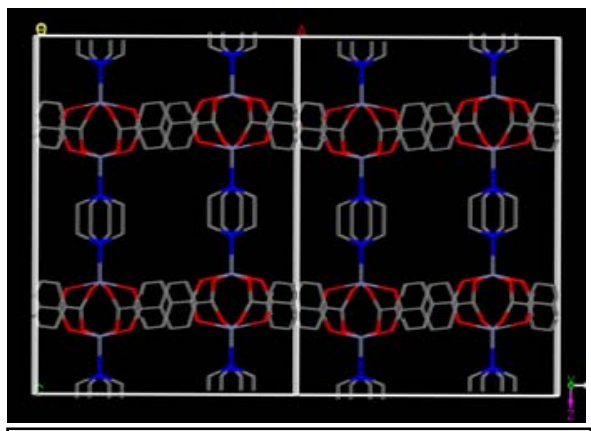

A mixture of copper(II) nitrate trihydrate $(740 \mathrm{mg})$, terephthalic acid $(680 \mathrm{mg})$ and triethylenediamine (480

Fig. 13. $\left[\mathrm{Cu}(\mathrm{bdc})(\mathrm{ted})_{0.5}\right] \cdot 2 \mathrm{DMF}$.

$\mathrm{mg})$ in DMF $(150 \mathrm{~mL})$ was heated at $100^{\circ} \mathrm{C}$ in an oven for $36 \mathrm{hrs}$. The product was obtained as blue Powder $(\sim 1.4 \mathrm{~g})$ after filtering, rinsing with DMF and drying under vacuum.

\section{Crystal Structure:}

A 3D porous framework formed by layers bridging the copper (II) ions with the dicarboxylate ions are linked with TED as a pillar ligand as shown in Figure 13.

\section{(15) $\left.\underline{\alpha-\left[\mathrm{La}_{2}\right.} \underline{\mathrm{Hpdc}}_{2} \underline{\mathrm{C}}_{2} \underline{\mathrm{O}}_{4} \underline{\mathrm{H}}_{2} \underline{\mathrm{H}}_{2} \underline{\mathrm{O}}_{4}\right] \cdot 2 \mathrm{H}_{2} \underline{\mathrm{O}}$}

The transparent, colorless, plate-like crystals suitable for single crystal X-ray diffraction were obtained by heating a mixture of lanthanum(III) nitrate hexahydrate $\left(\mathrm{La}\left(\mathrm{NO}_{3}\right)_{3} \cdot 6 \mathrm{H}_{2} \mathrm{O}, 99.9 \%, 43.2 \mathrm{mg}, 0.10 \mathrm{mmol}\right), 3,5-$ pyridinedicarboxilic acid $\left(\mathrm{H}_{2} \mathrm{pdc}, 98 \%, 26.1 \mathrm{mg}, 0.15\right.$ $\mathrm{mmol})$ and ethanol $(95 \%, 0.2 \mathrm{~mL})$ in distilled water $(5$ $\mathrm{mL})$ at $160{ }^{\circ} \mathrm{C}$ (in an oven) for about 5 days.

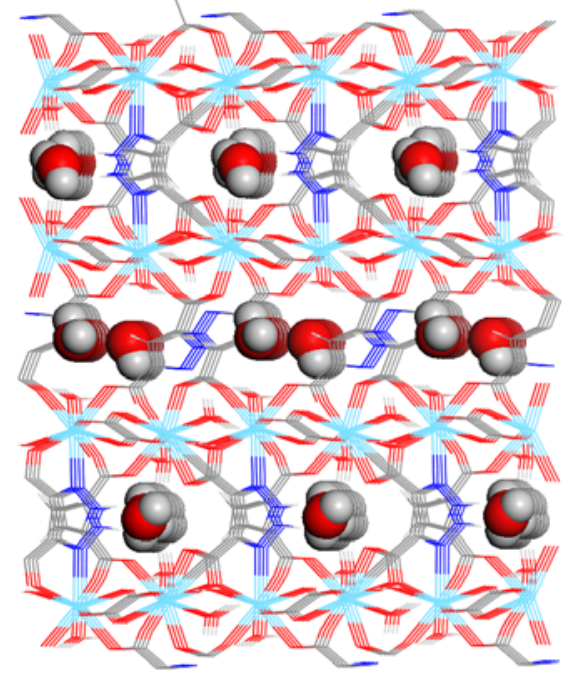

Fig. 14. $\alpha-\left[\mathrm{La}_{2}(\mathrm{Hpdc})_{2}\left(\mathrm{C}_{2} \mathrm{O}_{4}\right)\left(\mathrm{H}_{2} \mathrm{O}\right)_{4}\right] \cdot 2 \mathrm{H}_{2} \mathrm{O}$

The $\alpha$ - $\left[\mathrm{La}_{2}(\mathrm{Hpdc})_{2}\left(\mathrm{C}_{2} \mathrm{O}_{4}\right)\left(\mathrm{H}_{2} \mathrm{O}\right)_{4}\right] \cdot 2 \mathrm{H}_{2} \mathrm{O}$ structure is a $3 \mathrm{D}$ microporous MOF framework (see Figure 14). The polyhedron of each 9-coordinate La metal can be described as a three-face centered trigonal prism, which is connected to the adjacent La atoms via $4 \mathrm{Hpdc}$ ligands to form the 3D structure. To complete the coordination sphere, each La also connects to one oxalate and two water molecules. Two guest water molecules per formula unit are trapped in the channels.

\section{(16) $\left.\beta-\mathrm{La}_{2}(\mathrm{Hpdc})_{2}\left(\mathrm{C}_{2} \underline{\mathrm{O}}_{4}\right)\left(\mathrm{H}_{2} \underline{\mathrm{O}}\right)_{4}\right] \cdot 2 \mathrm{H}_{2} \underline{\mathrm{O}}$}

\section{Synthesis:}

The transparent, colorless, block-like crystals suitable for single crystal $\mathrm{X}$-ray diffraction were obtained by heating a mixture of $\mathrm{La}\left(\mathrm{NO}_{3}\right)_{3} \cdot 6 \mathrm{H}_{2} \mathrm{O}(99.9 \%, 43.0 \mathrm{mg}$, $0.10 \mathrm{mmol}), \mathrm{H}_{2} \mathrm{pdc}(98 \%, 25.2 \mathrm{mg}, 0.15 \mathrm{mmol})$, and ethanol $(95 \%, 0.2 \mathrm{~mL})$ in distilled water $(5 \mathrm{~mL})$ at 150 ${ }^{\circ} \mathrm{C}$ (in an oven) for about 9 days.

\section{Crystal Structure:}

The $\beta$ - $\left[\mathrm{La}_{2}(\mathrm{Hpdc})_{2}\left(\mathrm{C}_{2} \mathrm{O}_{4}\right)\left(\mathrm{H}_{2} \mathrm{O}\right)_{4}\right] \cdot 2 \mathrm{H}_{2} \mathrm{O}$ structure is a polymorph of the $\alpha$ phase (I). It is a $3 \mathrm{D}$ microporous MOF framework (see Figure 15). The polyhedron of each 9-coordinate La metal can be described as a distorted monocapped square antiprism, which is

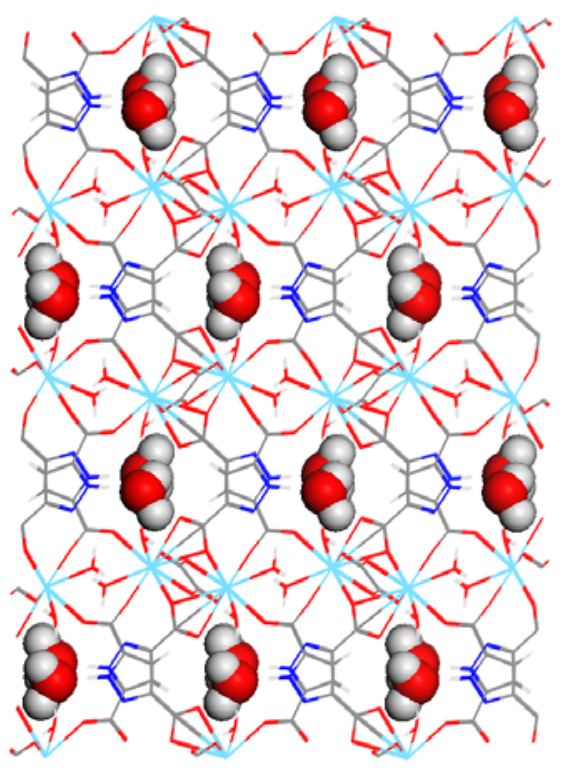

Fig. 15. $\beta-\left[\mathrm{La}_{2}(\mathrm{Hpdc})_{2}\left(\mathrm{C}_{2} \mathrm{O}_{4}\right)\left(\mathrm{H}_{2} \mathrm{O}\right)_{4}\right] \cdot 2 \mathrm{H}_{2} \mathrm{O}$ 
connected to the adjacent La atoms via $4 \mathrm{Hpdc}$ ligands to form the 3D structure. Other than the differences in the coordination geometry of the lanthanum(III) atoms, one $\mathrm{N}$ atom from one of the two types of the Hpdc ligands coordinates to a La(III) in I; however, $\mathrm{N}$ atoms from Hpdc do not participate in the coordination in II. To complete the coordination sphere, each La also connects to one oxalate and two water molecules. Two guest water molecules per formula unit are trapped in the channels.

\section{(17) $\left[\mathrm{Co}_{2}(\mathrm{OBBA})_{2}(\mathrm{APY}-\mathrm{re})_{2}(\mathrm{OH})\right] \cdot 3 \mathrm{DMF}$}

Synthesis:

Cobalt(II) acetate tetrahydrate $(0.260 \mathrm{~g}, 0.1 \mathrm{mmol}), 4.4^{\prime}-$ oxybisbenzoicacid (OBBA, $0.262 \mathrm{~g}, 0.1 \mathrm{mmol}$ ) and 4,4'azodipyridine (APY, $0.184 \mathrm{~g}, 0.1 \mathrm{mmol}$ ) were mixed in $\mathrm{DMF}(10 \mathrm{~mL})$ in a glass vial. The vial was then heated at $120^{\circ} \mathrm{C}$ for 2 days. A wine red color solution was obtained, which was then kept at room temperature undisturbed for $\sim 2$ weeks. Pink colored diamond shape crystals were then isolated, washed with DMF and dried

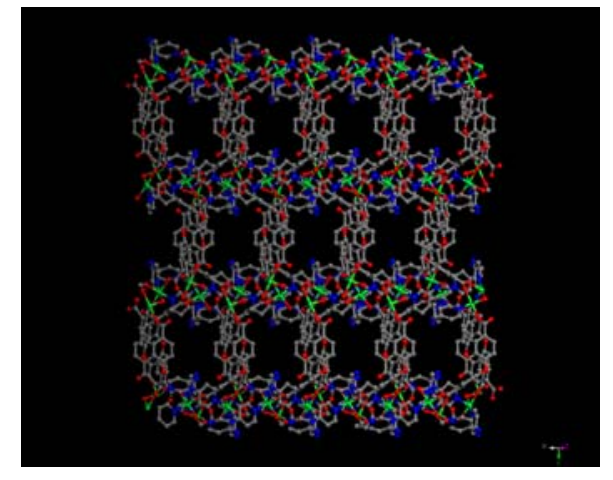
in air.

Fig. 16. $\left[\mathrm{Co}_{2}(\mathrm{OBBA})_{2}(\mathrm{APY}-\mathrm{re})_{2}(\mathrm{OH})\right] \cdot 3 \mathrm{DMF}$

\section{Crystal Structure:}

In $\left[\mathrm{Co}_{2}(\mathrm{OBBA})_{2}(\mathrm{APY}-\mathrm{re})_{2}(\mathrm{OH})\right] \cdot 3 \mathrm{DMF}$, the nitrogen-nitrogen double bond in the APY ligand was reduced in situ to single bond (APY-re). This 3D metal organic framework features a novel SBU as shown in Figure 2. Different from the paddle-wheel shaped SBU in the previous MOF, this new SBU involves two Co(II), six oxygens from OBBA and one hydroxyl oxygen that is bridging the two $\mathrm{Co}$ (II) centers, connecting the OBBA ligands to form 2D layers parallel to the $a b$ plane. Nitrogen atoms from the APY-re ligands come in from above and bellow this plane roughly along $c$ direction, connecting the layers to form the 3 dimensional structure (see Figure 16).

\section{(18) $\left[\mathrm{Co}_{3}(\mathrm{HCOO})_{6}\right] \cdot \mathrm{DMF}$}

Synthesis:

The pink red, block-like single crystals were obtained serendipitously by heating a mixture of cobalt (II) nitrate hexahydrate $(0.016 \mathrm{~g}, 0.05 \mathrm{mmol}), \mathrm{H}_{2} \mathrm{BODC}(0.013 \mathrm{~g}, 0.06 \mathrm{mmol}), \mathrm{TED}(0.007 \mathrm{~g}$, $0.06 \mathrm{mmol})$, and concentrated nitric acid (60-70\%, 4 drops) in dimethylformamide (DMF, $2 \mathrm{~mL}$ ) at $90^{\circ} \mathrm{C}$ in an oven for 14 days. The single crystals and pure phase bulk samples were also prepared by heating a DMF solution of cobalt(II) nitrate hexahydrate $(0.60 \mathrm{~g}, 2.1 \mathrm{mmol})$ and glacial acetic acid $(1 \mathrm{~mL})$ at $100 \mathrm{C}$ for 2 days (yield: $0.36 \mathrm{~g}$, $100 \%$ based on cobalt).

\section{Crystal Structure:}

$\left[\mathrm{Co}_{3}(\mathrm{HCOO})_{6}\right] \cdot \mathrm{DMF}$ is a three dimensional microporous MOF crystallized in monoclinic space group $P 2_{1} / \mathrm{n}$. The asymmetric unit contains four crystallographically independent $\mathrm{Co}(\mathrm{II})$ centers, which are coordinated by six oxygen atoms from formate ions resembling distorted

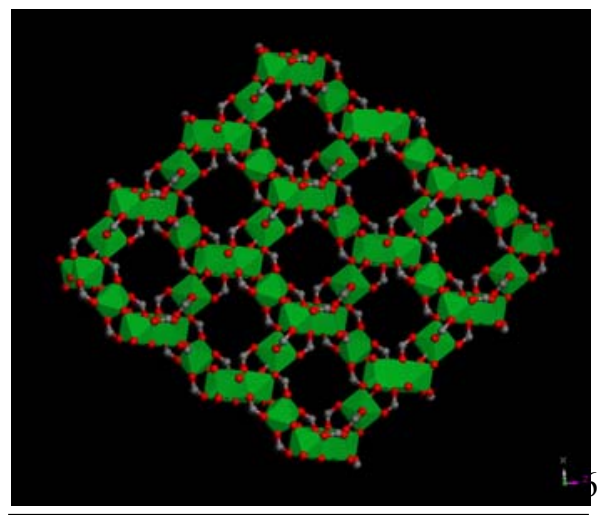

Fig. 17. $\left[\mathrm{Co}_{3}(\mathrm{HCOO})_{6}\right] \cdot \mathrm{DMF}$. 
octahedra (see Figure 17). The shortest Co-Co distances vary from 3.169 to $3.534 \AA$ and a diamondoid network will form if the closest $\mathrm{Co}(\mathrm{II})$ are connected $[\mathrm{Co}(1)$ is at the tetrahedral node and $\mathrm{Co}(2), \operatorname{Co}\left(2^{\prime}\right), \operatorname{Co}(3)$ and $\mathrm{Co}(4)$ lie between four $\left.\mathrm{Co}(1)\right]$. However, the channels can only be observed from $a$ and $b$ directions.

\section{(19) $\left[\mathrm{Mn}_{3}\left(\mathrm{HCOO}_{6}\right] \cdot \mathrm{DMF}\right.$}

\section{Synthesis:}

The colorless block-like single crystals were obtained by heating manganese(II) nitrate hexahydrate $(0.020 \mathrm{~g}, \mathrm{mmol})$ and formic acid $(67 \mu \mathrm{L})$ in $\operatorname{DMF}(2 \mathrm{~mL})$ at $100^{\circ} \mathrm{C}$ in an oven for 26 hours.

\section{Crystal Structure:}

$\left[\mathrm{Mn}_{3}(\mathrm{HCOO})_{6}\right] \cdot \mathrm{DMF}$ is a three dimensional microporous MOF crystallized in monoclinic space group $P 2_{1} / \mathrm{n}$ that feature similar topology as $\left[\mathrm{Co}_{3}(\mathrm{HCOO})_{6}\right] \cdot \mathrm{DMF}$ that was reported in the January report. The shortest Mn-Mn

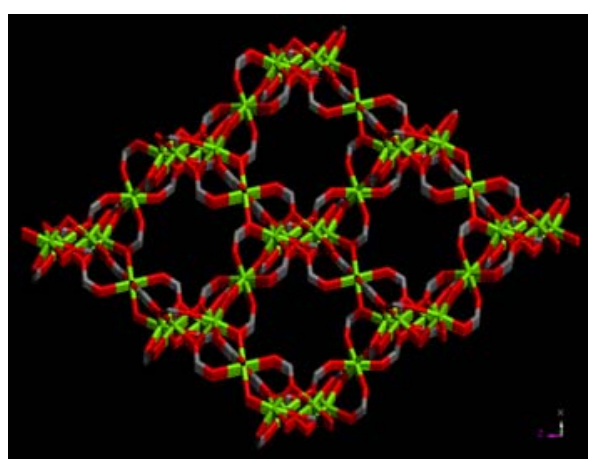

Fig. 18. $\left[\mathrm{Mn}_{3}(\mathrm{HCOO})_{6}\right] \cdot \mathrm{DMF}$. distances vary from 3.313 to $3.625 \AA$ and a diamondoid network will form if the closest $\mathrm{Mn}(\mathrm{II})$ are connected $\left[\mathrm{Mn}(1)\right.$ is at the tetrahedral node and $\operatorname{Mn}(2), \operatorname{Mn}\left(2^{\prime}\right), \operatorname{Mn}(3)$ and $\operatorname{Mn}(4)$ lie between four $\mathrm{Mn}(1)]$. However, the channels can only be observed from $a$ and $b$ directions (Fig. $18)$.

\section{(20) $\left[\mathrm{Co}(\mathrm{OBBA})(\mathrm{BPy})_{0.5}\right]$}

Synthesis:

A mixture of cobalt chloride hexahydrate $(0.0237 \mathrm{~g}, 0.1$ mmol), OBBA (4,4'-oxybisbenzoic acid, $0.0258 \mathrm{~g}, 0.1$ $\mathrm{mmol}$ ), and BPy (4,4'-bispyridine, $0.0156 \mathrm{~g}, 0.1 \mathrm{mmol})$ in water (distil. $5 \mathrm{~mL}$ ) was heated at $120^{\circ} \mathrm{C}$ for 24 hours. The needle-like purple single crystals thus obtained were rinsed with water and DMF, and dried in air.

\section{Crystal Structure:}

$\left[\mathrm{Co}(\mathrm{OBBA})(\mathrm{BPy})_{0.5}\right]$ is a three dimensional guest-free

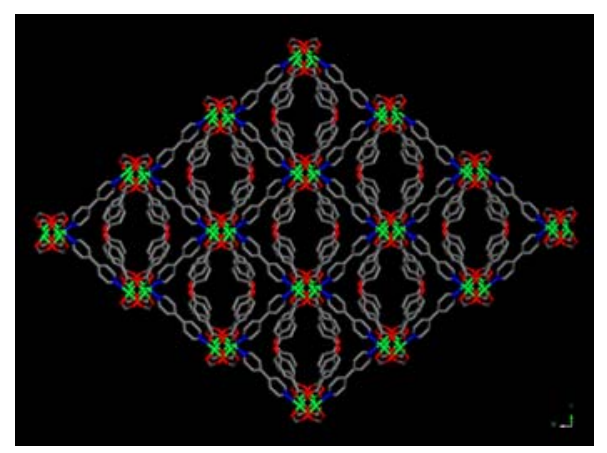

Fig. $19\left[\mathrm{Co}(\mathrm{OBBA})(\mathrm{BPy})_{0.5}\right]$. frmework crystalized in monoclinic space group $C 2 / \mathrm{c}$. The $\mathrm{Co}(\mathrm{II})$ coordinates to four oxygen atoms from two OBBA and one nitrogen atom from BPy. The coordination geometry of $\mathrm{Co}(\mathrm{II})$ resembles a trigonal bipyramid with the nitrogen residing at one apex. The $\mathrm{Co}$ (II) centers are bridged by the carboxylate groups from OBBA to form a chain travalling along $c$ axis and OBBA connects the chains into double-walled layers that are parallel to $b c$ plane. The BPy ligands come in between the planes, adjoining the layers into three dimensional structure (see Figure 19)

\section{(21) $\left[\mathrm{Zn}(\mathrm{FODC})(\mathrm{BPy})_{0.5}\right] \bullet \mathrm{nDMF}$}

Synthesis:

A homogeneous mixture of 9-florenone-2,7dicarboxylic acid (FODC, $0.015 \mathrm{~g}, 0.55 \mathrm{mmol}$ ), zinc

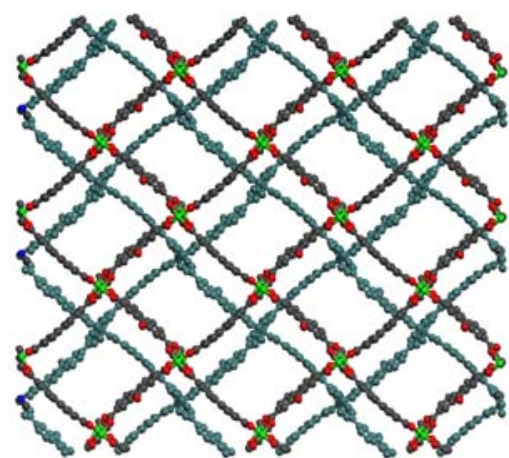


nitrate hexahydrate $(0.022 \mathrm{~g}, 0.072 \mathrm{mmol})$ and 4,4'-dipyridyl (BPy, $0.008 \mathrm{~g}, 0.5 \mathrm{mmol})$ in $N, N$ dimethylformamide (DMF, $4 \mathrm{~mL}$ ) was heated at $100{ }^{\circ} \mathrm{C}$ for 4 days. One of the light yellow block-like single crystals was used for single crystal X-ray diffraction study.

\section{Crystal Structure:}

$\left[\mathrm{Zn}(\mathrm{FODC})(\mathrm{BPy})_{0.5}\right] \cdot \mathrm{nDMF}$ is a three dimensional microporous metal organic framework crystallized in monoclinic space group $P 2{ }_{1} / \mathrm{c}$, which feature interpenetration of two identical 3D nets (see Figure 20). The FODC ligankds connect the $\mathrm{Zn}_{2} \mathrm{O}_{8}$ paddle-wheel SBUs to form $2 \mathrm{D}$ square-grid like layers and BPy coordinate to $\mathrm{Zn}$ from the axial directions of paddle-wheels to integrate the layers into the three-dimensional open framework structure. Channels are of $\sim 13 \AA \times \sim 16 \AA$ size and are filled with solvent guest molecules which were hardly located by single crystal X-ray diffraction study.

\section{(22) $\left[\mathrm{Zn}_{3}(\mathrm{BPDC})_{3}(\mathrm{APy})\right] \cdot \mathrm{nDMF}$}

\section{Synthesis:}

Orange-colored block-like single crystals were obtained

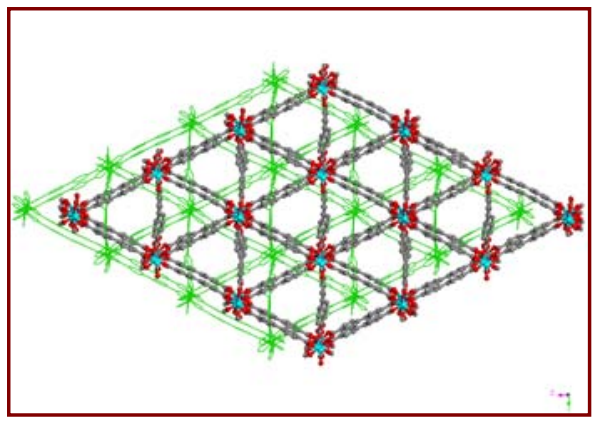

Fig. 21. $\left[\mathrm{Zn}_{3}(\mathrm{BPDC})_{3}(\mathrm{APy})\right] \cdot n \mathrm{nMMF}$ by heating a mixture of $\mathrm{Zn}\left(\mathrm{NO}_{3}\right)_{2} \cdot 6 \mathrm{H} 2 \mathrm{O}(0.0297 \mathrm{~g})$, BPDC $(0.024 \mathrm{~g})$ and APy $(0.009 \mathrm{~g})$ in $10 \mathrm{~mL}$ $\mathrm{DMF}$ as solvent at $100{ }^{\circ} \mathrm{C}$ for 2 days. One of the crystals was used for single crystal X-ray diffraction study.

\section{Crystal Structure:}

$\left[\mathrm{Zn}_{3}(\mathrm{BPDC})_{3}(\mathrm{APy})\right] \cdot \mathrm{nDMF}$ is a three-dimensional microporous metal organic framework crystallized in monoclinic space group $P 2{ }_{1} / \mathrm{c}$, which features interpenetration of two identical 3D nets (see Figure 21). The structure of one of the two identical 3D nets was constructed upon a trinuclear SBU. Each SBU connects, through six BPDC ligands, to six neighboring SBUs to form 2D networks which are connected into 3-dimensional by APy ligands (see also Figure 2). The pores in hl2-14d are filled with highly disordered guest solvent molecules, which were hardly located by single crystal X-ray diffraction study.

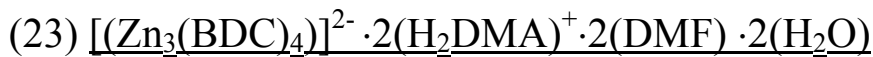

\section{Synthesis:}

After dissolution of zinc(II) nitrate hexahydrate $(80.0 \mathrm{mg}$, $0.27 \mathrm{mmol}$ ), terephthalic acid (BDC, $45.0 \mathrm{mg}, 0.27 \mathrm{mmol})$ and triethylenediamine- $N, N$-dioxide (TEDDO, selfprepared, $49.0 \mathrm{mg}, 0.27 \mathrm{mmol}$ ) in dimethylformamide (15 $\mathrm{mL})$ and water $(3 \mathrm{~mL})$ in a glass vial, the mixture was heated at $80{ }^{\circ} \mathrm{C}$ for 3 days before it was cooled to room temperature naturally. Big, colorless, transparent blocklike crystals thus obtained were suitable for single-crystal $\mathrm{X}$-ray diffraction study.

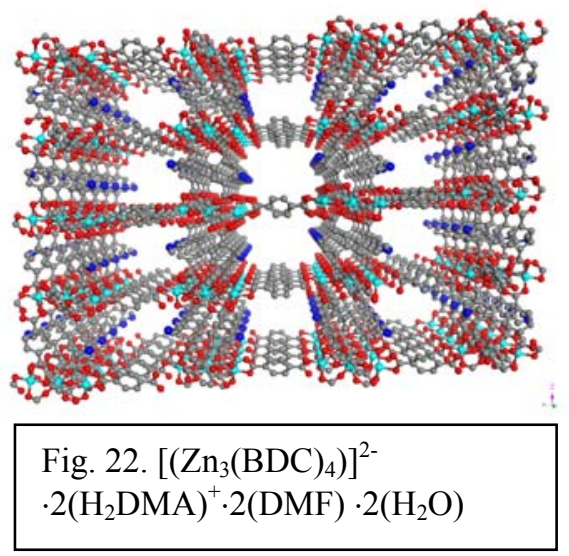




\section{Crystal Structure:}

$\left[\left(\mathrm{Zn}_{3}(\mathrm{BDC})_{4}\right)\right]^{2-} \cdot 2\left(\mathrm{H}_{2} \mathrm{DMA}\right)^{+} \cdot 2(\mathrm{DMF}) \cdot 2\left(\mathrm{H}_{2} \mathrm{O}\right)$ is a three-dimensional microporous metal organic framework that crystallizes in monoclinic space groups $C 2 / \mathrm{c}$ (Figure 22). The asymetric unit includes two crystallographically different zinc (for $\mathrm{Zn} 2$, the occupation factor is 0.5 ), two BDC, one dimethylammonium cation (probably from the decomposition of DMF), one DMF molecule, and one water molecule.

The structure features a negatively charged framework that is constructed upon secondary bulding units that are shown in Figure 2. The tri-nuclear SBU consists of three Zn(II) centers arranged in a almost linear fashion with $\mathrm{Zn} 2$ in the middle and two $\mathrm{Zn} 1$ at the end. Three carboxyl groups from three BDC ligands coordinate to a pair of Zn1-Zn2 in two diiferent modes. For two of the three carboxyls, both oxygen atoms bind to $\mathrm{Zn} 1$ and $\mathrm{Zn} 2$, respectively, in the monodentate syn/syn bridging mode. For a third carboxyl, only one oxygen binds to both $\mathrm{Zn} 1$ and $\mathrm{Zn} 2$ in $\mu 2$ mode. Thus, $\mathrm{Zn} 2$ is of octahedral coordination geometry with six oxygen. The BDC ligands strech out and connect to the adjacent SBUs to form double-layers that are roughly parallel with the $b c$ plane. The oxygen from a fourth BDC ligandand coordinates to Zn1 along the $\mathrm{Zn} 1-\mathrm{Zn} 2-\mathrm{Zn} 1$ axis to complete the tetrahrdral coordination sphere of $\mathrm{Zn} 1$ and effectively integrate the double-layers described above into three-dimentional negatively charged framework structure. The negative charge of the framework is balanced by the dimethylammonium cations that are found to reside in close vincinity of the SBUs, which partially obstruct the channels along $a$ axis. Disordered DMF and water guest molecules were located inside the interconnected 3D channels of irregular shape and size.

\section{(24) $\left[\mathrm{Mn}_{1.5}(\mathrm{OBBA})_{1.5}\left(\mathrm{H}_{2} \mathrm{O}\right)(\mathrm{Py})\right] \cdot \mathrm{Py}$}

Synthesis:

Manganese(II) chloride (62.9 $\mathrm{mg}, 0.5 \mathrm{mmol})$ and 4,4'-oxybis(benzoic acid) (OBBA, $130.8 \mathrm{mg}, 0.5$ mmol) were placed into a Teflon-lined acid digestion bomb. After addition of pyridine (Py, 2 $\mathrm{mL})$ and water $(5 \mathrm{~mL})$, the mixture was homogenized by ultrasonication for 3 minutes. Thereafter, the bomb was sealed and heated at 120 ${ }^{\circ} \mathrm{C}$ under autogenous pressure for 70 hours before it was cooled to room temperature naturally. The Pale pink single crystals thus obtained were suitable for

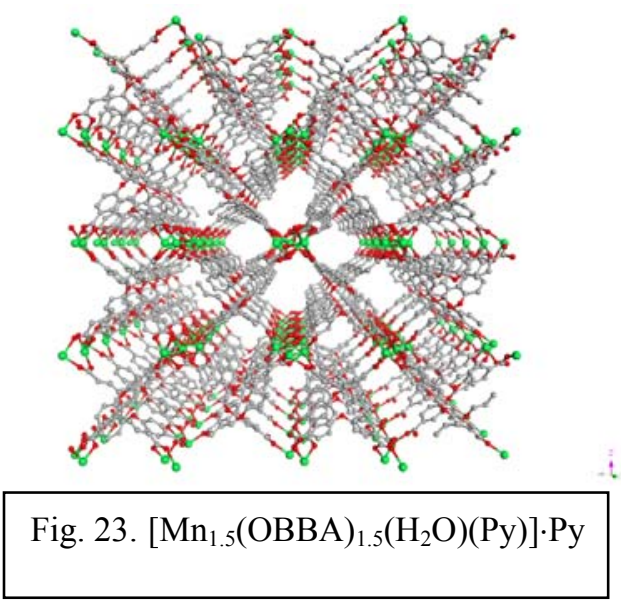
single-crystal X-ray diffraction study.

\section{Crystal Structure:}

$\left[\mathrm{Mn}_{1.5}(\mathrm{OBBA})_{1.5}\left(\mathrm{H}_{2} \mathrm{O}\right)(\mathrm{Py})\right] \cdot \mathrm{Py}$ is a three-dimensional microporous metal-organic framework crystallized in a orthorhombic space group Pccn (Figure 3). The 3D network structure is also built upon centrosymetric tri-nuclear SBUs as shown in Figure 23.

Compared to the tri-nuclear SBUs found in $\left[\left(\mathrm{Zn}_{3}(\mathrm{BDC})_{4}\right)\right]^{2-} \cdot 2\left(\mathrm{H}_{2} \mathrm{DMA}\right)^{+} \cdot 2(\mathrm{DMF}) \cdot 2\left(\mathrm{H}_{2} \mathrm{O}\right)$, all $\mathrm{Mn}(\mathrm{II})$ centers are six-coordinated. There are three carbxyls from OBBA that bind to each pair of $\mathrm{Mn} 2-\mathrm{Mn} 1$ in two different modes. Two carboxyls bind to Mn2 and Mn1, respectively, with both oxygen in monodentate bridging mode, similar as in $\left[\left(\mathrm{Zn}_{3}(\mathrm{BDC})_{4}\right)\right]^{2-}$ $\cdot 2\left(\mathrm{H}_{2} \mathrm{DMA}\right)^{+} \cdot 2(\mathrm{DMF}) \cdot 2\left(\mathrm{H}_{2} \mathrm{O}\right)$. Another carboxyl binds to $\mathrm{Mn} 2$ in chelation mode with one of the two oxygens further binding to Mn1. A oxygen from water and a nitrogen from pyridine also 
coordinate to $\mathrm{Mn} 2$ to complete the distorted octahedral coordination gometry. The OBBA ligands, due to their bent conformation, connect to adjacent SBUs above and below to form the overall three-dimensional structure. Pyridine molecules are also located as free guest molecules inside the mainly two-dimensionally interconnected channels.

If the coordinated pyridine molecules can be removed without affecting the framework sturcture, the channel system becomes three dimensional and unsaturated Mn2 sites may become avalable for catalysis and stronger hydrogen binding. The shortest Mn2-Mn1 distance is found to be 3.592 $\AA$, indicating potential electron spin interactions which may lead to interesting magnetic properties.

\section{(25) $\left[\left(\mathrm{Zn}_{4.5}(\mathrm{BDC})_{3}\right)(\mathrm{OH})_{3}\right] \cdot 3 \mathrm{DEF}$}

\section{Synthesis:}

Zinc (II) nitrate hexahydrate $(0.947 \mathrm{~g})$ and terephthalic acid (BDC, 98\%, 0.150g) were mixed in DEF $(10 \mathrm{~mL})$ and heated at $100{ }^{\circ} \mathrm{C}$ in an isothermal oven for one day before it was cooled to room temperature naturally. After filtration, the crystals were rinsed with DMF $(10 \mathrm{~mL})$ three times and dried at $50{ }^{\circ} \mathrm{C}$ under vacuum for 5 minutes. Yellowish cubic crystals thus obtained were suitable for single-crystal X-ray diffraction study.

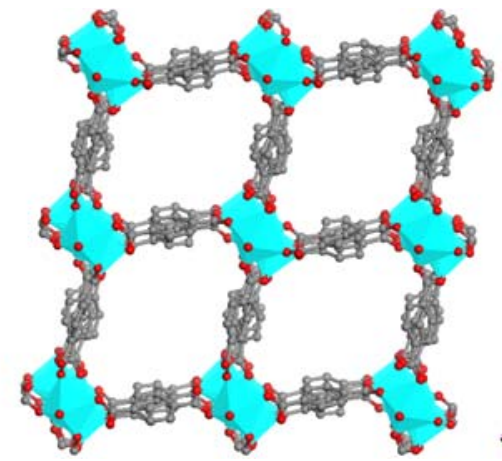

Fig. 24. $\left[\left(\mathrm{Zn}_{4.5}(\mathrm{BDC})_{3}\right)(\mathrm{OH})_{3}\right] \cdot 3 \mathrm{DEF}$.

Crystal Structure:

$\left[\left(\mathrm{Zn}_{4.5}(\mathrm{BDC})_{3}\right)(\mathrm{OH})_{3}\right] \cdot 3 \mathrm{DEF}$ exhibits a three-dimensional microporous framework strucutre consisting of infinite one-dimensional chains of zinc oxyhydroxide connected to each other by BDC ligands (Figure 24). Diethylformamide molecules are located inside the one-dimesional channels by singl crystal X-ray diffraction study (not shown in the figures). The overall structure closely resembles that of MOF-69. [Rosi et al., Angew. Chem., Int. Ed. 2002, 2, 284].

The DEF guest molecules are hydrogen bonded to the $\mathrm{OH}$ group on the 1D infinite SBU and therefore are difficult to remove (see Thermogravimetric Analysis below) and the material change to another unidentified structure after removal of the DEF guests (see PXRD below).

\section{(26) $[\mathrm{Mn}(\mathrm{hfipbb})(\mathrm{Py})] \cdot 0.5 \mathrm{H}_{2} \underline{\mathrm{O}}$}

\section{Synthesis:}

A mixture of $\mathrm{MnCl}_{2} \quad(0.0629 \mathrm{~g}, 0.5 \mathrm{mmol}), 4,4$ '(hexafluoroisopropylidene)bis(benzoic acid) (hfipbb, 0.195, $0.5 \mathrm{mmol})$, pyridine $(2 \mathrm{~mL})$ and $\mathrm{H}_{2} \mathrm{O}(5 \mathrm{~mL})$ was sealed in a Teflon-lined acid digestion bomb and heated at $150{ }^{\circ} \mathrm{C}$ for 3 days under autogenous pressure. After cooling down to room temperature, $0.18 \mathrm{~g}$ pale pink column-shaped crystals were collected $(68 \%$ yield $)$. A suitable crystal was selected for structure determination by single-crystal X-ray

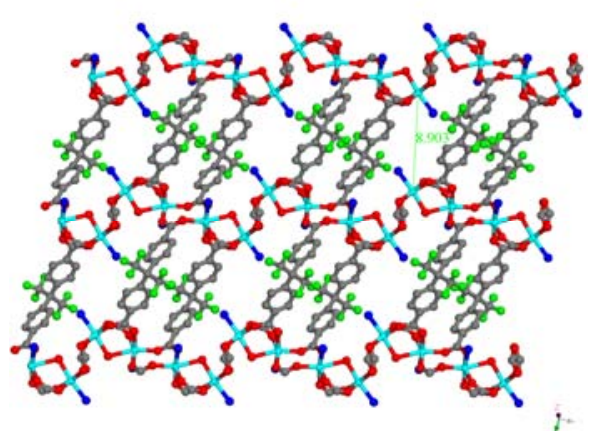

Figure 25. [Mn(hfipbb)(Py)] $0.5 \mathrm{H}_{2} \mathrm{O}$ diffraction. 


\section{Crystal Structure:}

All coordination geometries around $\mathrm{Mn}$ are octahedral. Two crystallographically independent $\mathrm{Mn}$ atoms (Mn1 and Mn2) exist in this structure. Mn2 is bound to four oxygen atoms (O2, O3, $\mathrm{O} 4, \mathrm{O} 8$ ) from four carboxylate groups, forming the equatorial plane; the apical positions are taken by a bridging oxygen atom (O9 from water) and a nitrogen from pyridine (N2). Mn1 is also bound to five oxygen atoms, four from carboxylate groups $(\mathrm{O} 1, \mathrm{O} 5, \mathrm{O} 6, \mathrm{O} 7)$ and one from bridging water oxygen (O9), In contrast to $\mathrm{Mn} 2$, the equatorial plane are formed by three carboxylate oxygen $(\mathrm{O} 1, \mathrm{O} 5, \mathrm{O} 6)$ and a bridging water oxygen atom $(\mathrm{O} 9)$. One carboxylate oxygen $\mathrm{O} 7$ and pyridine $\mathrm{N}$ occupy the apical positions. Mn1 and Mn1 are connected (Mn1-Mn1 distance: $4.726 \AA$ ) by two carboxylate groups in bidentate mode, whereas the $\mathrm{Mn} 1$ and $\mathrm{Mn} 2$ (Mn1-Mn2 distance: $3.813 \AA$ ) are bridged by two carboxylate groups and one bridged oxygen. $\mathrm{Mn} 2$ and $\mathrm{Mn} 2$ are connected (Mn2-Mn2 distance: $4.680 \AA$ ) by two carboxylate groups. The alternately connection (-Mn2-Mn2-Mn1-Mn1-Mn2-Mn2-Mn1-Mn1) along $x$-axis forms 1D chain. There are two types of hfipbb ligands. Each chain is connected by one type of ligand via its carboxylate oxygen $(\mathrm{O} 5, \mathrm{O} 6, \mathrm{O} 7, \mathrm{O} 8)$ approximately running along $x y$ plane to form $2 \mathrm{D}$ structure. The adjacent planes are connected by another hfipbb ligand through its carboxylate oxygen $(\mathrm{O} 1, \mathrm{O} 2, \mathrm{O} 3, \mathrm{O} 4)$ along $\mathrm{z}$ axis to generate a 3D structure. The shortest inter-chain MnMn distance is $8.903 \AA$ (Figure 25). If the coordinated pyridine molecules can be removed without affecting the framework sturcture, the unsaturated Mn2 sites may become avalable for catalysis and stronger hydrogen binding.

\section{(27) $\left[\mathrm{Cu}_{2} \underline{3}(\mathrm{btc})_{2}\left(\mathrm{H}_{2} \underline{\mathrm{O}}\right)_{3}\right]$}

\section{Synthesis:}

Pure crystalline samples of $\left[\mathrm{Cu}_{3}(\mathrm{btc})_{2}\left(\mathrm{H}_{2} \mathrm{O}\right)_{3}\right]$ (btc $=$ benzene-1,3,5-tricarboxylate) were synthesized by solvothermal reactions of $\mathrm{Cu}\left(\mathrm{NO}_{3}\right)_{2}$ and btc in water and ethanol. All reactions were conducted at $130^{\circ} \mathrm{C}$ for four hours. A total amount of $800 \mathrm{mg}$ of samples (turquoisecolored, powder-like solid) was prepared, all identified by PXRD analysis.

\section{Crystal Structure and Data:}

Description of this structure can be found in the paper published by S. Chui, S. Lo, J. Charmant, A. G. Orpen, and I. D. Williams, Science, 1999, 283, 1148. 
Table 1. Important Crystal Structure Data

\begin{tabular}{|c|c|c|c|c|c|c|c|c|c|c|c|c|c|}
\hline \multicolumn{14}{|c|}{ Porous Structures } \\
\hline & Formula & Fw & struc. & $\mathrm{z}$ & $a$ & $b$ & $c$ & $\alpha$ & $\beta$ & $\gamma$ & $\mathrm{V}$ & $D_{c}$ & $S p G r$ \\
\hline 1 & {$\left[\mathrm{Co}_{3}(\mathrm{bpdc})_{3}(\mathrm{bpy})\right] \cdot 4 \mathrm{DMF} \cdot \mathrm{H}_{2} \mathrm{O}$} & 1363.99 & $3 \mathrm{D}$ & 4 & 14.195 & 25.645 & 18.210 & 90 & 90 & 90 & 6629 & 1.367 & $P b c n$ \\
\hline 2 & {$\left[\mathrm{Co}_{2}(\mathrm{bpdc})_{2}(\mathrm{bpy})_{2}\right] \cdot \mathrm{DMF}$} & 983.33 & $3 \mathrm{D}$ & 4 & 9.523 & 20.618 & 25.874 & 90 & 96.20 & 90 & 5050 & 1.294 & $C 2 / c$ \\
\hline 3 & {$\left[\mathrm{Co}_{3}(\mathrm{hfipbb})_{2}\left(\mathrm{CHO}_{2}\right)_{2}(\mathrm{dpp})\left(\mathrm{H}_{2} \mathrm{O}\right)_{2}\right] \cdot 2 \mathrm{DMF} \cdot \mathrm{PhBr}_{2}$} & 1663.69 & $3 \mathrm{D}$ & 4 & 23.658 & 8.293 & 35.091 & 90 & 92.03 & 90 & 6880 & 1.606 & $P 2_{1} / c$ \\
\hline 4 & {$\left[\mathrm{Cu}_{4}(\mathrm{ipa})_{4}(\mathrm{bpe})_{3}\left(\mathrm{H}_{2} \mathrm{O}\right)\right] \cdot 1.7 \mathrm{H}_{2} \mathrm{O}$} & 1511.96 & $3 \mathrm{D}$ & 3 & 11.0441 & 11.0441 & 46.956 & 90 & 90 & 120 & 4960.0 & 1.519 & $P 3_{1}$ \\
\hline 5 & {$[\mathrm{Mg}(\mathrm{bpdc})(\mathrm{DMF})] \cdot \mathrm{nDMF}$} & 4114.77 & $3 \mathrm{D}$ & 4 & 24.7754 & 26.9938 & 33.458 & 90 & 109.96 & 90 & 4114.77 & 1.299 & $P 2_{1} / n$ \\
\hline 6 & {$\left[\mathrm{Y}_{2}(\mathrm{sdba})_{3}\left(\mathrm{H}_{2} \mathrm{O}\right)_{2}\right] \cdot 0.616 \mathrm{EtOH} \cdot 0.125 \mathrm{H}_{2} \mathrm{O}$} & 1157.69 & $3 \mathrm{D}$ & 2 & 12.5152 & 12.7345 & 17.5488 & 102.216 & 94.234 & 117.727 & 2371.2 & 1.621 & $P-1$ \\
\hline 7 & {$\left[\mathrm{Zn}(\mathrm{bdc})(\mathrm{ted})_{0.5}\right] \cdot 2 \mathrm{DMF} \cdot 0.05 \mathrm{H}_{2} \mathrm{O}$} & 432.69 & $3 \mathrm{D}$ & 8 & 14.8999 & 14.8999 & 19.1362 & 90 & 90 & 90 & 4248.4 & 1.893 & P4/ncc \\
\hline 8 & {$\left[\mathrm{Zn}(\mathrm{btc})(\mathrm{ted})_{0.5}\right] \cdot \mathrm{nDMF}$} & 323 & $3 \mathrm{D}$ & 4 & 18.9183 & 19.9173 & 13.9877 & 90 & 90 & 90 & 5270.6 & 0.828 & $P b c n$ \\
\hline 9 & {$[\mathrm{Zn}(\mathrm{bpdc})(\mathrm{bpe})] \cdot \mathrm{DMF}$} & 562.91 & $3 \mathrm{D}$ & 4 & 14.728 & 8.163 & 23.249 & 90 & 90 & 90 & 2807.1 & 1.332 & Pna21 \\
\hline 10 & {$\left[\mathrm{Zn}(\mathrm{bpdc})(\mathrm{ted})_{0.5}\right] \cdot \mathrm{nDMF}$} & 355.63 & $3 \mathrm{D}$ & 2 & 15.2312 & 15.2312 & 9.663 & 90 & 90 & 90 & 2241.7 & 0.5269 & $P 422$ \\
\hline 11 & {$\left[\mathrm{Zn}_{4} \mathrm{O}(\mathrm{bdc})_{3}\right] \cdot 3 \mathrm{DMF} \cdot 2 \mathrm{H}_{2} \mathrm{O}$} & 1186.14 & $3 \mathrm{D}$ & 8 & 25.833 & 25.833 & 25.833 & 90 & 90 & 90 & 17239 & 0.914 & $F m-3 m$ \\
\hline 12 & Zn(tbip) & 285.59 & $3 \mathrm{D}$ & 18 & 28.863 & 28.863 & 7.977 & 90 & 90 & 120 & 5755.1 & 1.483 & $R-3 m$ \\
\hline 13 & {$\left[\mathrm{Zn}_{3}(\mathrm{bpdc})_{3}(\mathrm{DMF})_{2}\right] \cdot 4 \mathrm{DMF}$} & 1361.35 & $2 \mathrm{D}$ & 2 & 11.8499 & 14.6902 & 19.6054 & 90 & 101.825 & 90 & 3346.9 & 1.351 & $P 2_{1} / n$ \\
\hline 14 & $\alpha-\left[\mathrm{La}_{2}(\mathrm{Hpdc})_{2}\left(\mathrm{C}_{2} \mathrm{O}_{4}\right)\left(\mathrm{H}_{2} \mathrm{O}\right)_{4}\right] \cdot 2 \mathrm{H}_{2} \mathrm{O}$ & 782.11 & $3 \mathrm{D}$ & 4 & 8.633 & 32.599 & 8.122 & 90 & 107.76 & 90 & 2176.8 & 2.386 & $P 2_{1} / c$ \\
\hline 15 & $\left.\beta-\mathrm{La}_{2}(\mathrm{Hpdc})_{2}\left(\mathrm{C}_{2} \mathrm{O}_{4}\right)\left(\mathrm{H}_{2} \mathrm{O}\right)_{4}\right] \cdot 2 \mathrm{H}_{2} \mathrm{O}$ & 782.11 & $3 \mathrm{D}$ & 2 & 8.892 & 17.307 & 8.008 & 90 & 108.84 & 90 & 1140.1 & 2.278 & $P 2_{1} / c$ \\
\hline 16 & {$\left[\mathrm{Co}_{2}(\mathrm{OBBA})_{2}(\mathrm{APY}-\mathrm{re})_{2}(\mathrm{OH})\right] \cdot 3 \mathrm{DMF}$} & 1235.98 & $3 \mathrm{D}$ & 4 & 11.138 & 27.137 & 19.692 & 90 & 99.25 & 90 & 5875 & 1.397 & $P 2_{1} / c$ \\
\hline 17 & {$\left[\mathrm{Co}_{3}(\mathrm{HCOO})_{6}\right] \cdot \mathrm{DMF}$} & 520.00 & $3 \mathrm{D}$ & 4 & 11.383 & 9.929 & 14.432 & 90 & 91.250 & 90 & 1630.9 & 2.118 & $P 2_{1} / c$ \\
\hline 18 & {$\left[\mathrm{Mn}_{3}(\mathrm{HCOO})_{6}\right] \cdot \mathrm{DMF}$} & 508.02 & $3 \mathrm{D}$ & 4 & 11.683 & 10.250 & 15.154 & 90 & 91.86 & 90 & 1813.8 & 1.860 & $P 2_{1} / n$ \\
\hline 19 & {$\left[\mathrm{Co}(\mathrm{OBBA})(\mathrm{BPy})_{0.5}\right]$} & 393.23 & $3 \mathrm{D}$ & 8 & 22.456 & 13.667 & 12.748 & 90 & 115.74 & 90 & 3524.2 & 1.482 & $C 2 / c$ \\
\hline 20 & {$[\mathrm{Zn}(\mathrm{FODC})(\mathrm{BPy}) 0.5] \cdot \mathrm{nDMF}$} & $409.68 *$ & $3 \mathrm{D}$ & 11 & 13.826 & 21.787 & 20.199 & 90 & 123.027 & 90 & 5927.8 & $1.059 *$ & $P 2_{1} / c$ \\
\hline 21 & {$\left[\mathrm{Zn}_{3}(\mathrm{BPDC})_{3}(\mathrm{APy})\right] \cdot \mathrm{nDMF}$} & 1088.96* & $3 \mathrm{D}$ & 4 & 19.698 & 13.800 & 26.288 & 90 & 96.244 & 90 & 7103.7 & $1.02 *$ & $P 2_{1} / c$ \\
\hline 22 & {$\left[\mathrm{Zn}_{3}(\mathrm{BDC})_{4}\right]^{2-} \cdot 2\left(\mathrm{H}_{2} \mathrm{DMA}\right)^{+} \cdot 2 \mathrm{DMF} \cdot 2 \mathrm{H}_{2} \mathrm{O}$} & 1127.09 & $3 \mathrm{D}$ & 4 & 33.106 & 9.687 & 18.325 & 90 & 94.338 & 90 & 5859.7 & 1.277 & $C 2 / c$ \\
\hline 23 & {$\left[\mathrm{Mn}_{1.5}(\mathrm{OBBA})_{1.5}\left(\mathrm{H}_{2} \mathrm{O}\right)(\mathrm{Py})\right] \cdot \mathrm{Py}$} & 640.92 & $3 \mathrm{D}$ & 8 & 23.189 & 11.2185 & 22.884 & 90 & 90 & 90 & 5953.0 & 1.430 & Pccn \\
\hline 24 & {$\left[\mathrm{Zn}_{4.5}(\mathrm{BDC})_{3}(\mathrm{OH})_{3}\right] \cdot 3 \mathrm{DEF}$} & 1140.97 & $3 \mathrm{D}$ & 4 & 17.653 & 14.765 & 18.133 & 90 & 111.934 & 90 & 4384.1 & 1.729 & $P 2_{1} / n$ \\
\hline
\end{tabular}




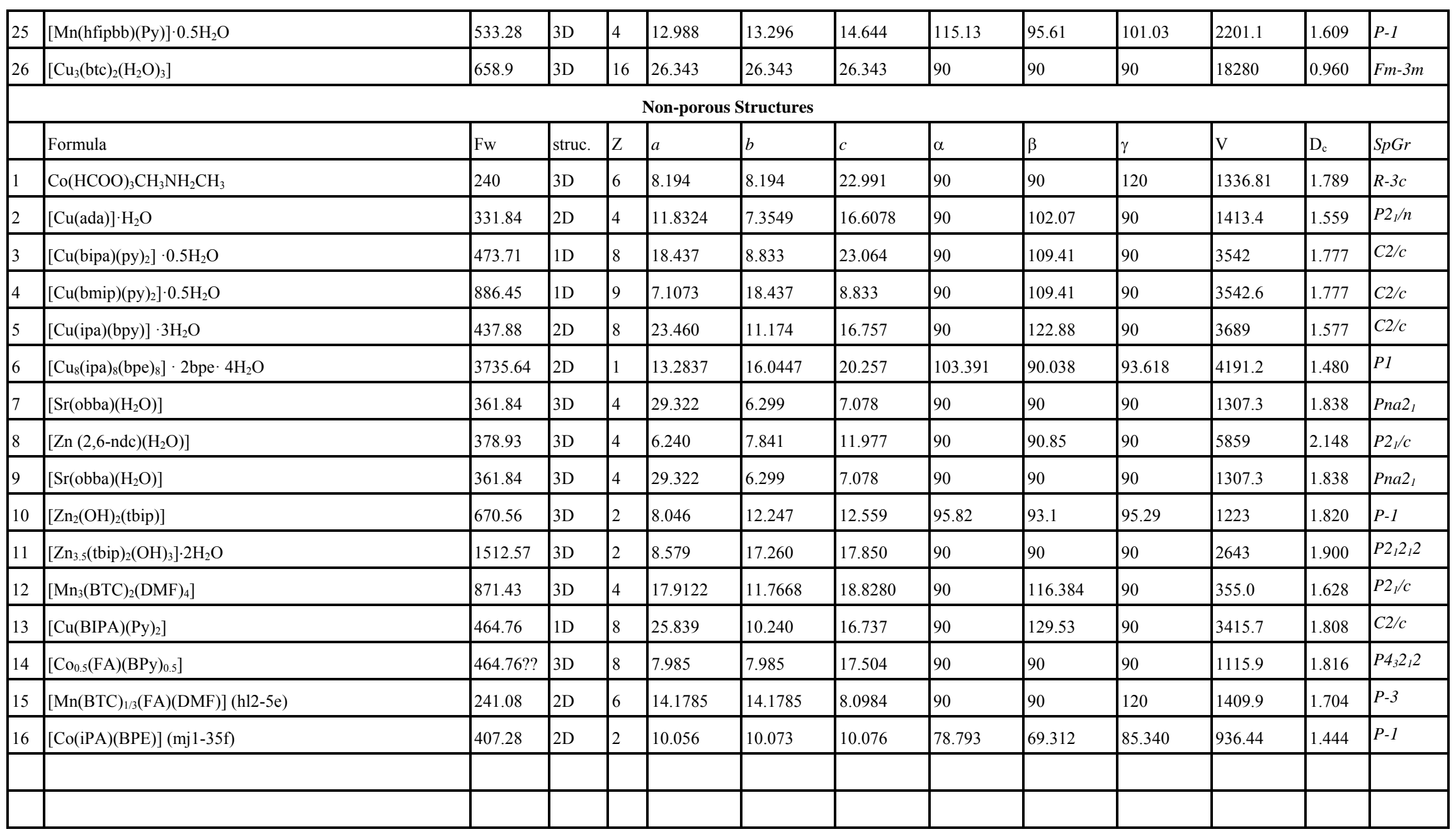


1,4-ndc $=1,4$-napthalenedicarboxylic acid $-2 \mathrm{H}$

obba $=4,4$ '-oxybis(benzoic acid)

$\mathrm{dpa}=2,2$ '-dipyridylamine

bipa $=5$-bromoisophthalic acid

ipa $=$ isophthalic acid

btc $=1,3,5$-benzenetricarboxylic acid

ada $=1,3$-adamantanediacetic acid

DMA $=\mathrm{N}, \mathrm{N}$-dimethylacetamide

$\mathrm{DMF}=\mathrm{N}, \mathrm{N}$-dimethylformamide

tbipa $=5$-tert-butylisophthalic Acid tbip $=$ tbipa $-2 \mathrm{H}$ ?

hfipbb $=4,4$ '-hexafluoroisopropyldienebis(benzoic acid) $-2 \mathrm{H}$ ?

$\mathrm{dpp}=$ 1,3-Di(4-pyridyl)propane 


\section{GAS SORPTION PROPERTIES OF THE MICROPOROUS MOFs.}

The Rutgers team has investigated hydrogen adsorption-desorption properties of a selected number of porous structures at low temperatures. The results are summarized in Table 2 and briefly described below.

The low temperature high-resolution gas adsorption-desorption measurements were performed using an automated micropore gas analyzer, Autosorb-1 MP (Quantachrome Instruments). The hydrogen sorption isotherms were collected in a relative pressure range from $10^{-4}$ to $1 \mathrm{~atm}$ at $77 \mathrm{~K}$ and $87 \mathrm{~K}$. The initial outgassing process for each sample was carried out under vacuum at $393 \mathrm{~K}$ for 15 16 hours. About 50 100 mg of degassed samples were used for gas sorption studies and the weight of sample was recorded and the PXRD patterns were taken before and after outgassing to confirm the removal of all guest molecules and the structural integrity. The outgassing procedure was repeated on the same sample between experiments for $0.5 \sim 1$ hour. A total analysis time was ca. 9 10 hours for hydrogen sorption. For nitrogen adsorption, it took 77hours for first fifteen points and it took another 48hours to complete adsorption and desorption. Ultra high purity of compressed $\mathrm{H}_{2}$ gas (UHP 5.0) and nitrogen gas (UHP 5.0) were used for analysis. The pore properties including pore volume, pore size, and surface area were analyzed using Autosorb v1.50 software.

$\left[\mathrm{CO}_{3}(\mathrm{bpdc})_{3}(\mathrm{bpy})\right] \cdot 4 \mathrm{DMF} \cdot \mathrm{H}_{2} \underline{\mathrm{O}}$

We carried out gas adsorption study at cryogenic temperatures (77 and $87 \mathrm{~K}$ ). We measured argon adsorption-desorption isotherms at $87 \mathrm{~K}$ and hydrogen adsorption-desorption isotherms at both 77 and $87 \mathrm{~K}$ under pressures below 1 atmosphere. The argon sorption follows a typical Type I isotherm with an estimated langmuir surface area of $1129 \mathrm{~m}^{2} / \mathrm{g}$. The hydrogen adsorptiondesorption isotherms at 87 and $77 \mathrm{~K}$ are plotted in Fig. 26a. No hysteresis was observed in these isotherms. At 87 and $77 \mathrm{~K}$ and $1 \mathrm{~atm}$, the values are $1.13 \mathrm{wt} \%$ and $1.52 \mathrm{wt} \%$, respectively.

\section{$\left[\mathrm{Cu}_{3}\left(\mathrm{BTC}_{2}\right)_{2}\left(\mathrm{H}_{2} \underline{\mathrm{O}}\right)_{3}\right]$}

We performed both argon and hydrogen sorption experiments at low temperatures on this structure. The Ar isotherms (Type-1) were obtained at $87 \mathrm{~K}$ at pressures ranging from $p<10^{-6}$ to $p=1 \mathrm{~atm}$. The DA pore volume was estimated to be $0.37 \mathrm{cc} / \mathrm{g}$. The hydrogen uptakes were 1.07 and $1.44 \mathrm{wt} \%$ at $87 \mathrm{~K}(1 \mathrm{~atm})$ and $77 \mathrm{~K}(1 \mathrm{~atm})$, respectively, as plotted in Fig. 26b.

$\left[\mathrm{Zn}(\mathrm{L})(\mathrm{ted})_{0.5}\right] \cdot 2 \mathrm{DMF}(\mathrm{L}=$ bdc, bpdc)

Hydrogen adsorption-desorption isotherms were measured at low temperatures. Fig. 29 (left) show the data for $\left[\mathrm{Zn}(\mathrm{bdc})(\text { ted })_{0.5}\right] \cdot 2 \mathrm{DMF}$ at both 77 and $87 \mathrm{~K}$. The maximum $\mathrm{H}_{2}$ uptake is 2.15 and $1.21 \mathrm{wt} \%$ at 77 and $87 \mathrm{~K}$, respectively. As seen in the figure, the process was completely reversible for both temperatures. The $\mathrm{H}_{2}$ isotherm for $\left[\mathrm{Zn}(\mathrm{bpdc})(\mathrm{ted})_{0.5}\right] \cdot 2 \mathrm{DMF}$ at $77 \mathrm{~K}$ is plotted in Fig. 27 (right). The amount of $\mathrm{H}_{2}$ uptake is significantly smaller than that of $\left[\mathrm{Zn}(\mathrm{bdc})(\mathrm{ted})_{0.5}\right] \cdot 2 \mathrm{DMF}$, most likely due to the less framework stability after removal of the guest molecules. 


\section{$\underline{\mathrm{Zn}(\mathrm{tbip})}$}

We analyzed pore properties of $\mathrm{Zn}$ (tbip) via $\mathrm{Ar}$ and $\mathrm{N}_{2}$ sorption at 87 and $77 \mathrm{~K}$, respectively. The DA (Dubinin-Astakhov) pore volume was calculated to be $0.14 \mathrm{~cm}^{3} / \mathrm{g}$ and $0.15 \mathrm{~cm}^{3} / \mathrm{g} \mathrm{based}$ on the $\mathrm{N}_{2}$ and Ar data, respectively. Both follow a typical Type I isotherm. A gravimetric density of $0.76 \mathrm{wt} \%$ and $0.51 \mathrm{wt} \%$ of hydrogen was achieved at $77 \mathrm{~K}$ and $87 \mathrm{~K}$ and $1 \mathrm{~atm}$, respectively. The hydrogen isotherms at 77 and $87 \mathrm{~K}$ are shown in Fig. 28 (left).

\section{$\left[\mathrm{Co}_{3}(\mathrm{HCOO})_{6}\right] \cdot \mathrm{DMF}$}

The Ar sorption study showed $0.16 \mathrm{~cm}^{3} / \mathrm{g}$ DA pore volume and $354 \mathrm{~m}^{2} / \mathrm{g}$ of langmuir surface area on $\left[\mathrm{Co}_{3}(\mathrm{HCOO})_{6}\right]$. The amount of hydrogen uptake was $0.75 \mathrm{wt} \%$ at $77 \mathrm{~K}$ and $0.65 \mathrm{wt} \%$ at $87 \mathrm{~K}$ and $1 \mathrm{~atm}$ (Fig. 28, right). Interestingly the pore volume and hydrogen uptake capability of this compound are very close to those values of $\mathrm{Zn}$ (tbip) indicating correlation between pore volume and hydrogen uptake.

\section{$\left[\mathrm{Zn}_{3}(\mathrm{bpdc})_{3}\right.$ (apy) $] \cdot \mathrm{nDMF}$}

The hydrogen sorption study was performed on $\left[\mathrm{Zn}_{3}(\mathrm{bpdc})_{3}(\right.$ apy) $]$ compound. The uptake value is $1.38 \mathrm{wt} \%$ at $77 \mathrm{~K} 1 \mathrm{~atm}$ as shown in Fig. 29 (left).

\section{$[\mathrm{Mg}(\mathrm{bpdc})(\mathrm{DMF}) 1.3] \cdot \mathrm{nDMF}$}

The hydrogen sorption study was performed on $\left[\mathrm{Mg}(\mathrm{bpdc})(\mathrm{DMF})_{1.3}\right]$ compound. The uptake value is $0.70 \mathrm{wt} \%$ at $77 \mathrm{~K}$ and 0.52 at $87 \mathrm{~K}$, respectively (see Fig. 29 , right).

Table 2. Summary of Hydrogen Adsorption Data at 77K and 1 atm

\begin{tabular}{|c|c|c|c|c|c|c|c|c|}
\hline \multicolumn{4}{|c|}{ Sample Information } & \multicolumn{2}{|c|}{$\begin{array}{c}\mathrm{H}_{2} \text { Uptake (wt\%) } \\
\text { (1 atm) }\end{array}$} & \multicolumn{3}{|c|}{ Pore Volume (cc/g) } \\
\hline Molecular Formula & $\begin{array}{l}\text { Density } \\
\left(\mathrm{g} / \mathrm{cm}^{3}\right)\end{array}$ & $\begin{array}{c}\text { Acc.Vol. } \\
\%\end{array}$ & $\begin{array}{c}\text { Density\# } \\
\left(\mathrm{g} / \mathrm{cm}^{3}\right)\end{array}$ & $77 \mathrm{~K}$ & $87 \mathrm{~K}$ & DA & DR & $0.99\left(\mathrm{P} / \mathrm{P}_{0}\right)$ \\
\hline$\left[\mathrm{Co}_{3}(\mathrm{bpdc})_{3}(\mathrm{bpy})\right] \cdot 4 \mathrm{DMF} \cdot \mathrm{H}_{2} \mathrm{O}-\mathrm{RPM} 1-\mathrm{Co}$ & 1.367 & 40.6 & 1.158 & 1.51 & 1.13 & 0.39 & 0.35 & 0.38 \\
\hline [Co(bpdc)(bpy)]·0.5DMF - RPM2 & 1.294 & 28.6 & 1.198 & 0.09 & 0.09 & 0.01 & 0.002 & 0.02 \\
\hline$\left.[\text { Mg(bpdc)(DMF) })_{1.3}\right] \cdot \mathrm{nDMF}$ & 1.299 & 58.1 & 0.767 & 0.70 & 0.52 & - & - & - \\
\hline$\left[\mathrm{Y}_{2}(\mathrm{sdba})_{3}\left(\mathrm{H}_{2} \mathrm{O}\right)_{2}\right] \cdot 0.616 \mathrm{EtOH} \cdot 0.125 \mathrm{H}_{2} \mathrm{O}$ & 1.621 & 17.7 & 1.285 & 0.52 & 0.41 & 0.01 & 0.003 & 0.02 \\
\hline$\left[\mathrm{Zn}(\mathrm{bdc})(\mathrm{ted})_{0.5}\right] \cdot 2 \mathrm{DMF}$ & 1.353 & 56.7 & 0.893 & 2.15 & 1.21 & 0.84 & 0.97 & 0.73 \\
\hline [Zn(bpdc)(bpe)]·DMF - RPM3 & 1.332 & 29.1 & 1.159 & 0.069 & - & - & - & - \\
\hline [Zn(bpdc)(ted) $\left.)_{0.5}\right] \cdot \mathbf{n D M F}$ & $0.710^{*}$ & 73.1 & 0.568 & 0.29 & - & - & - & - \\
\hline [Zn(tbip)] & 1.483 & 17.7 & 1.483 & 0.76 & 0.51 & 0.14 & 0.12 & 0.17 \\
\hline$\left[\mathrm{Co}_{3}(\mathrm{HCOO})_{6}\right] \cdot \mathrm{DMF}$ & $2.068^{*}$ & 32.5 & 1.798 & 0.75 & 0.65 & 0.16 & 0.18 & 0.14 \\
\hline$\left[\mathrm{Zn}_{3}(\mathrm{BPDC})_{3}(\mathrm{APy})\right] \cdot \mathrm{nDMF}$ & $1.046^{*}$ & 45.9 & 0.996 & 1.38 & - & - & - & - \\
\hline$\left[\mathrm{Cu}_{3}(\mathrm{btc})_{2}\left(\mathrm{H}_{2} \mathrm{O}\right)_{3}\right]$ & 0.958 & 69.5 & 0.879 & 1.44 & 1.07 & 0.37 & 0.27 & 0.31 \\
\hline
\end{tabular}

${ }^{*}$ Estimated based on PLATON

\# Estimated based on PLATON after removal of the all guest molecules 

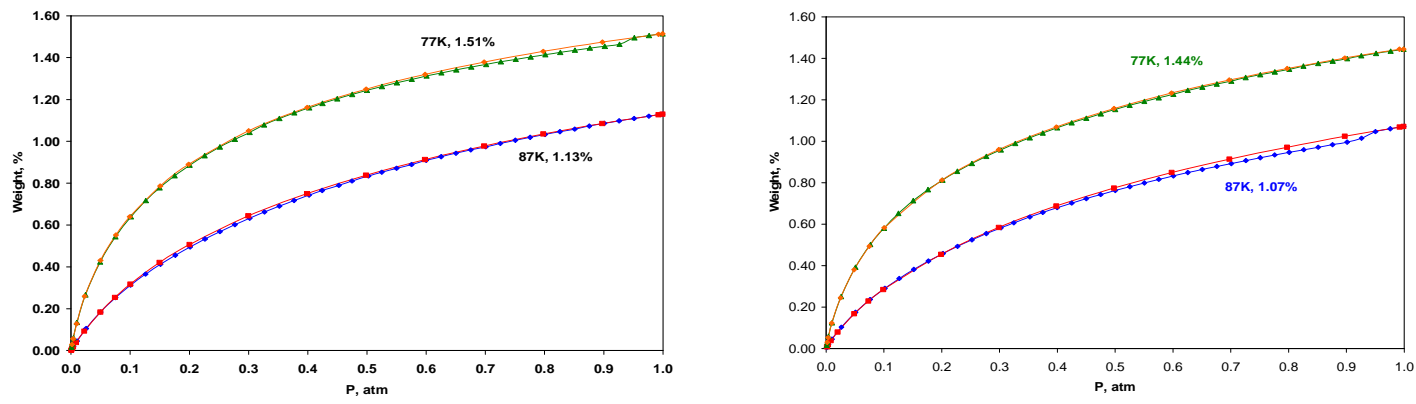

Fig. 26. Hydrogen adsorption-desorption isotherms at 77 and $87 \mathrm{~K}$ for $\left[\mathrm{Co}_{3}(\mathrm{bpdc})_{3}(\mathrm{bpy})\right]$ (left) and $\left.\mathrm{CCu}_{3}(\mathrm{BTC})_{2}\left(\mathrm{H}_{2} \mathrm{O}\right)_{3}\right\rceil$ (right).
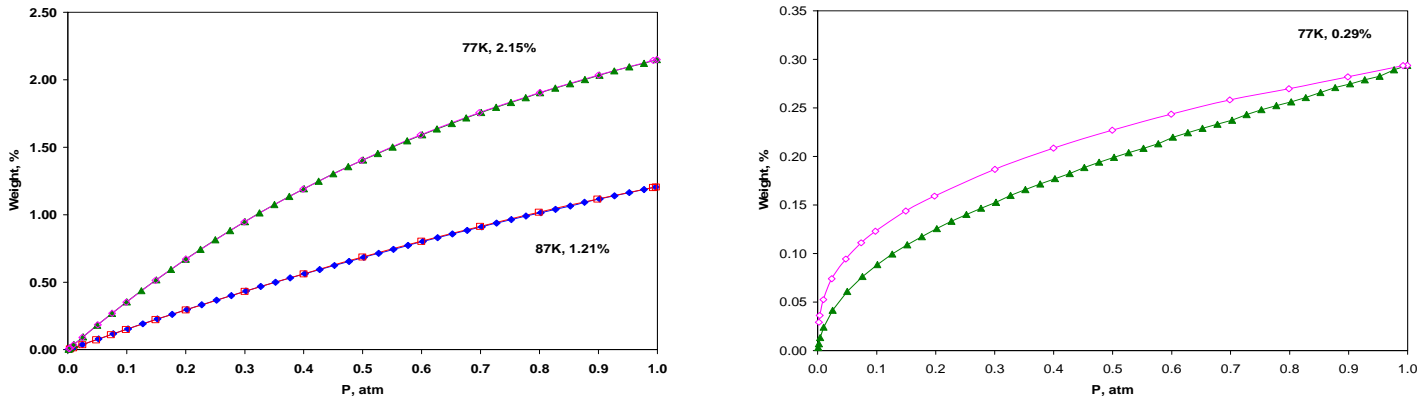

Fig. 27. Hydrogen adsorption-desorption isotherms for $\left[\mathrm{Zn}(\mathrm{bdc})(\mathrm{ted})_{0.5}\right](\mathrm{left})$ and $\left[\mathrm{Zn}(\mathrm{bpdc})(\mathrm{ted})_{0.5}\right]$ (right).
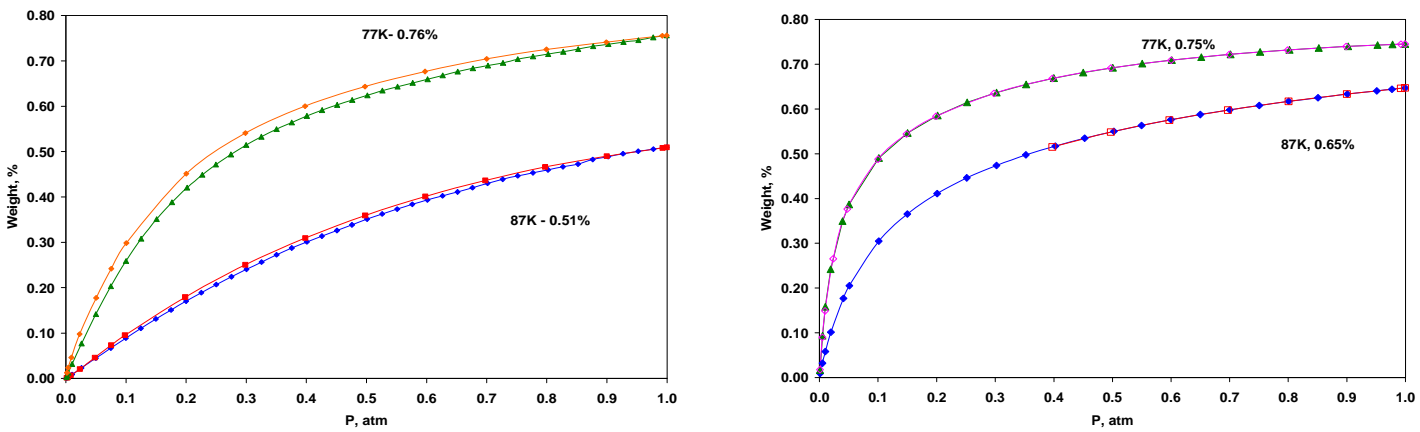

Fig. 28. Hydrogen adsorption-desorption isotherms at 77 and $87 \mathrm{~K}$ for $\mathrm{Zn}$ (tbip) (left) and $\left[\mathrm{Co}_{3}(\mathrm{HCOO})_{6}(\right.$ right $)$.
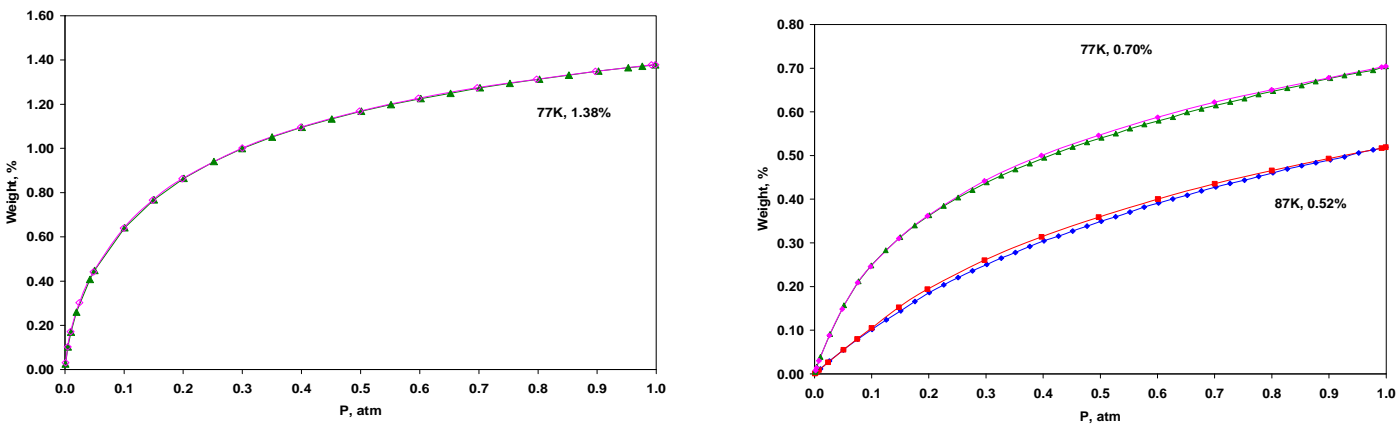

Fig. 29. Hydrogen adsorption-desorption isotherms at 77 and $87 \mathrm{~K}$ for $\left[\mathrm{Zn}_{3}(\mathrm{bpdc})_{3}(\mathrm{apy})\right]$ (left) and $\left[\mathrm{Mg}(\mathrm{bpdc})(\mathrm{DMF})_{1.3}\right]$ (right). 


\section{GAS SORPTION MEASUREMENTS AT HIGH PRESSURES}

We have subjected a number of MOF samples for further tests using the Pressure-Composition Isotherm Measurements instrument at Advanced Materials Corporation. Experiments were performed on MOF-5 and HKUST-1 (Cu-btc) for base-line study.

Prior to loading into the sample chamber of the PCI instrument, the samples were activated by heating them under a vacuum of $\sim 10^{-5}$ torr at temperatures ranging from 100 to $200{ }^{\circ} \mathrm{C}$ for several hours to remove the organic volatiles, water of crystallization etc. About 300 to $500 \mathrm{mg}$. of the activated sample was loaded into the sample holder in the PCI Instrument. Hydrogen sorption experiments were performed at room temperature as well as at $77 \mathrm{~K}$ at hydrogen pressures varying between 0 and $\sim 50$ atm.

A discussion on these results is presented in Section V below. In general, we note the following important features:

1. We have identified a new family of porous metal organic framework materials with the compositions $\mathrm{M}$ (bdc) (ted) $0.5, \mathrm{M}=\mathrm{Zn}$ or $\mathrm{Co}$, bdc= biphenyl dicarboxylate and ted $=$ triethylene diamine) that adsorb large quantities of hydrogen $(\sim 4.6 \mathrm{wt} \%)$ at $77 \mathrm{~K}$ and hydrogen pressure of $50 \mathrm{~atm}$. The modeling performed on these materials agree reasonably well with the experimental results.

2. In some instances, such as in $\mathrm{Y}_{2}(\mathrm{sdba}) 3$, even though the modeling predicts the possibility of hydrogen adsorption (although only samll quantities, $\sim 1.2 \mathrm{wt} \%, 77 \mathrm{~K}, 50 \mathrm{~atm}$. hydrogen), our experiments indicate that the sample does not adsorb any hydrogen. This may be related to the fact that the pores are extremely small or may be attributed to the lack of proper activation procedures.

3. Some samples such as $\mathrm{Zn}$ (tbip) (tbip=5-tert butyl isophthalate) exhibit hysteresis characteristics in hydrogen sorption between adsorption and desorption runs. Modeling studies on this sample show reasonable agreement with the desorption behavior. It is necessary to conduct additional experiments to fully understand this behavior.

4. Molecular simulations have demonstrated the need to enhance the solid-fluid potential of interaction in order to achieve much higher adsorption amounts at room temperature. We speculate that this may be accomplished through incorporation of light transition metals, such as $\mathrm{Ti}$ and Sc, into the metal organic framework materials. 


\section{MOLECULAR MODELING RESULTS}

During the course of the project, the main tasks we undertook are: (A) Perform pressurecomposition isotherm sorption measurements on a number of MOFs; (B) Perform molecular simulations for gases (mainly $\mathrm{H}_{2}$ ) adsorption on the existing and new MOFs synthesized by Rutgers team and compare with experimental asdorption data; (C) Study the reasons for overprediction of $\mathrm{H}_{2}$ adsorption in MOFs; (D) From VDOS calculations identifying adsorption potentials needed to facilitate uptake of large amounts of $\mathrm{H}_{2}$ in MOFs; (E) Study the pore-filling process for $\mathrm{H}_{2}$ adsorption in MOFs; (F) Calculate the diffusivity for $\mathrm{H}_{2}$ in MOFs using molecular dynamics simulations.

\section{A. Pressure - Composition Isotherm measurements were described in section III.}

\section{B. Molecular Simulations for Gases Adsorption on MOFs}

\section{(1) MMOF-2 Co and Zn}

The University of Pittsburgh team has performed molecular simulations for hydrogen adsorption isotherms on the so-called MMOF-2 Co and $\mathrm{Zn}$ materials at 77 and $87 \mathrm{~K}$, up to about 55 bar. Experimental data has been measured for MMOF-2-Co at $78 \mathrm{~K}$ up to about 15 bar. We present our simulation results up to 16 bar in Figure 30 below. The computed isotherm is type I, according to the IUPAC convention. The uptake is very steep at low pressure and the amount adsorbed essentially saturates at about 10 bar. Our simulations are in very good qualitative agreement with data from experiments. The amount adsorbed at $\sim 15$ bar from experiments is 3 $\mathrm{wt} \%$ at $78 \mathrm{~K}$. The amount from simulations is $\sim 3.3 \mathrm{wt} \%$. We plot the simulation data over the entire pressure range on a semi-log plot in Figure 30 (lower left). This shows more clearly the low pressure range and the approach to saturation. We have predicted the room temperature isotherm of $\mathrm{H}_{2}$ in MMOF-2 $\mathrm{Co}$ and $\mathrm{Zn}$ from computer simulations. The predicted isotherm is plotted in Figure 30 (lower left). The uptake is predicted to be quite small.

We have also computed the isosteric heats of adsorption for $\mathrm{H}_{2}$ on MMOF-2-Co and MMOF-2$\mathrm{Zn}$ at 77 and $87 \mathrm{~K}$ computed from simulations. These values are plotted in Figure 31 (left figure). The data show a rapid drop with increasing coverage at the lowest coverage. This is due to the highest energy adsorption sites being filled. The data then exhibit a plateau with coverage, giving isosteric heats of about $7.5 \mathrm{~kJ} / \mathrm{mol}$. At complete filling, around $3 \%$ by weight, the isosteric heat again drops dramatically, as adsorbate-adsorbate crowding leads to unfavorable energetics. The isosteric heats of adsorption for $\mathrm{H}_{2}$ on MMOF-2-Co and MMOF-2-Zn at $298 \mathrm{~K}$ are shown in Figure 31 (right figure). The data show that the isosteric heats are nearly independent of coverage and almost constant. 
$\mathrm{H}_{2}$ Adsorption on MMOFs at 77 and $87 \mathrm{~K}$

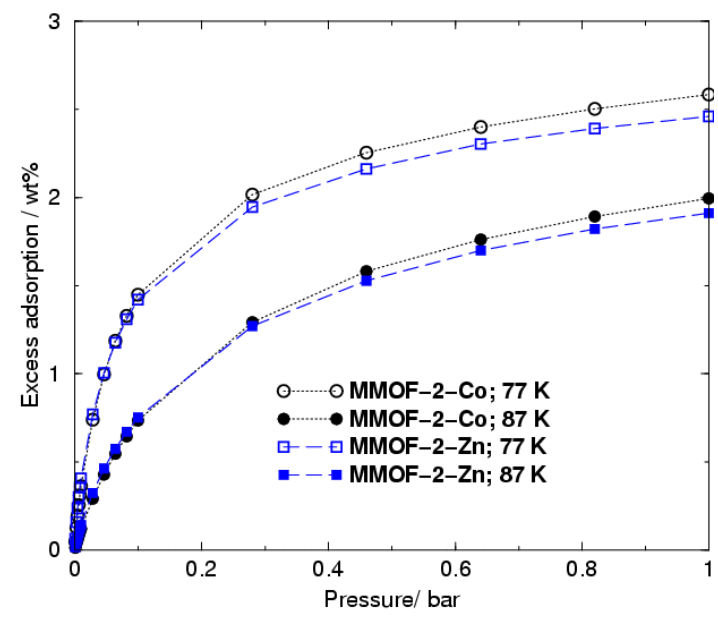

$\mathrm{H}_{2}$ Adsorption on MMOFs at 77 and $87 \mathrm{~K}$

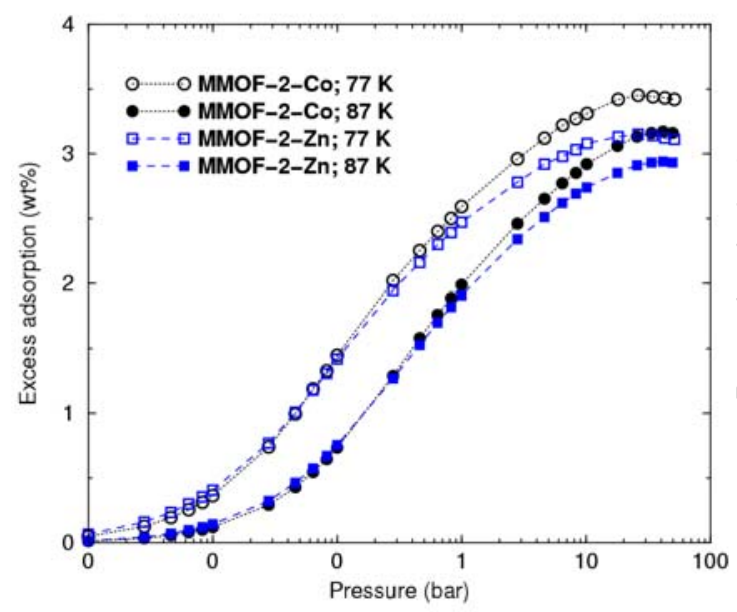

$\mathrm{H}_{2}$ Adsorption on MMOFs at 77 and $87 \mathrm{~K}$

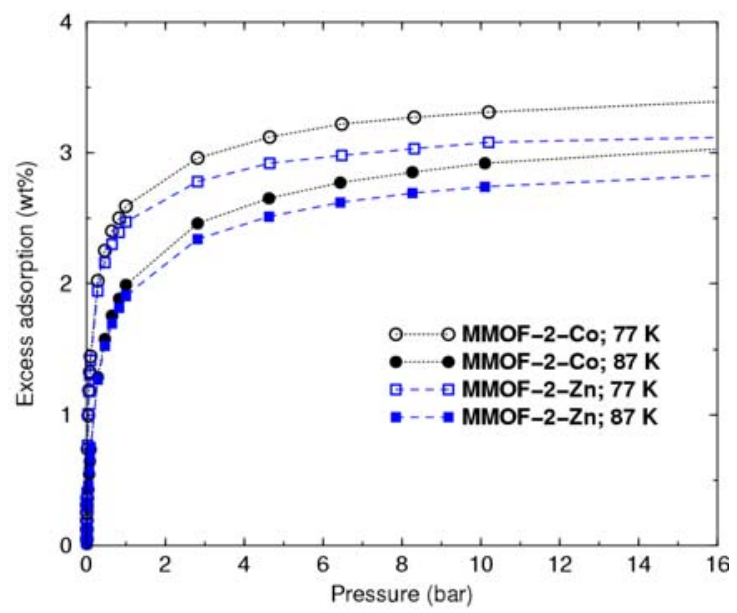

$\mathrm{H}_{2}$ Adsorption on MMOFs at $298 \mathrm{~K}$

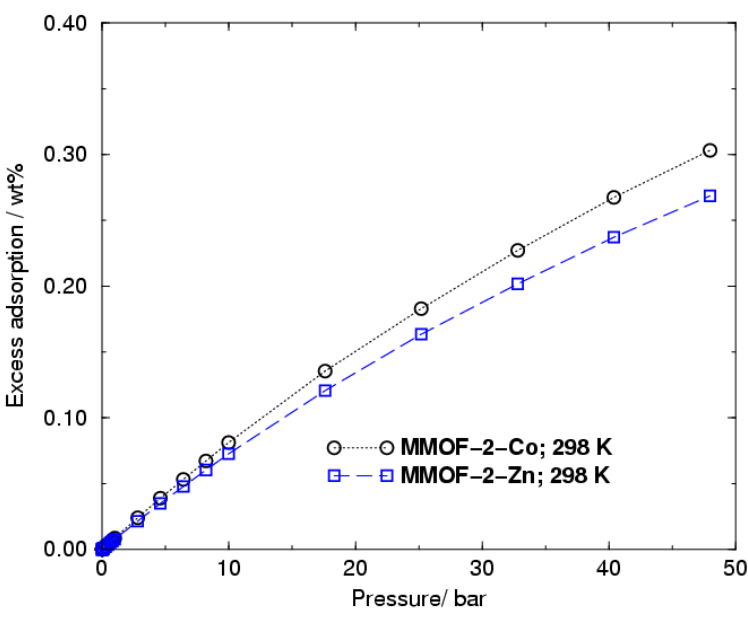

Figure 30. Adsorption of $\mathrm{H}_{2}$ on MMOF-2-Co and MMOF-2-Zn at 77 and $87 \mathrm{~K}$ for pressure $<1$ bar (upper left figure), pressure $<16$ bar (upper right figure), and pressure $<50$ bar in logarithm scale (lower left figure) and $298 \mathrm{~K}$ (lower right figure). The simulated isotherms give slightly higher adsorption than experimental data measured in the laboratory. 
Isosteric Heat for $\mathrm{H}_{2}$ Adsorption on MMOFs at 77 \& $87 \mathrm{~K}$
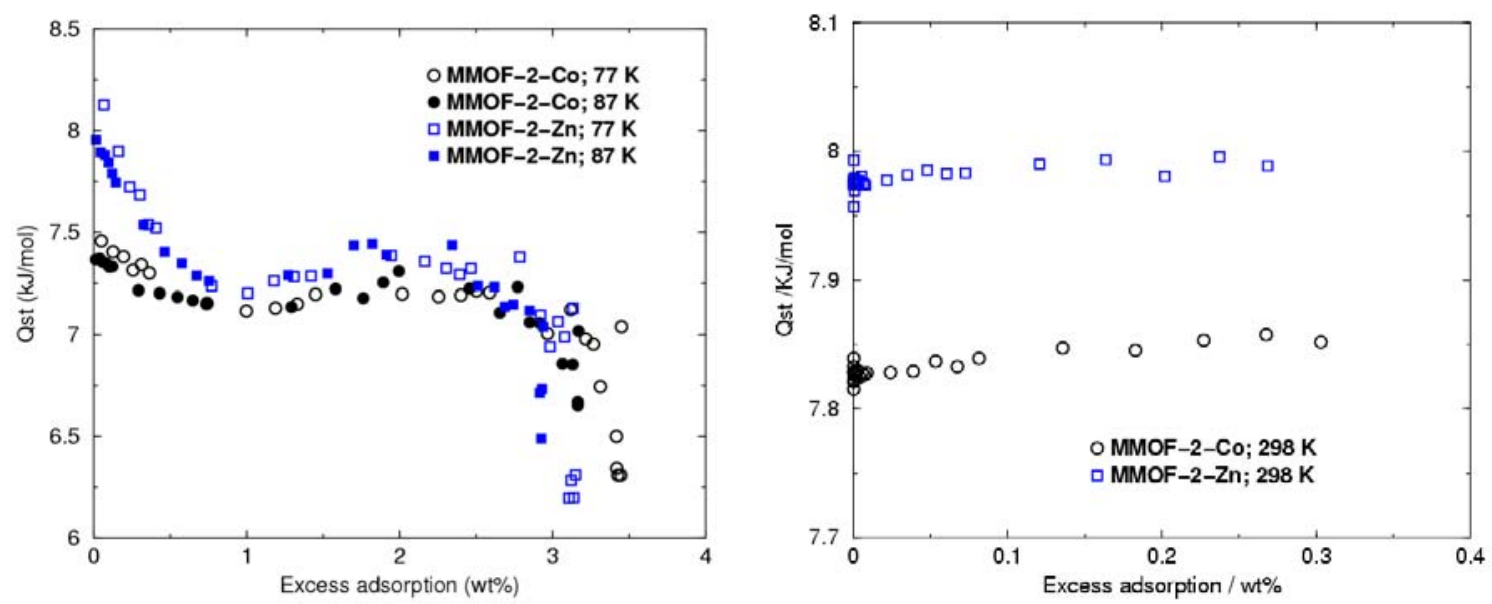

Figure 31. Isosteric heats of adsorption for $\mathrm{H}_{2}$ adsorbed on MMOF-2-Co and MMOF-2-Zn at 77 and $87 \mathrm{~K}$ (left figure) and $298 \mathrm{~K}$ (right figure).

\section{(2) Zn(tbip) and $\mathbf{Y}_{2}(\text { sdba })_{3}$}

An adsorption isotherm has been experimentally measured for $\mathrm{H}_{2}$ in $\mathrm{Zn}$ (tbip) at $77 \mathrm{~K}$. The experimental data for this material are qualitatively different from many other MOFs. Comparison of the adsorption and desorption branches of the isotherm reveal significant hysteresis, as shown in Figure 32. However, the observed hysteresis is not due to capillary condensation, as is commonly the case. There may be substantial transport limitations in the adsorption of $\mathrm{H}_{2}$ in $\mathrm{Zn}$ (tbip), which cause the observed hysteresis. The desorption branch of the experimental isotherm is in remarkably good agreement with the simulation data. Both sets of data indicate that $\mathrm{Zn}$ (tbip) is a material that displays a dramatic uptake of $\mathrm{H}_{2}$ at lower pressures, but the saturation loading is reached at moderate pressures (about 10 bar).

We have predicted the room temperature isotherm of $\mathrm{H}_{2}$ in $\mathrm{Zn}$ (tbip) from computer simulations. The predicted isotherm is plotted in Figure 33. The uptake is predicted to be quite small. 


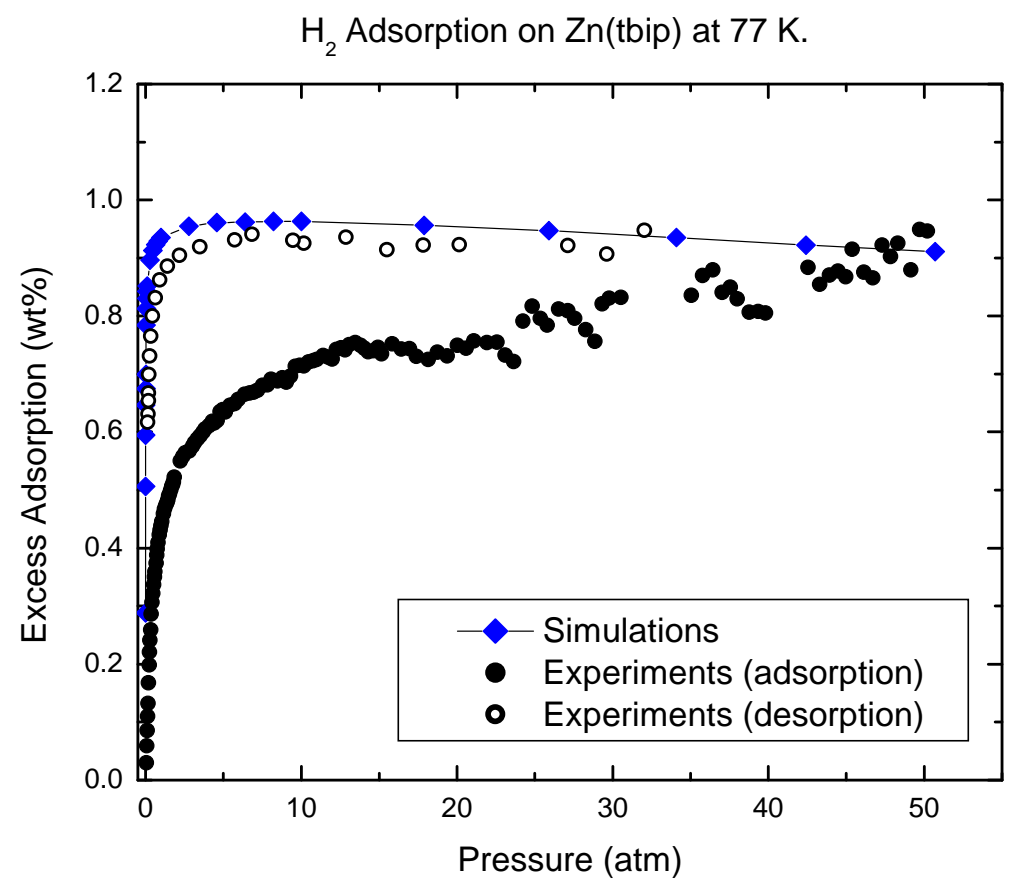

Figure 32. Adsorption and desorption of $\mathrm{H}_{2}$ in $\mathrm{Zn}$ (tbip) at $77 \mathrm{~K}$ from experiments. The adsorption isotherm computed from molecular simulations is also presented.

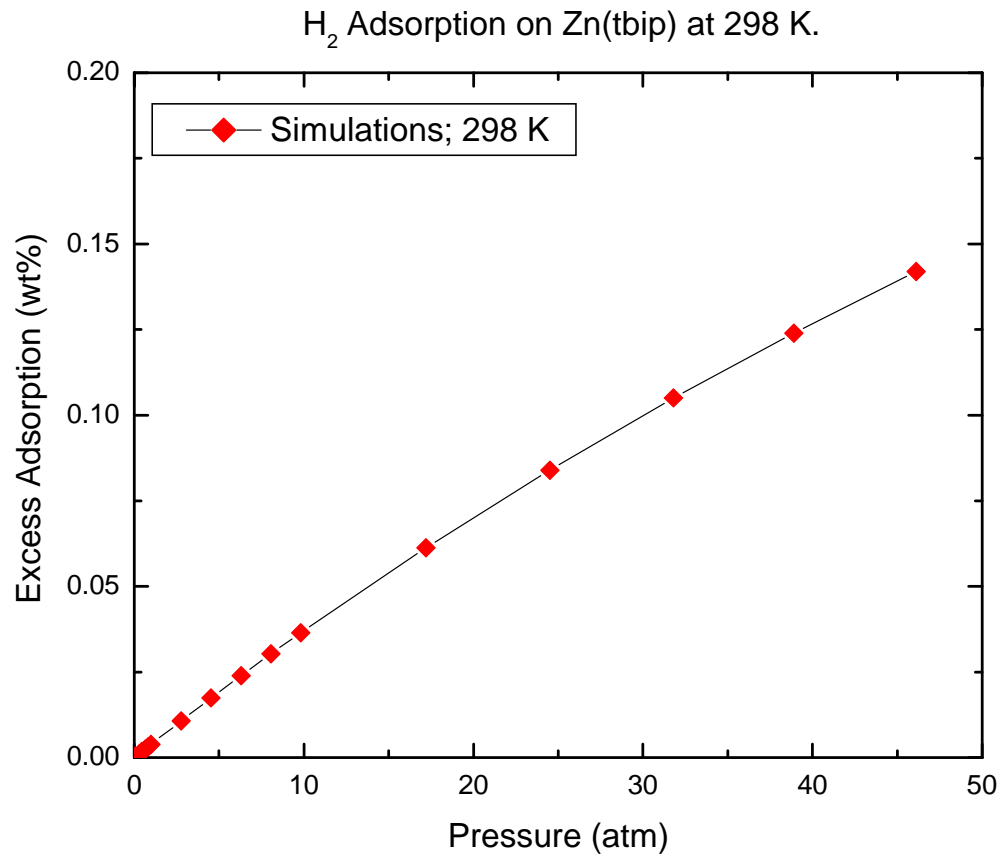

Figure 33. The $\mathrm{H}_{2}$ isotherm at $298 \mathrm{~K}$ for $\mathrm{Zn}$ (tbip) predicted from molecular simulations.

We have predicted adsorption isotherms for hydrogen in $\mathrm{Y}_{2}(\mathrm{sdba})_{3}$ at both 77 and $298 \mathrm{~K}$. These data are plotted in Figures 34 and 35, respectively. The isotherms for $\mathrm{Y}_{2}(\mathrm{sdba})_{3}$ are predicted to 
be similar to those for $\mathrm{Zn}$ (tbip). However, experimental measurements at $77 \mathrm{~K}$ indicate that $\mathrm{Y}_{2}(\mathrm{sdba})_{3}$ does not show any uptake of $\mathrm{H}_{2}$. This probably indicates that the $\mathrm{Y}_{2}(\mathrm{sdba})_{3}$ sample had pores that were blocked in some way.

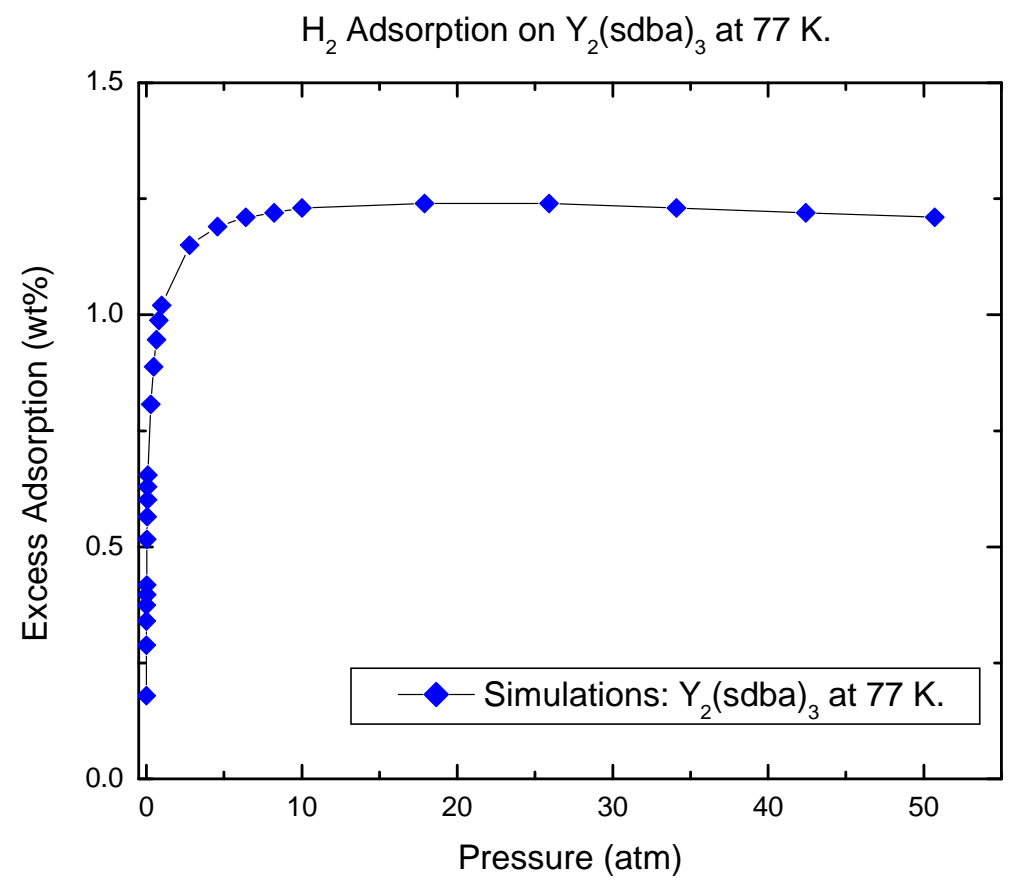

Figure 34. Predicted isotherm at $77 \mathrm{~K}$ for hydrogen in $\mathrm{Y}_{2}(\mathrm{sdba})_{3}$

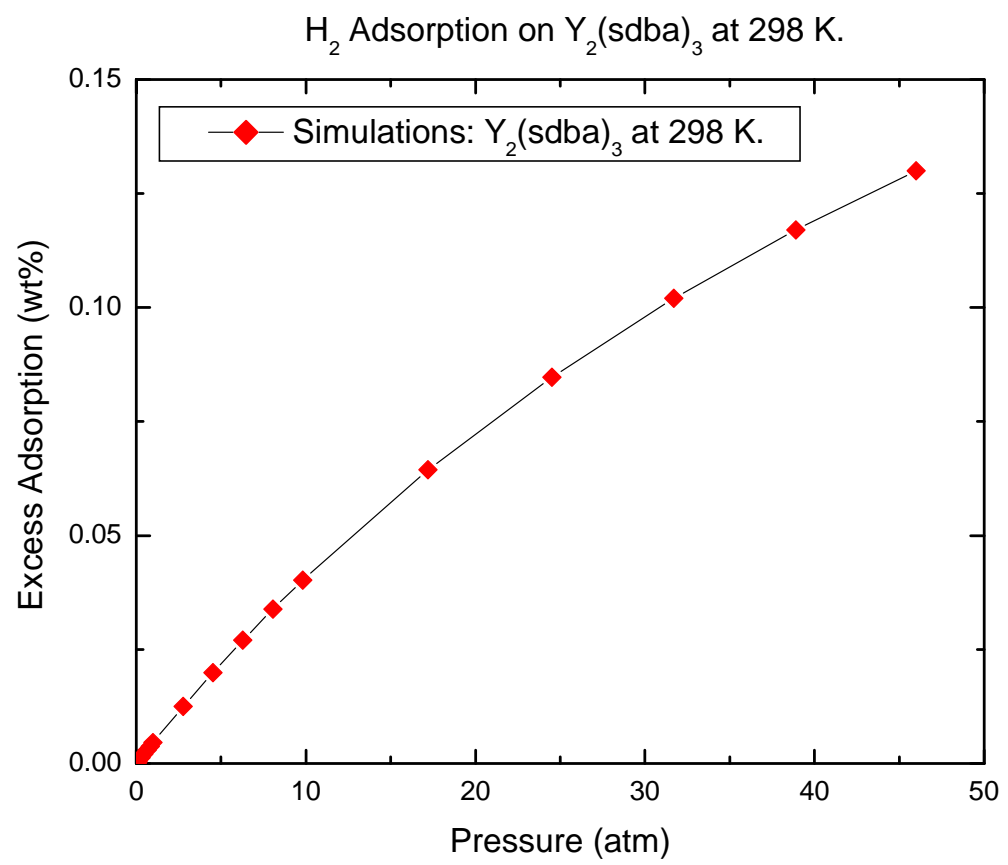

Figure 35. Predicted isotherm at $298 \mathrm{~K}$ for hydrogen in $\mathrm{Y}_{2}(\mathrm{sdba})_{3}$. 


\section{(3) $\left[\mathrm{Co}_{3}(\mathrm{bpdc})(\mathrm{bpy})\right]$}

We have performed simulations for hydrogen adsorption on $\left[\mathrm{Co}_{3}(\mathrm{bpdc})(\mathrm{bpy})\right]$. The simulated adsorption isotherms are very similar to $\mathrm{Zn}$ (tbip) as shown in Figure 36 for $\mathrm{T}=77$ and $87 \mathrm{~K}$. We have also predicted the room temperature isotherm from computer simulations. The predicted isotherm is plotted in Figure 37. The uptake is predicted to be quite small.
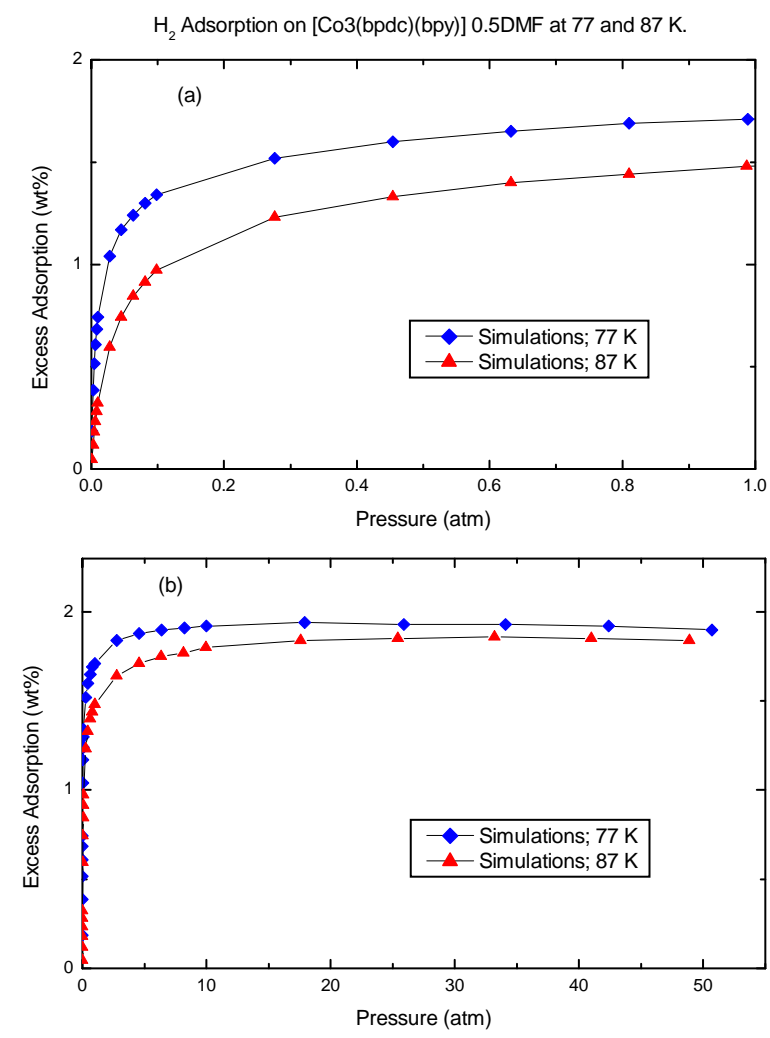

Figure 36: Adsorption isotherms for hydrogen on $\left[\mathrm{Co}_{3}(\mathrm{bpdc})(\mathrm{bpy})\right]$ at $77 \& 87 \mathrm{~K}$.

(a) $\mathrm{P}<1$ atm; (b) $0<\mathrm{P}<50$ atm 


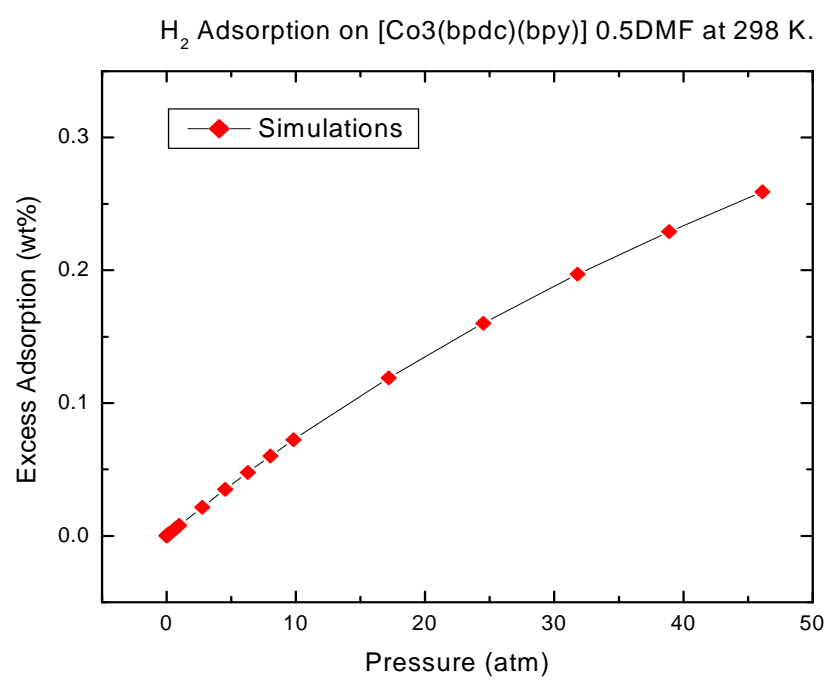

Figure 37: Adsorption isotherms for hydrogen on $\left[\mathrm{Co}_{3}(\mathrm{bpdc})(\mathrm{bpy})\right]$ at $298 \mathrm{~K}$.

\section{(4) IRMOF-1}

We have carried out simulations of existing MOFs and have compared the results with experimental data where available. Hydrogen uptake in MOF-5 (also known as IRMOF-1) at 298 $\mathrm{K}$ and $77 \mathrm{~K}$ are plotted in Figures 38 and 39 below. It is interesting to note that the experimental data from three different sources, AMC (Sankar et al.), and Ahn et al. (from .J. Phys. Chem. B, 110, 1099 (2006)), and Panella et al. (Adv. Fun. Mat., 16: 520 (2006)) are in qualitative, but not quantitative agreement. The simulation data are in excellent agreement with the data from Ahn and co-workers at $298 \mathrm{~K}$, as seen in Figure 38. The AMC data, shown as the black diamonds, are quite a bit larger than either the simulations or the experiments of Ahn et al. and Panella et al. on a percentage basis. However, in absolute terms, the error is fairly small, since the uptake is small. Further, the bulk density of the MOF sample employed in these experiments by different groups may also account for the differences in the experimental results.

At $77 \mathrm{~K}$ the comparison of simulations and experiments is quite different. The simulations over-predict the amount adsorbed when compared with all sets of experiments (See Figure 39). Moreover, the AMC data at low pressure are higher than the data of other groups, while the opposite is true at high pressures. This suggests that there are differences in the materials, with the MOF-5 sample used by Sankar et al. having a stronger set of binding sites at low pressure that fill up with hydrogen at lower pressures, giving an overall decrease in the amount adsorbed near saturation. This may be partly due to the differences in the structure or the differences in the activation procedures used by the different groups. We will discuss the possible reasons for the discrepancy between the simulations and experiments later.

We have also performed simulations for $\mathrm{N}_{2}, \mathrm{Ar}$ and $\mathrm{CH}_{4}$ adsorption in IRMOF-1. The adsorption isotherms at $298 \mathrm{~K}$ are shown in Fig. 40. We don't have experimental results to compare with. 

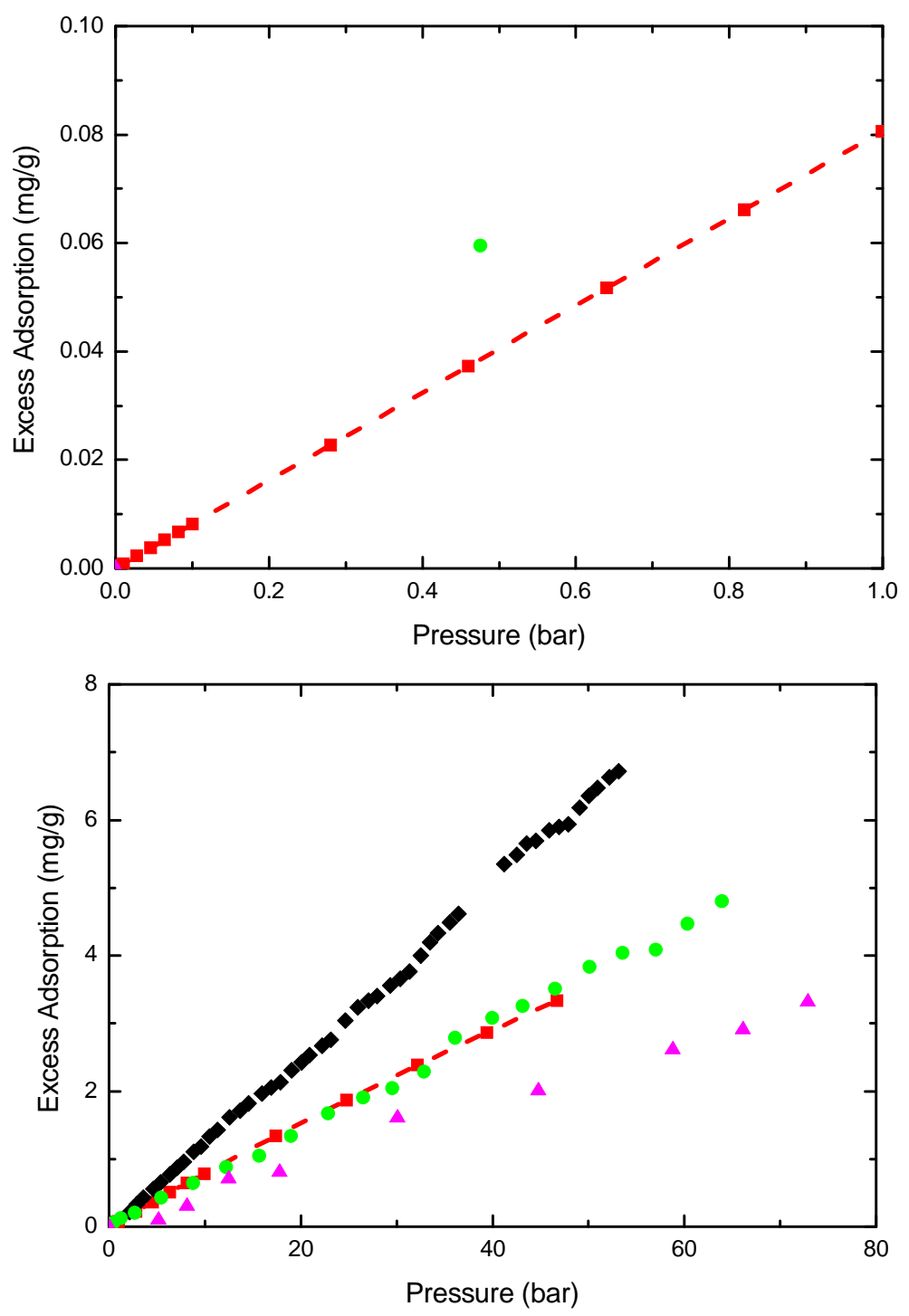

- Simulations

- Experiment (Sankar, AMC)

- Experiment (Ahn et al.)

- Panella et al., Adv. Fun. Mat., 16: 520 (2006)

Figure 38. Hydrogen uptake at $298 \mathrm{~K}$ in IRMOF-1 calculated from molecular simulations (red squares) and measured experimentally by our group (black diamonds, Sankar et al.) and reported in a recent publication by Ahn et al., J. Phys. Chem. B, 110, 1099 (2006) (green circles), and Panella et al., Adv. Fun. Mat., 16: 520 (2006) (purple triangles). 

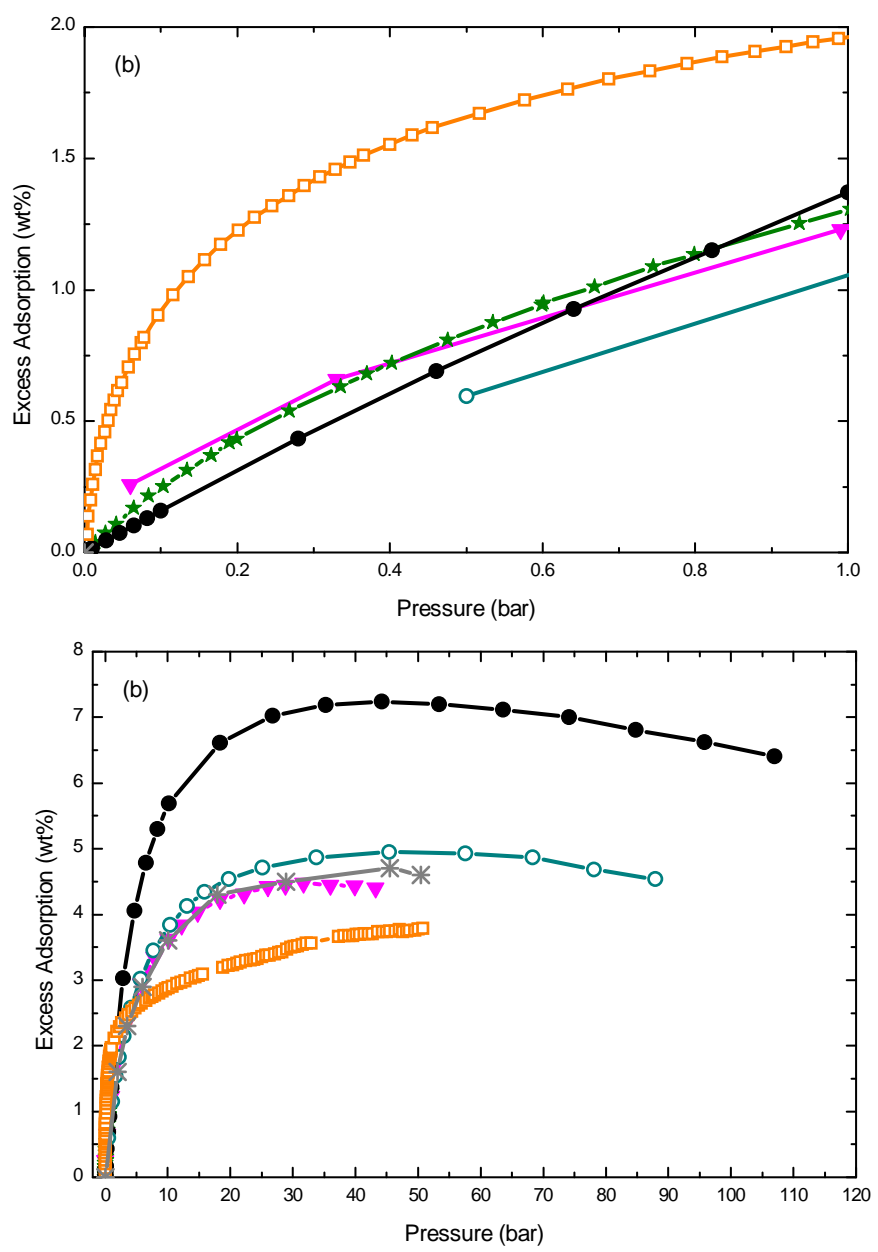

$\rightarrow$ Simulations

- - Wong-Foy et al., JACS, 128, 3494 (2006)

- Panella et al., Adv. Fun. Mat., 16: 520 (2006)

$\rightarrow$ Ahn group, JPCB, 110, 1099 (2006)

- Sankar, AMC (2006)

^-Rowsell et al. JACS, 126, 5666 (2004)

Figure 39. Hydrogen uptake at $77 \mathrm{~K}$ in IRMOF-1 calculated from molecular simulations (black circles) and measured experimentally by our group (orange squares, Sankar et al.) and reported in recent publications. 


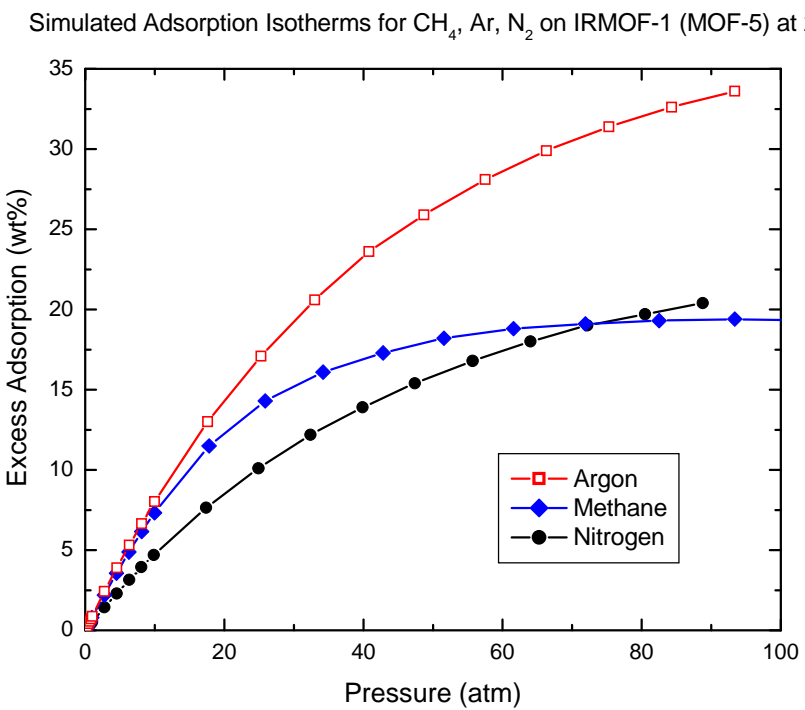

Figure 40: Comparison of simulated $\mathrm{CH}_{4}, \mathrm{Ar}, \mathrm{N}_{2}$ adsorption isotherms in IRMOF-1 at $298 \mathrm{~K}$.

\section{(5) MOF-177}

We have investigated the results published by the Yaghi group in the Journal of the American Chemical Society, 128, 3494, 2006. They have claimed to achieve very high uptake at liquid nitrogen temperatures using a material known as MOF-177. We obtained the refined structural data for this compound from Dr. Jesse Rowsell, a former member of the Yaghi research group. We compare our simulation results for $\mathrm{H}_{2}$ uptake in MOF-177 and two other MOFs, namely IRMOF-1 and $\mathrm{Cu}_{3}(\mathrm{BTC})_{2}$ (CuBTC, also known as HKUST-1), with the experimental data measured by the Yaghi group in Figure 41. The filled symbols are the experimental data and the open symbols are calculated from simulations. The simulation results are in good agreement with the experimental data at pressures up to a few bar. However, the simulations substantially overestimate the amount of $\mathrm{H}_{2}$ adsorbed at higher pressures. It is not exactly clear why the predicted isotherms are always larger than the experimental isotherms at higher pressures (we will discuss the possible reasons from simulations aspects later). One reason may be that the real material has some fraction of the pores blocked, whereas the simulations only consider perfect material, with all pores equally accessible. Experimental samples may have guest molecules partially blocking many of the pores. 
Comparison of Simulated $\mathrm{H}_{2}$ Adsorption Isotherms at $77 \mathrm{~K}$

with Experiments (Yaghi group, JACS, 128, 3494 (2006))

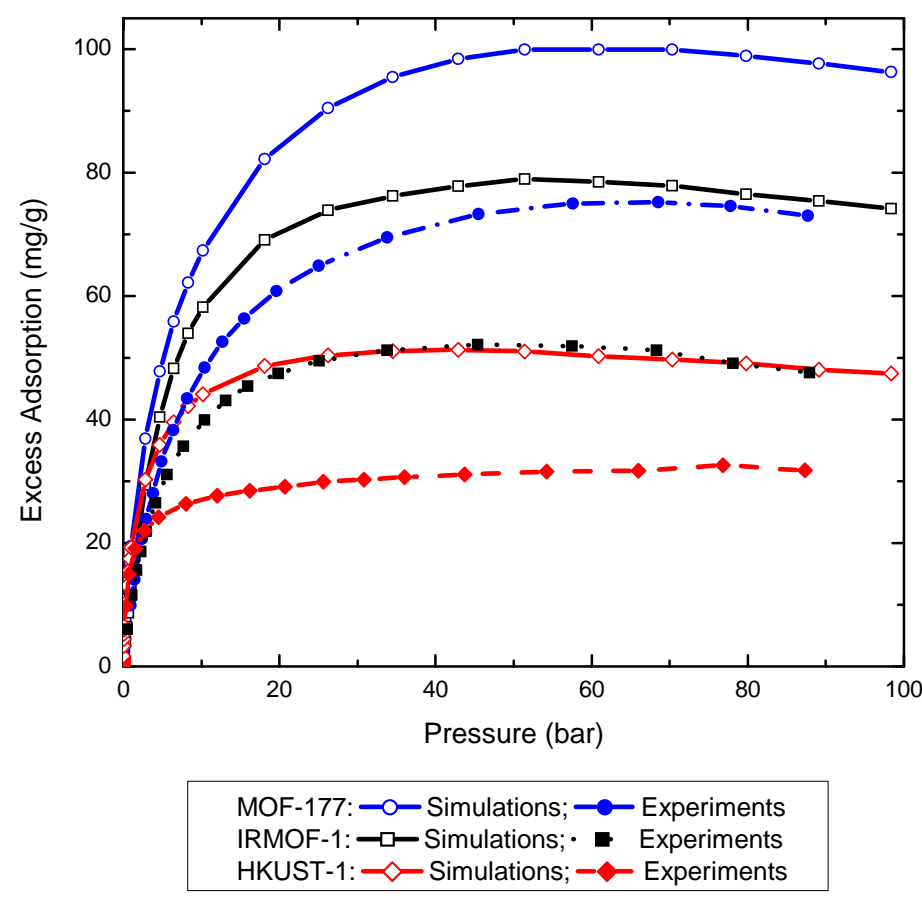

Figure 41. Adsorption isotherms from experiments by the Yaghi group and from computer simulations. The simulations are in good agreement with experiments at low pressure (up to a few bar) but substantially over-estimate the amount adsorbed at high pressures.

\section{(6) IRMOF-8, IRMOF-11 and IRMOF-13}

Quantitative prediction of the amount of $\mathrm{H}_{2}$ adsorbed on MOFs by molecular simulation is required in designing new MOF materials using computational approaches. However, our previous simulation results for most of the MOFs over-estimate the amount of $\mathrm{H}_{2}$ adsorbed at higher pressures. It is not clear why the predicted isotherms are always larger than the experimental isotherms at higher pressures. One reason may be that the real materials have a substantial fraction of blocked pores. However, for some materials it is possible that the experimental material is catenated (interpenetrated). This is a possibility for the material IRMOF-8. It has been noted (Jesse Rowsell, personal communication) that the IRMOF-8 experimental isotherm is qualitatively more like known catenated materials than like other noncatenated IRMOFs.

We have investigated three MOFs: IRMOF-8, IRMOF-11, and IRMOF-13. We obtained the refined structural data for these three compounds from Dr. Jesse Rowsell, a former member of the Yaghi research group. IRMOF-8 is regard as a non-catenated structure as it was synthesized, based on XRD data. However, the X-ray data may also be consistent with a catenated structure. We compare our simulation results for $\mathrm{H}_{2}$ uptake in several non-catenated and catenated models of IRMOF- 8 with the experimental data measured by the Yaghi group in Figure 42. The filled circles are the experimental data and the other symbols are calculated from 
simulations. The simulation results for non-catenated structures agree with each other and are in good agreement with the experimental data at $1 \mathrm{bar}$, but the curvature of the simulated isotherms is essentially different from experiments. The simulated isotherms for catenated structures have similar curvature compared with experiments, but over-estimate the adsorption amount at low pressures (Fig. 42A). The saturation adsorption amounts for catenated structures are lower than that of non-catenated structures as can be seen in Fig. 42B. The lower adsorption amount at high pressures for catenated structures is closer to experiments. However, the higher adsorption at low pressures casts doubt on the catenated models for IRMOF-8, provided that simulations can be shown to agree with experiments for other catenated structures. 

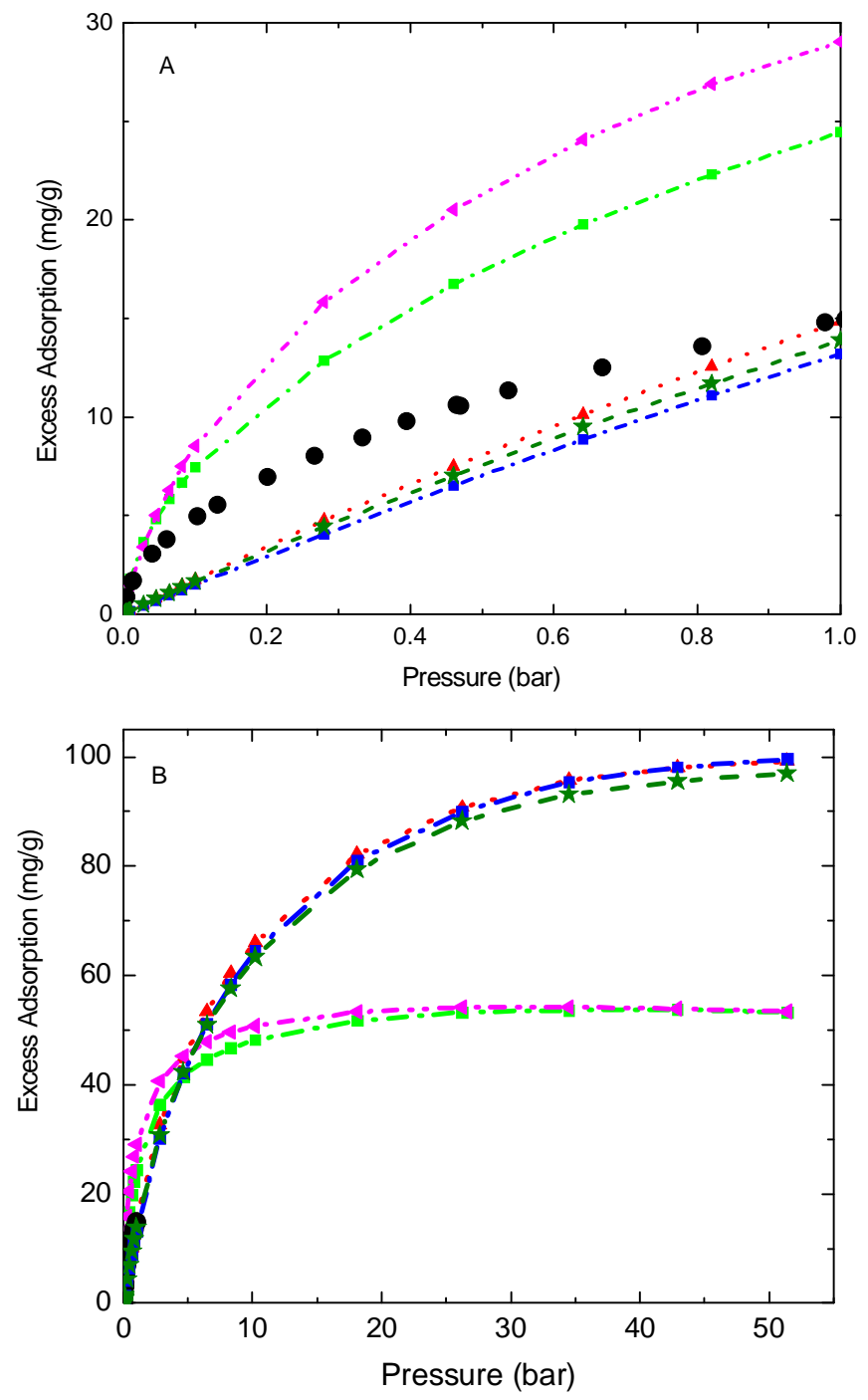

- Experiments (Rowsell et al. JACS, 126, 5666 (2004))

- * Simulations (Structure used by: Garberoglio et al. JPC B, 109, 13094 (2005))

- Simulations (Structure from Rowsell, non-catenated, non-disordered: original)

- - Simulations (Structure from Rowsell, non-catenated, non-disordered: energy minimized)

- - Simulations (Structure from Rowsell, Model-B: based on catenation modes in IRMOF-9)

-4 . Simulations (Structure from Rowsell, Model-C: based on catenation modes in IRMOF-11/13)

Figure 42: IRMOF-8 Adsorption Isotherms from Experiments by the Yaghi group and from Computer Simulations at 77K. (A) $\mathrm{P}=0 \sim 1$ bar; (B) $\mathrm{P}=0 \sim 50$ bar.

In order to check how well simulations predict the adsorption isotherms for catenated MOF structures, we have performed Monte Carlo simulations for IRMOF-11 and IRMOF-13 and 
compared with experiments. We have used two models for IRMOF-11/-13 from Rowsell, one for which the coordinates of the R3m structures have been taken directly from the paper Science 295, 469 (2002) and reorganized in space group R3 to remove the ligand disorder and another where the R3 structure was minimized using Cerius2. Both models were kindly provided by Dr. Rowsell. The comparison of simulated and experimental adsorption isotherms for $\mathrm{H}_{2}$ on IRMOF11 at 77,87 , and $293 \mathrm{~K}$ and on IRMOF-13 at $77 \mathrm{~K}$ are shown in Fig. 43-46, respectively. Simulated isotherms for the two models of IRMOF-11 show a difference of about $10 \%$ in the low adsorption amount region (up to $30 \mathrm{mg} / \mathrm{g}$ ). The loading for the two models is essentially identical at saturation (Fig. 43B). Both models over-estimate experiments by about $40 \sim 50 \%$ for all three temperatures and for low pressure (1 bar) to high pressure (50 70 bar). This overestimation of experiments by molecular simulations is similar to that observed for non-catenated structure of MOFs. The difference between the ideal model structures, which are employed in the simulations, and the real materials, could be one of the reasons for the difference in adsorption isotherms. 

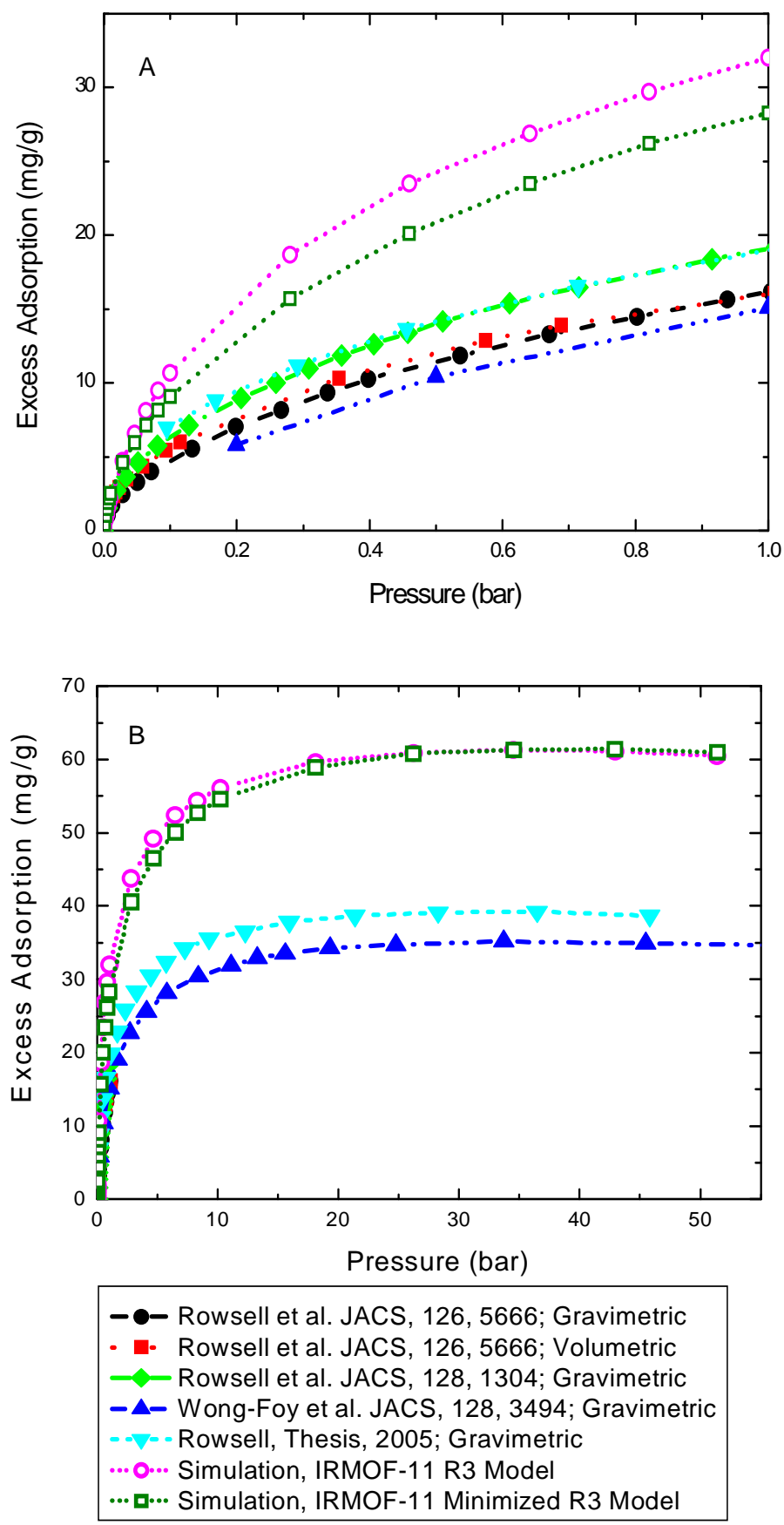

Figure 43: Comparison of Simulated and Experimental $\mathrm{H}_{2}$ Adsorption Isotherms on IRMOF-11 at $77 \mathrm{~K}$. (A) $\mathrm{P}=0 \sim 1$ bar; (B) $\mathrm{P}=0 \sim 50$ bar. 


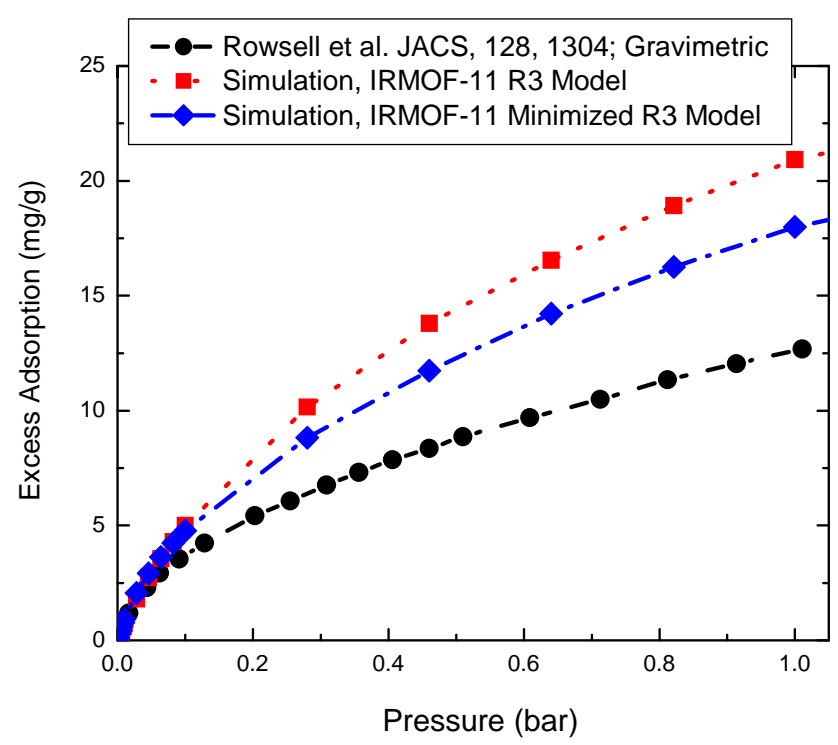

Figure 44: Comparison of Simulated and Experimental $\mathrm{H}_{2}$ Adsorption Isotherms on IRMOF-11 at $87 \mathrm{~K}$.

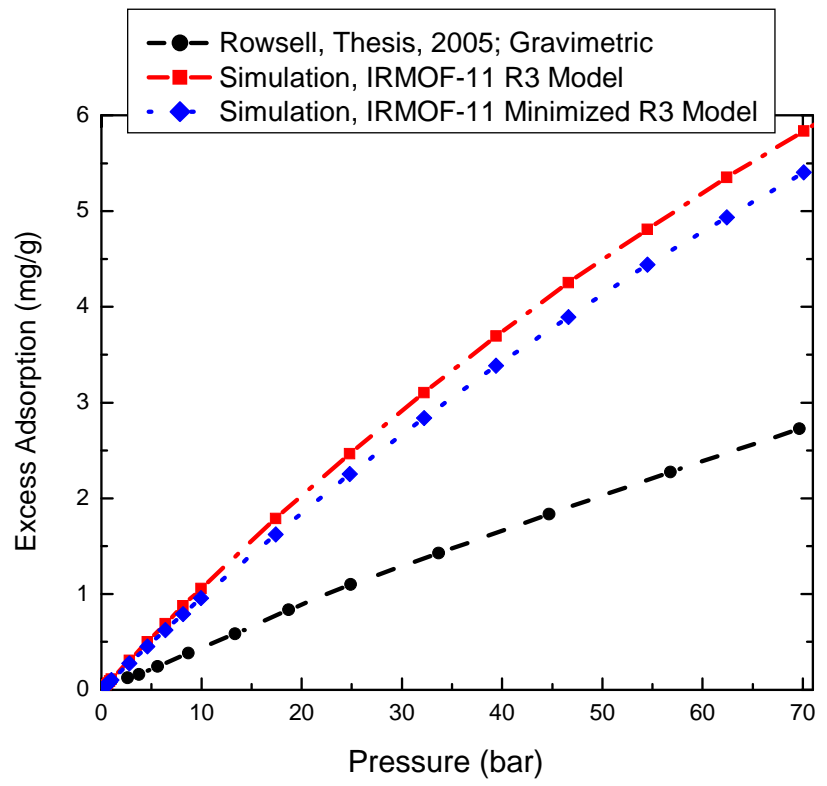

Figure 45: Comparison of Simulated and Experimental $\mathrm{H}_{2}$ Adsorption Isotherms on IRMOF-11 at $293 \mathrm{~K}$. 


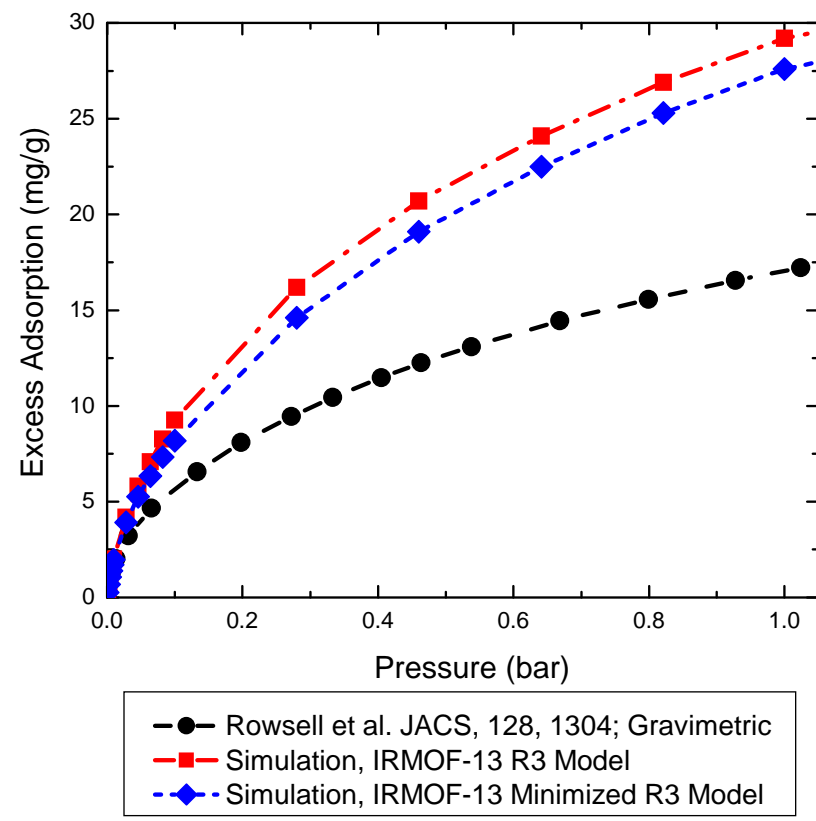

Figure 46: Comparison of Simulated and Experimental $\mathrm{H}_{2}$ Adsorption Isotherms on IRMOF-13 at $77 \mathrm{~K}$.

\section{(7) $\mathrm{Cu}_{3}(\mathrm{BTC})_{2}$}

We have carried out simulations of $\mathrm{H}_{2}$ adsorption in $\mathrm{Cu}_{3}(\mathrm{BTC})_{2}$ (CuBTC, also known as HKUST-1) at $77 \mathrm{~K}, 87 \mathrm{~K}$, and $298 \mathrm{~K}$ as a function of pressure up to about 50 bar. We plot our experimentally measured $\mathrm{H}_{2}$ isotherm at $77 \mathrm{~K}$ for CuBTC-MeOH (Methanol Solvent) (See Liu, J.-C.; Culp, J. T.; Natesakhawat, S.; Bockrath, B. C.; Zande, B.; Sankar, S. G.; Garberoglio, G.; Johnson, J. K. J. Phys. Chem. C 2007, 111, 9305.) along with predictions from our simulations in Figure 47. Both classical and Feynman-Hibbs (FH) calculations are plotted (see below for the discussion of Feynman-Hibbs effective potential). The low pressure isotherm plotted in Figure 47(a) was measured using the Quantachrome Autosorb-1-C analyzer. Neither the quantum corrected nor the classical simulations agree quantitatively with the low pressure data in Figure 47(a). The poor agreement between simulations and experiments at low pressures may largely be due to ignoring charge-quadrupole interactions between $\mathrm{H}_{2}$ and the framework. The high pressure experimental isotherm [Figure 47(b)] has a loading of about $3.8 \mathrm{wt} \%$ at the highest pressure of 50 bar. The classical simulations give a loading of $4.4 \mathrm{wt} \%$ at $P=27.6 \mathrm{bar}$ and the $\mathrm{FH}$ approach gives $3.6 \mathrm{wt} \%$ at $P=29.3$ bar. The $\mathrm{FH}$ effective Buch potential gives the best agreement with experiments at the highest pressures, but underestimates the amount adsorbed over the entire range, probably due to a combination of factors including (1) lack of charge-quadrupole interactions in the model, (2) overcorrection for quantum effects by the FH approach, and (3) errors in the solid-fluid potentials. Simulations with the classical Buch potential overestimate the experimental data for pressure $>5$ bar and underestimate the experimental data for pressure $<5$ bar. Thus, quantum effects become more important on an absolute basis as the loading increases. It is generally the case that quantum effects increase with increasing density. This is due to the hydrogen being more confined by collisions with neighboring $\mathrm{H}_{2}$ molecules at higher densities, both in the bulk and in the pores. 
Experimentally measured adsorption isotherms for $\mathrm{H}_{2}$ on $\mathrm{CuBTC}-\mathrm{MeOH}$ at 87,175 , and $298 \mathrm{~K}$ are plotted in Figure 1-19. Isotherms predicted from simulations are also plotted. The FH approach was used for the $87 \mathrm{~K}$ isotherm, but the classical potential was used for 175 and $298 \mathrm{~K}$. The maximum difference between the classical and $\mathrm{FH}$ simulations is about $0.1 \mathrm{wt} \%$ at $175 \mathrm{~K}$; this corresponds to a relative difference of about $10 \%$. We used the classical simulations at 175 and $298 \mathrm{~K}$ because the absolute differences between classical and FH are small and, as noted previously, the FH formalism overestimates quantum effects at high temperatures. Simulations are in good agreement with experiments at room temperature, but underestimate the adsorption capacities at 87 and $175 \mathrm{~K}$. Note that charge-quadrupole interactions for $\mathrm{H}_{2}$ in MOFs have been shown to have a small effect on adsorption at room temperature, (Garberoglio, G.; Skoulidas, A. I.; Johnson, J. K. J. Phys. Chem. B 2005, 109, 13094.) and this could partially explain why the high temperature results are in better agreement with experiments. Isotherms for $\mathrm{N}_{2}$ in $\mathrm{CuBTC}$ $\mathrm{MeOH}$ have been measured at 253 and $298 \mathrm{~K}$ up to pressures of 50 bar and are plotted in Figure 49. Simulations were performed using both the spherical and two-center LJ $\mathrm{N}_{2}$ potentials. Results from both potential models were very similar and only the two-center LJ potential results are plotted in Figure 49 for comparison with experiments. The simulations underestimate experiments over the entire pressure range and are about $16 \%$ and $12 \%$ too low at the highest pressures for 253 and $298 \mathrm{~K}$, respectively. Nitrogen has a quadrupole moment that is over twice as large as that for $\mathrm{H}_{2}$, (Gray, C. G.; Gubbins, K. E. Theory of Molecular Fluids. Volume 1: Fundamentals; Clarendon Press: Oxford, 1984 and Wolinski, K.; Sadlej, A. J.; Karlstrom, G. Mol. Phys. 1991, 72, 425.) suggesting that the discrepancy between simulations and experiments is due, at least in part, to ignoring charge-quadrupole interactions in the simulations. Nevertheless, the agreement between simulations and experiments is qualitatively reasonable.

The comparison between argon adsorption isotherms from simulations and experiments in CuBTC at 298 and $356 \mathrm{~K}$ is shown in Figure 50. Simulations are in remarkably good agreement with experiments at $298 \mathrm{~K}$. The simulations slightly over-predict the amount adsorbed at pressures less than 40 bar and slightly under-predict the amount adsorbed for higher pressures. However, the simulations overestimate experiments for $356 \mathrm{~K}$ over the entire pressure range. The reason for this is not clear, but may be due to inaccuracy in the potential models used, uncertainty in the experimental results, or a combination of both. We note that argon is a nonpolar molecule and therefore interactions with the charges on the framework atoms have a small effect on the adsorption isotherm. This may be one of the reasons for the very good agreement between simulations and experiments for argon in comparison to hydrogen and nitrogen, where simulations typically under-predict the amount adsorbed. 

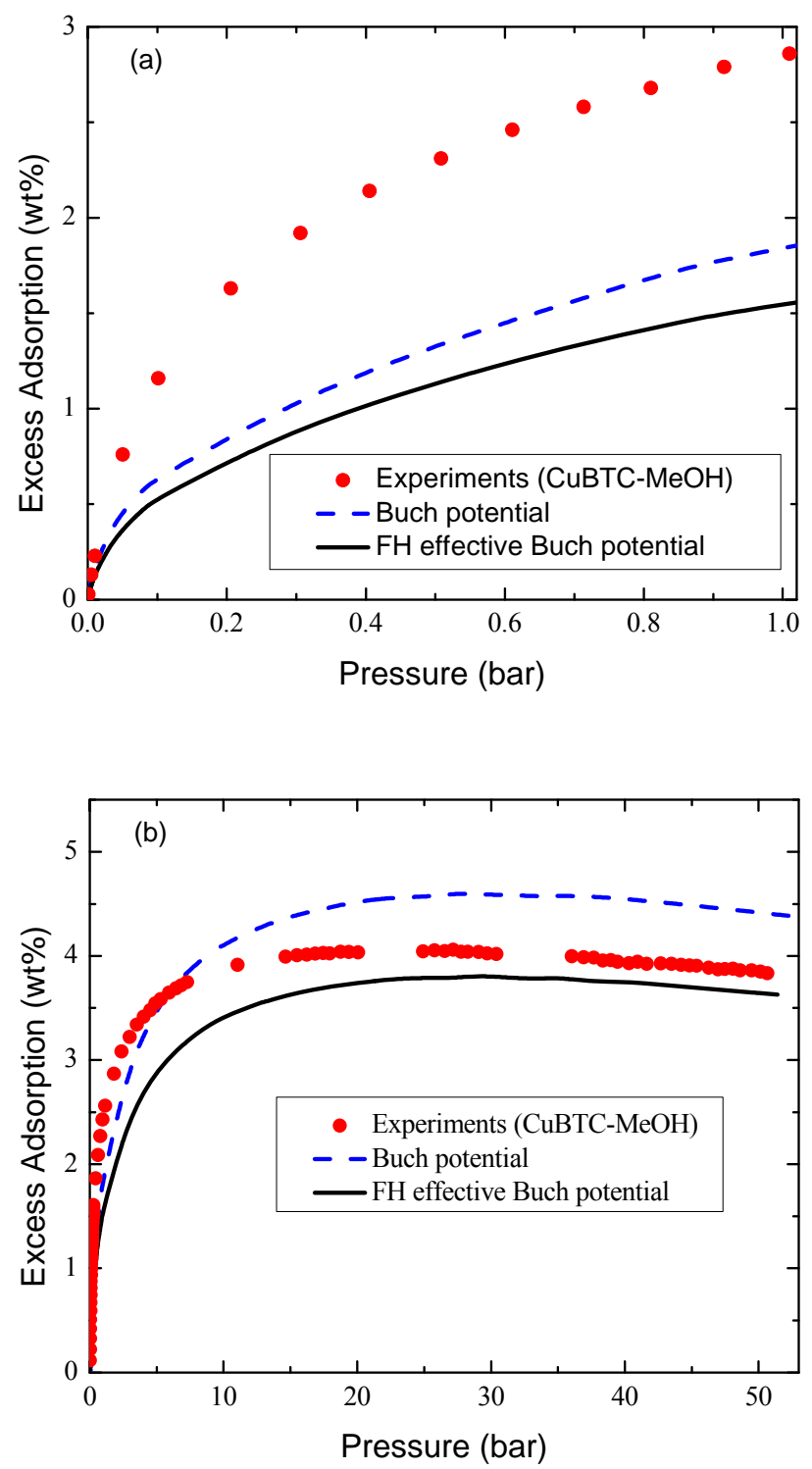

Figure 47. Comparison of simulated and experimental $\mathrm{H}_{2}$ adsorption isotherms in CuBTC$\mathrm{MeOH}$ at $77 \mathrm{~K}$. (a) $\mathrm{P}=0-1$ bar measured with the Quantachrome Autosorb-1-C analyzer. (b) $P=0-50$ bar measured with pressure-composition isotherm measurement system (Advanced Materials Corporation). The experimental results are represented by filled circles. The simulation results using classical Buch and FH effective Buch potentials are represented by dashed and solid lines, respectively. 


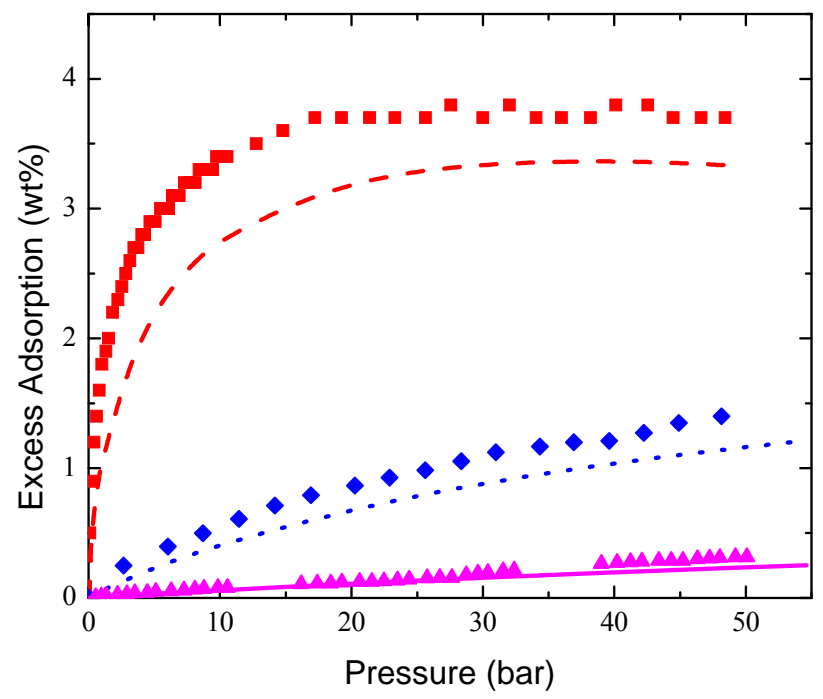

Figure 48. Comparison of simulated and experimental $\mathrm{H}_{2}$ adsorption isotherms in CuBTC$\mathrm{MeOH}$ at 87,175 , and $298 \mathrm{~K}$. Experimental results are represented by squares, diamonds, and triangles for 87,175 , and $298 \mathrm{~K}$, respectively. Simulations results are represented by dashed, dotted, and solid lines for 87,175 , and $298 \mathrm{~K}$, respectively.

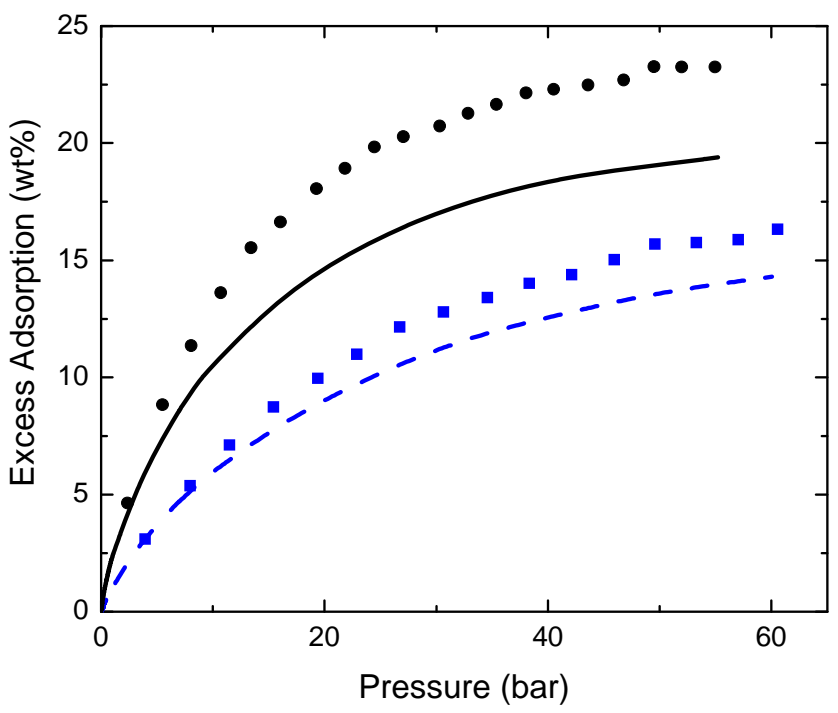

Figure 49. Comparison of simulated and experimental $\mathrm{N}_{2}$ adsorption isotherms in CuBTC$\mathrm{MeOH}$ at 253 and $298 \mathrm{~K}$. Experimental results are represented by circles and squares for 253 and $298 \mathrm{~K}$, respectively. Simulations results are represented by solid and dashed lines for 253 and $298 \mathrm{~K}$, respectively. 


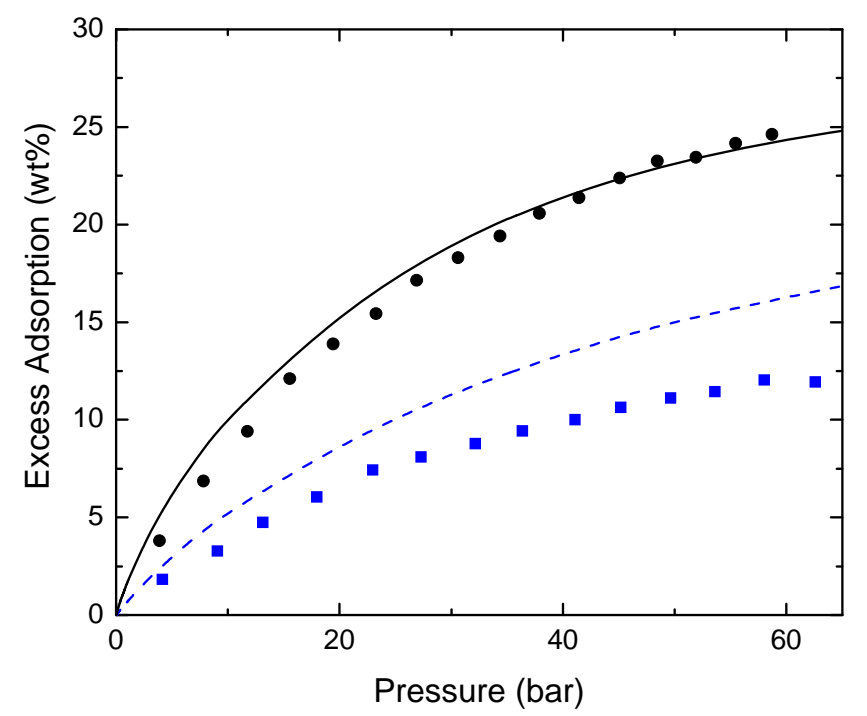

Figure 50. Comparison of simulated and experimental Ar adsorption isotherms in CuBTC$\mathrm{MeOH}$ at 298 and $356 \mathrm{~K}$. Experimental results are represented by circles and squares for 298 and $356 \mathrm{~K}$, respectively. Simulations results are represented by solid and dashed lines for 298 and $356 \mathrm{~K}$, respectively.

\section{(8) $\left[\mathrm{Zn}(\mathrm{bdc})(\text { ted) })_{0.5}\right]$}

We have used both the classical and the Feynman-Hibbs (FH) effective Buch potentials to simulate hydrogen adsorption in $\left[\mathrm{Zn}(\mathrm{bdc})(\mathrm{ted})_{0.5}\right]$ at $77 \mathrm{~K}$. We have found that the quantum corrected simulations are in better agreement with experiments than the classical simulations (see below for the discussion of Quantum Effects). The FH effective potential simulation results are plotted along with experiments in Figure 51. Simulations agree very well with experiments over the entire range of pressure. The UFF force field gives slightly better agreement, as can be seen in Figure 51. Both experimental and FH effective potential simulated isotherms reach a maximum at around 20 bar and then slightly decrease with increasing pressure, as expected for excess adsorption. The low pressure region is shown in Figure 52. There is apparently a slight hysteresis in experimental adsorption and desorption isotherms taken from the PCI apparatus at low pressure (Figure 52). We believe the hysteresis to be an artifact of the experiments; the PCI instrument is designed for high pressure measurements, so slight errors at low pressures are to be expected. Hence, the agreement between our experimental results and the experimental data by Lee et al. ${ }^{5}$ is acceptable. Simulations using the DREIDING force field agree very well with our experiments at low pressure (Figure 52) but underpredict the amount adsorbed at high pressure (Figure 51). In contrast, simulations using UFF significantly overpredicts the adsorption at low pressures and slightly overpredicts the adsorption at high pressures. We observe that the experimental data above a pressure of about 1 bar lie in between the predictions from the UFF and DREIDING force fields, indicating that the small discrepancy between simulations and experiments above 1 bar is likely due to errors in the solid-fluid potential. The overall good 
agreement between simulations and experiments indicates that the $\left[\mathrm{Zn}(\mathrm{bdc})(\mathrm{ted})_{0.5}\right]$ sample is of high purity and that guest molecules (solvents) were effectively removed.

We have also compared the simulation results at room temperature with experiments, shown in Figure 53. Simulations using the DREIDING potential agree very well with experiments, and simulations using UFF force field overestimate experiments. The largest error between simulations and experiments is about $0.07(0.02) \mathrm{wt} \%$ for the UFF (DREIDING) force field. The agreement between simulations and experiments is acceptable, considering that the estimated error in experiments is about $0.04 \mathrm{wt} \%$ at the highest pressure (50 bar). Note that we only employ the classical potential at room temperature. Using the $\mathrm{FH}$ effective potential at room temperature is known to overcorrect for quantum effects. ${ }^{1}$

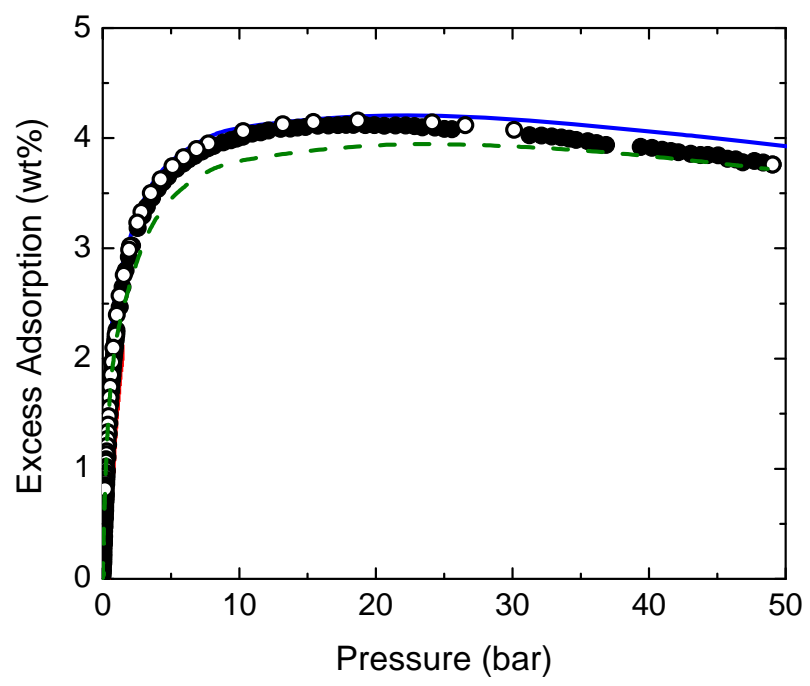

Figure 51: Comparison of simulated and experimental $\mathrm{H}_{2}$ adsorption isotherms in $\left[\mathrm{Zn}(\mathrm{bdc})(\text { ted })_{0.5}\right]$ at $77 \mathrm{~K}$. The experimental results are represented by filled (open) circles for adsorption (desorption). The simulation results using FH effective Buch potential are represented by the solid line (blue) and the dashed line (olive) for the UFF and DREIDING force fields, respectively. 


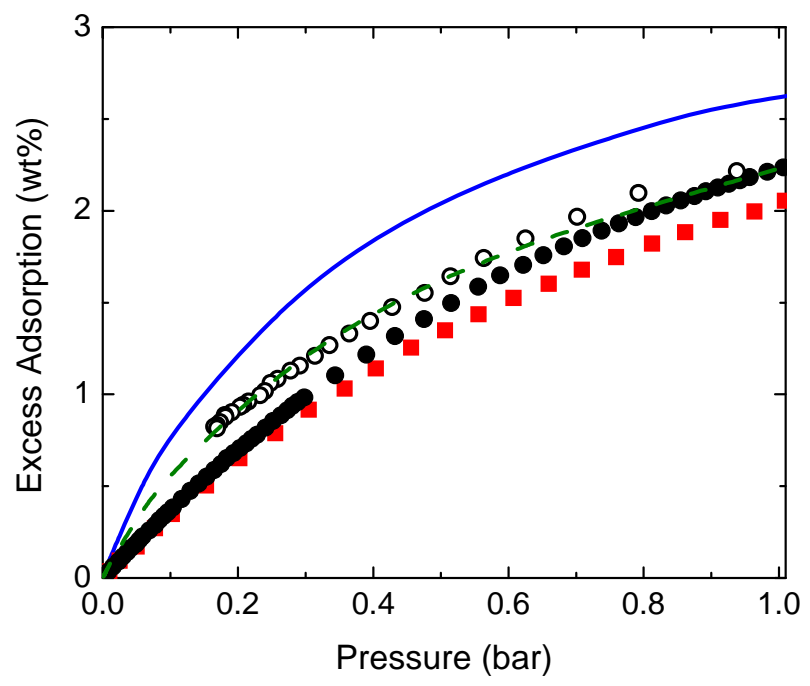

Figure 52: Comparison of simulated and experimental $\mathrm{H}_{2}$ adsorption isotherms in $\left[\mathrm{Zn}(\mathrm{bdc})(\text { ted })_{0.5}\right]$ at $77 \mathrm{~K}$ for low pressure region. The experimental results are represented by filled (open) circles for adsorption (desorption). The experimental data from Lee, J. Y.; Olson, D. H.; Pan, L.; Emge, T. J.; Li, J. Adv. Func. Mater. 2007, 17, 1255 are shown as filled squares. The simulation results using FH effective Buch potential are represented by the solid line (blue) and the dashed line (olive) for the UFF and DREIDING force fields, respectively.

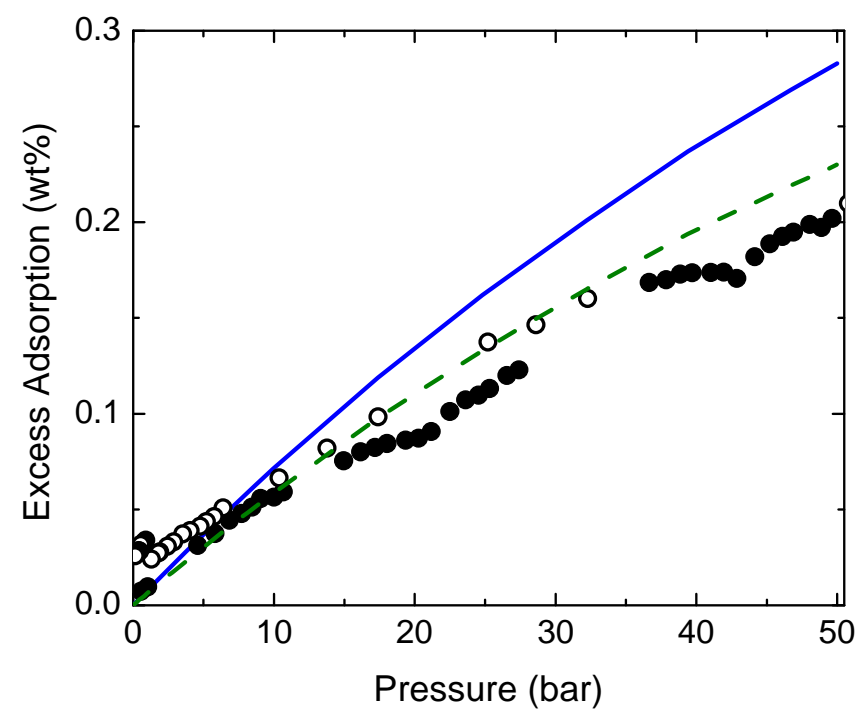

Figure 53: Comparison of simulated and experimental $\mathrm{H}_{2}$ adsorption isotherms in [Zn(bdc)(ted) $\left.)_{0.5}\right]$ at $298 \mathrm{~K}$. The experimental results are represented by filled (open) circles for adsorption (desorption). The simulation results using Buch potential are represented by the solid line (blue) and the dashed line (olive) for the UFF and DREIDING force fields, respectively. 


\section{B. Study on the Reasons for Over-prediction of $\mathrm{H}_{2}$ Adsorption in MOFs}

We have found that for some MOFs that the modeling with classical Buch potential predicts about $40-60 \%$ more adsorption than is observed from experiments, as shown in Figure 54.

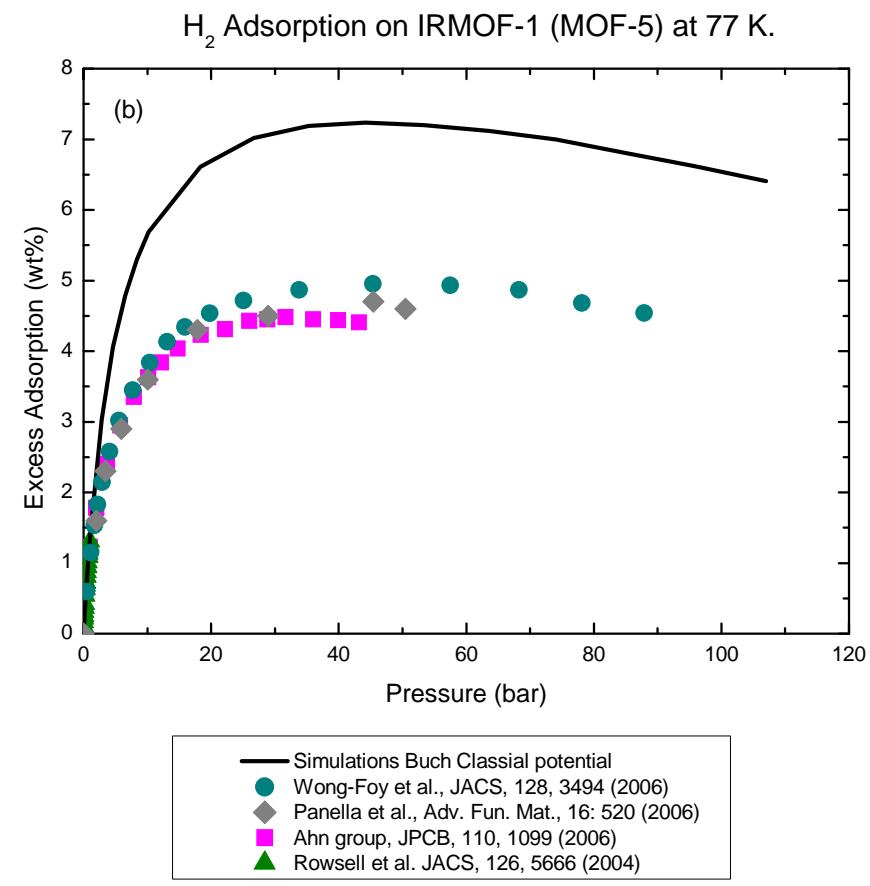

Figure 54: Comparison of simulated and experimental $\mathrm{H}_{2}$ adsorption isotherms in IRMOF-1 at $77 \mathrm{~K}$.

Possible reasons for differences in simulations and experiments include the following: (1) quantum effects for $\mathrm{H}_{2}$ at $77 \mathrm{~K}$, (2) errors in the $\mathrm{H}_{2}-\mathrm{H}_{2}$ potential, (3) errors in the $\mathrm{H}_{2}$-solid potentials, (4) the charge-charge interactions, (5) the polarizability effects, (6) the matrix flexibility of the MOFs, (7) crystal defects, (8) the presence of guest molecules (contaminants) in the samples use for experimental work. We have investigated the first four factors and present the results in this report.

\subsection{Quantum effects}

Ignoring quantum effects is a very good approximation at $298 \mathrm{~K}$. However, quantum effects are significant at $77 \mathrm{~K}$, especially at high pressures. We have used two methods to represent quantum effects. One is path integral Monte Carlo (PIMC) calculation; another method is to use effective potentials. It has been shown that Feynman-Hibbs effective potential (FH) with quadratic term can represent thermodynamics and structural results of quantum fluid fairly well, and agrees with PIMC results. The FH effective Buch potential has the following form: 


$$
U_{F H}(r)=U_{L J}(r)+\left(\frac{\hbar^{2}}{24 \mu k T}\right) \nabla^{2} U_{L J}(r)
$$

where,

$$
\nabla^{2} U_{L J}(r)=U_{L J}^{\prime \prime}(r)+\frac{2}{r} U_{L J}^{\prime}(r)=4 \varepsilon\left(\frac{132 \sigma^{12}}{r^{14}}-\frac{30 \sigma^{6}}{r^{8}}\right)
$$

and,

$$
\begin{aligned}
& \left(\frac{\hbar^{2}}{24 \mu k T}\right)=\frac{2.005}{T}, \AA^{2} K^{-1} \quad \text { (fluid-fluid) } \\
& \left(\frac{\hbar^{2}}{24 \mu k T}\right)=\frac{1.002}{T}, \AA^{2} K^{-1} \quad \text { (fluid-solid) }
\end{aligned}
$$

The classical Buch potential, the FH correction term [second term in eq. (1)], and the FH effective Buch potential for $\mathrm{H}_{2}$ at $77 \mathrm{~K}$ is shown in Figure 55.

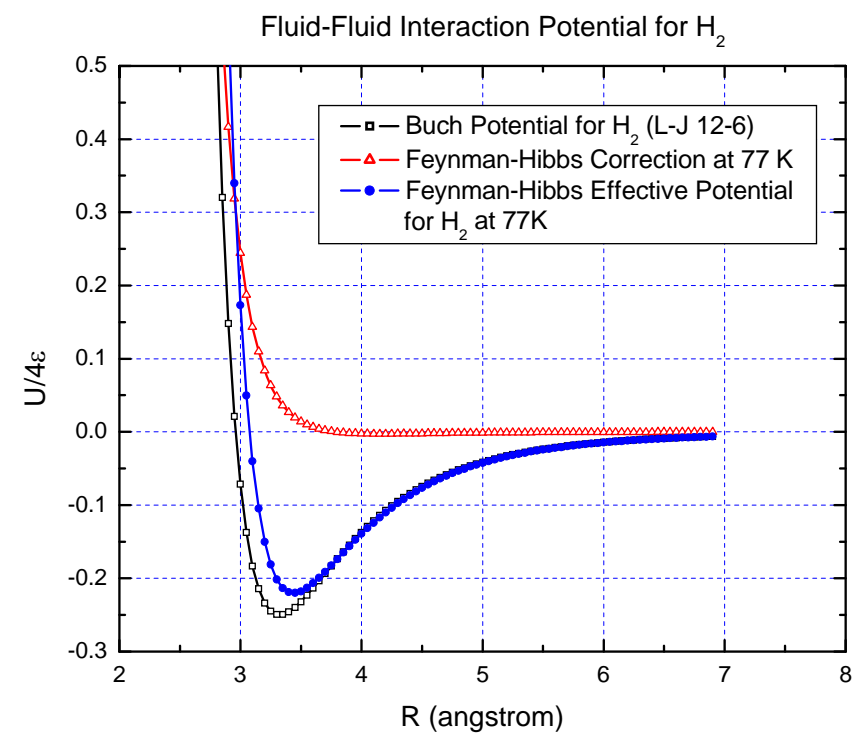

Figure 55: Fluid-fluid interaction potential for $\mathrm{H}_{2}$ at $77 \mathrm{~K}$.

We have performed simulations to calculate the bulk isothermal properties for $\mathrm{H}_{2}$ at $77 \mathrm{~K}$ using classical Buch potential and $\mathrm{FH}$ effective Buch potential. We can see that by considering the quantum effects, the bulk density is decreased by about $20 \%$ at pressures $>100$ bar, as shown in Figure 56. The equation of state for $\mathrm{H}_{2}$ is accurately represented by the Buch potential when quantum effects are included. 


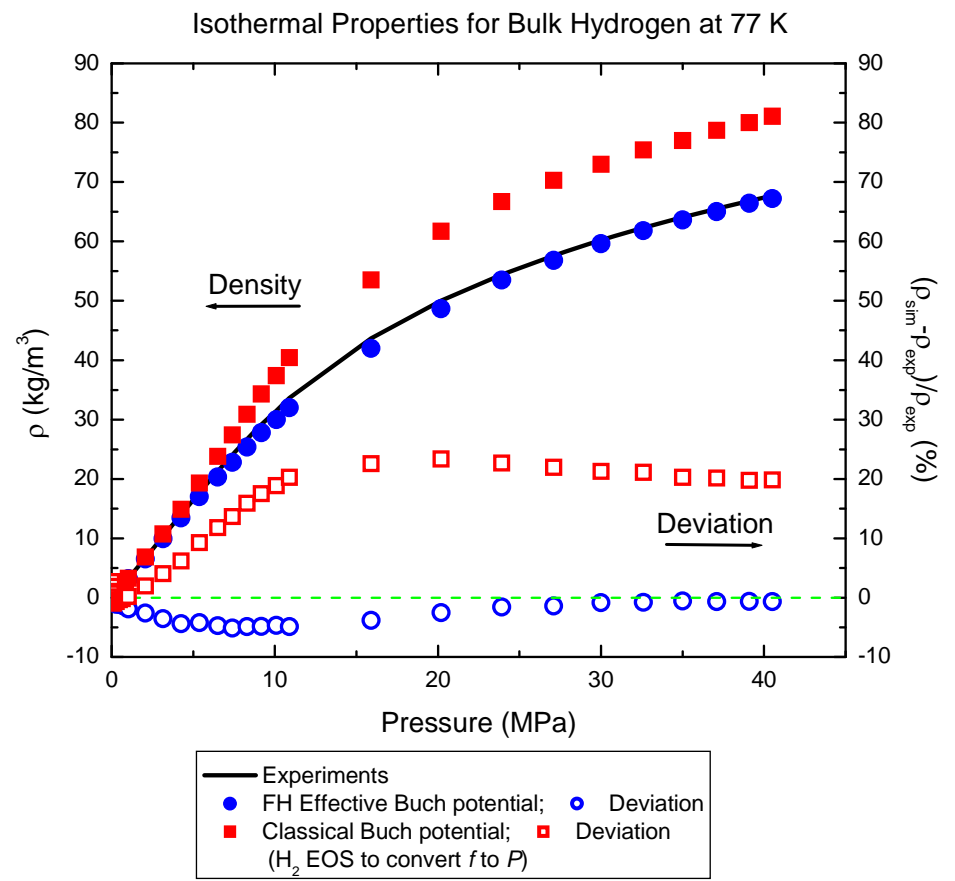

Figure 56: Bulk properties for $\mathrm{H}_{2}$ at $77 \mathrm{~K}$.

We have also used the path integral formalism adapted to the GCMC ensemble to account for quantum effects for simulating adsorption of $\mathrm{H}_{2}$. The simulations were performed at $77 \mathrm{~K}$ using 1 unit cell as the simulation box, and a Trotter number of 30 beads. For each state point the number of equilibration configurations was $10^{6}$, starting from the result of the previous computation, followed by $4 \times 10^{6}$ configurations for production. The probability of creation/deletion was set to $49 \%$, with $2 \%$ probability of performing a Hybrid Monte Carlo move.

We have compared the FH effective Buch potential with PIMC and classical Buch potential for $\mathrm{H}_{2}$ adsorption in IRMOF-1 and CuBTC at $77 \mathrm{~K}$. Reasonably good agreement between FH effective potential and PIMC is obtained as shown in Figure 57. It is concluded that $\mathrm{FH}$ potential is a reasonable approximation to full quantum effects at $77 \mathrm{~K}$. The total adsorption in IRMOF- 1 and CuBTC is decreased by about $15 \%$ at $77 \mathrm{~K}$ and $\sim 90$ bar for using both FH potential and PIMC compared with classical Buch potential. 
$\mathrm{H}_{2}$ Adsorption on IRMOF-1 (MOF-5) at $77 \mathrm{~K}$.

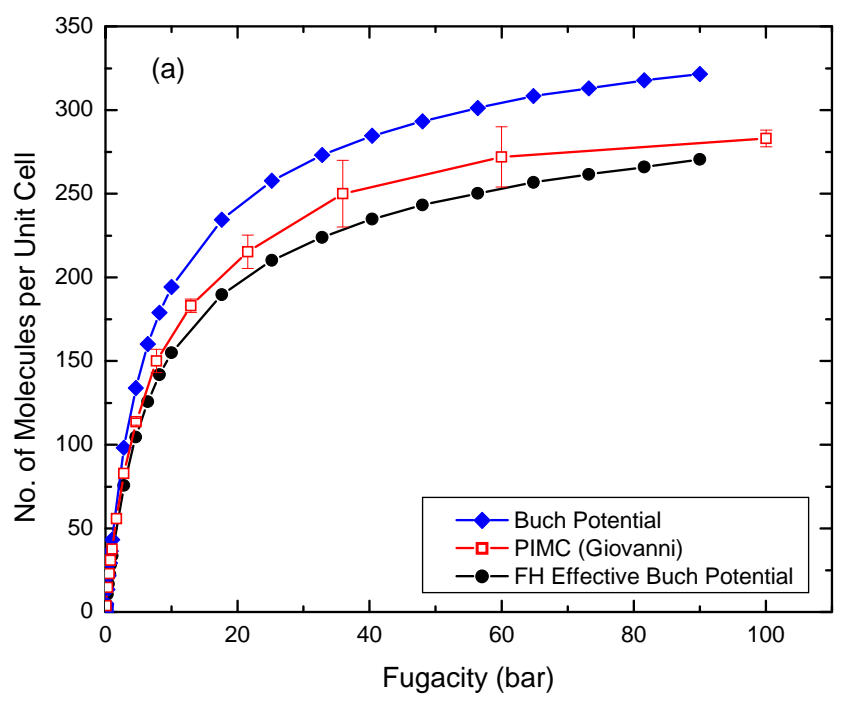

$\mathrm{H}_{2}$ Adsorption on HKUST-1 (CUBTC) at $77 \mathrm{~K}$.

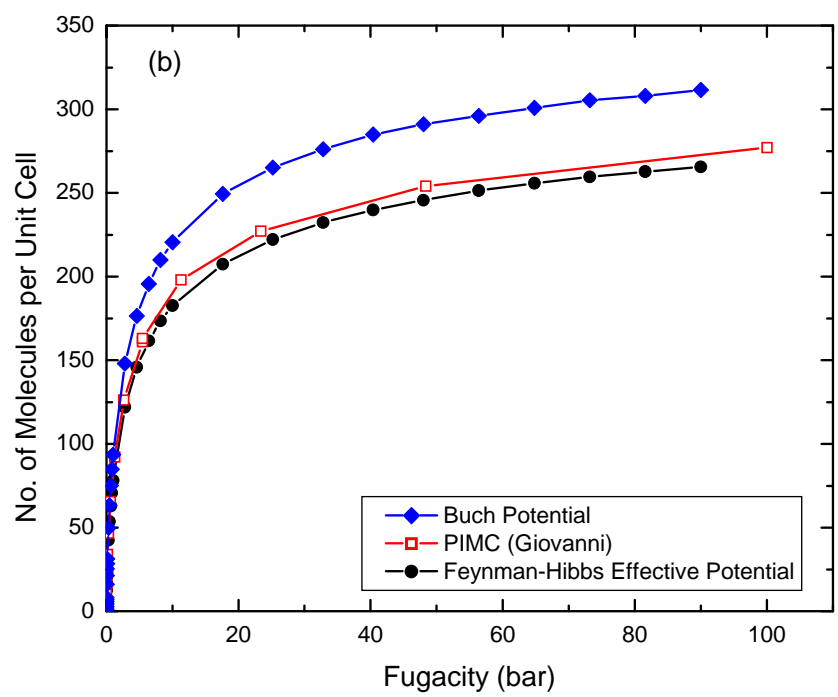

Figure 57: Comparison of simulated $\mathrm{H}_{2}$ adsorption isotherms in IRMOF-1 (a) and CuBTC (b) at $77 \mathrm{~K}$ using classical Buch potential, FH effective Buch potential, and PIMC.

The simulated excess adsorption vs. pressure and the comparison with experiments are shown in Figure 58 for IRMOF-1. Simulations with FH effective potential (red solid lines) agree fairly well with experiments for $\mathrm{p}<2$ bars, but overestimate for $\mathrm{p}>2$ bar. 


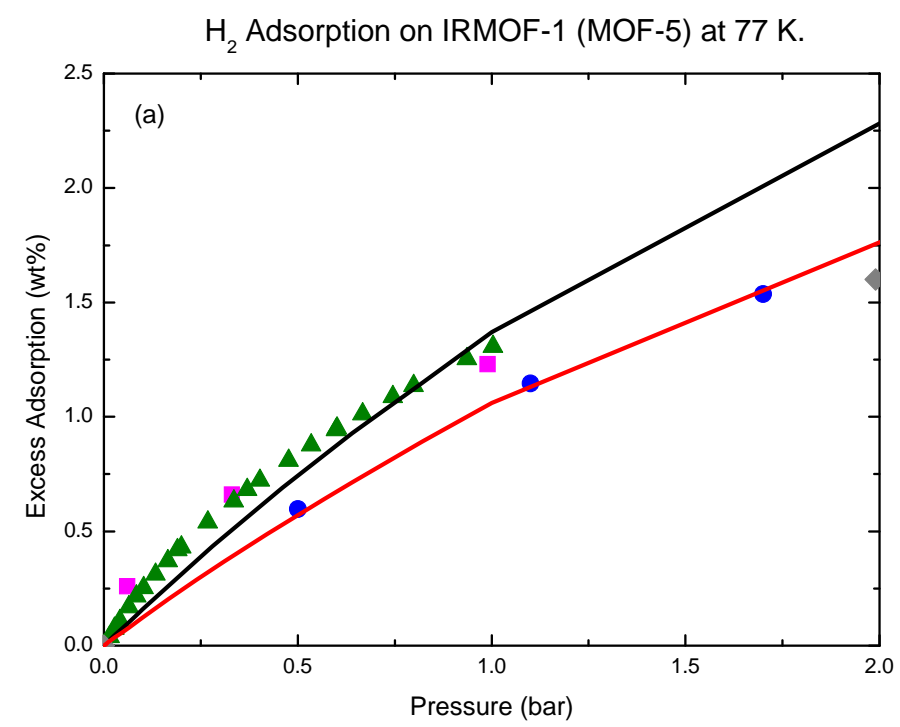

$\mathrm{H}_{2}$ Adsorption on IRMOF-1 (MOF-5) at $77 \mathrm{~K}$.

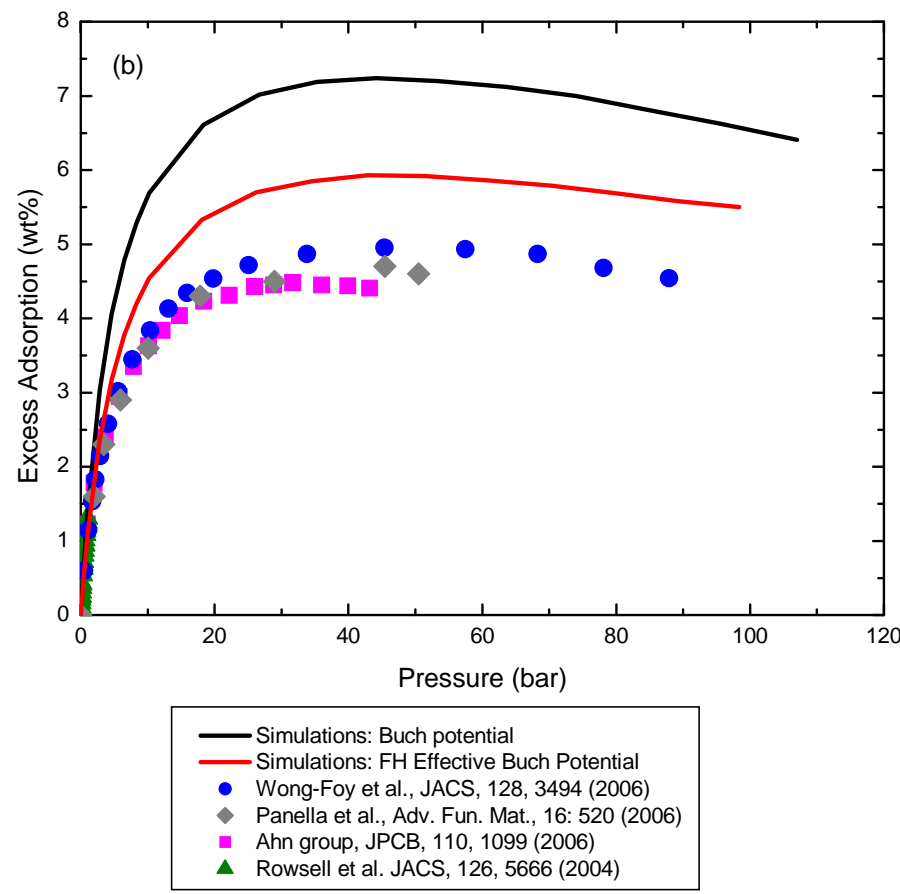

Figure 58: Comparison of simulated and experimental $\mathrm{H}_{2}$ adsorption isotherms in IRMOF-1 at 77 K. (A) $\mathrm{P}=0 \sim 2$ bar; (B) $\mathrm{P}=0 \sim 110$ bar.

\section{$2.2 \mathrm{H}_{2}$-solid interaction potential}

We have looked the snapshots for $\mathrm{H}_{2}$ adsorption on IRMOF-1 for $\mathrm{T}=77 \mathrm{~K}$ at $p=1,2$, and 10 bar. These snapshots are shown in Figure 59. $\mathrm{H}_{2}$ mainly adsorbed on the corners of IRMOF-1 (high 
adsorption energy sites, close to oxygen atoms) at low-pressure regime; at high pressures, $\mathrm{H}_{2}$ also populates the low adsorption energy sites (linkers). Low-pressure adsorption is mainly controlled by the interaction energy between $\mathrm{H}_{2}$ and oxygen atoms of the MOFs; high-pressure adsorption is mainly controlled by interaction energy between $\mathrm{H}_{2}$ and linker $(\mathrm{C}$ and $\mathrm{H})$ atoms of the MOFs.

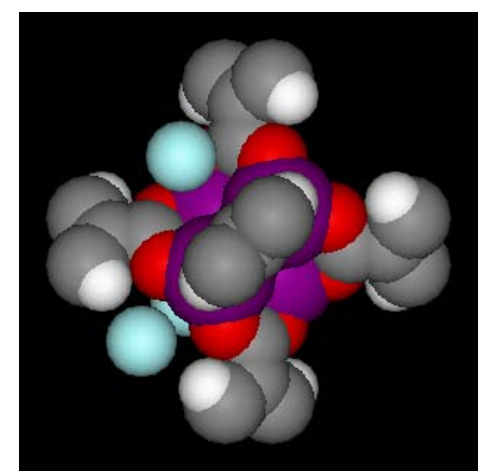

Corner

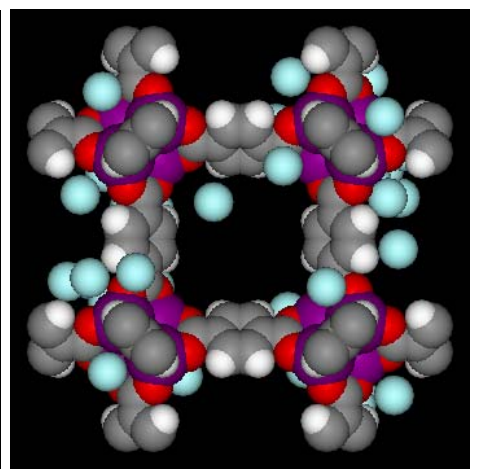

1 Unit Cell

(a) $p=1$ bar ( $\mathrm{H}_{2}$ adsorbed on corners.)

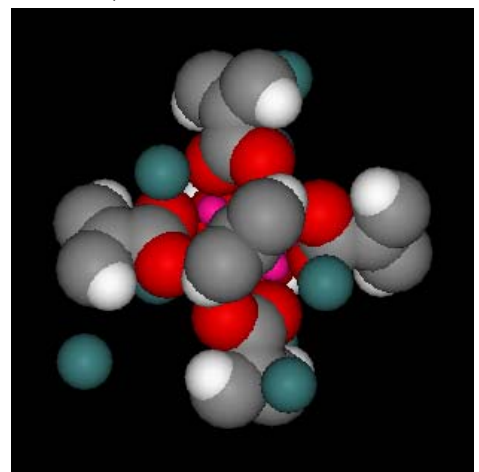

Corner

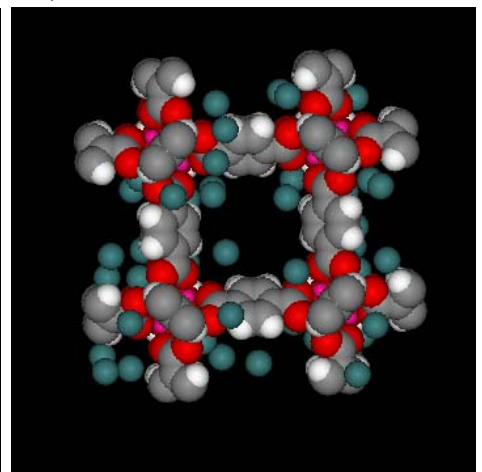

1 Unit Cell

(b) $p=2$ bar ( $\mathrm{H}_{2}$ Adsorbed mainly on corners.)

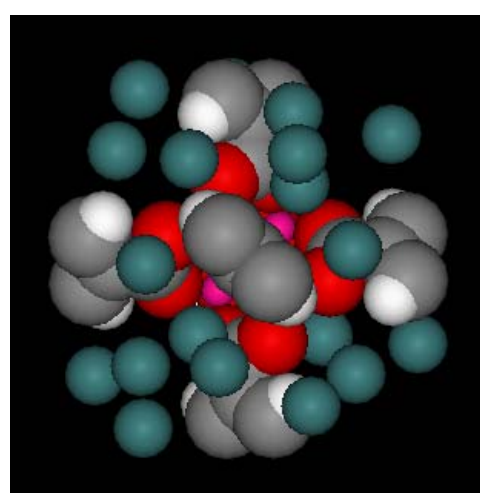

Corner

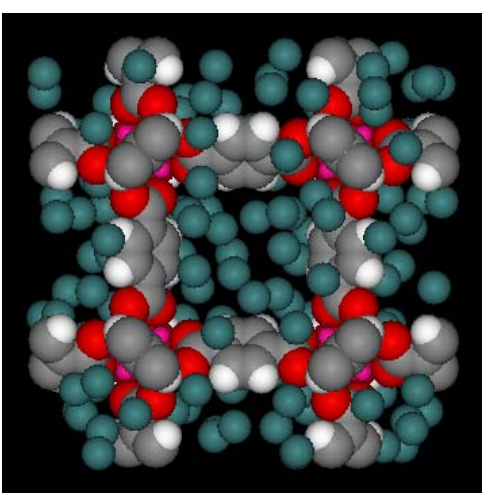

1 Unit Cell

(c) $p=10$ bar ( $\mathrm{H}_{2}$ Adsorbed on corners and linkers.)

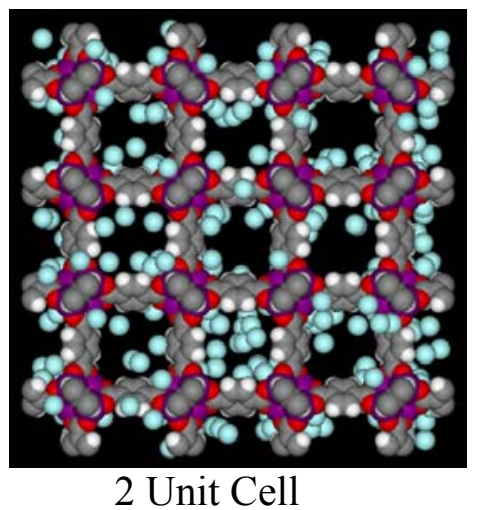

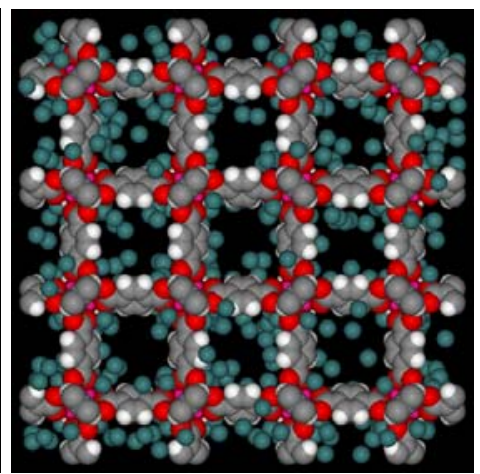

2 Unit Cell

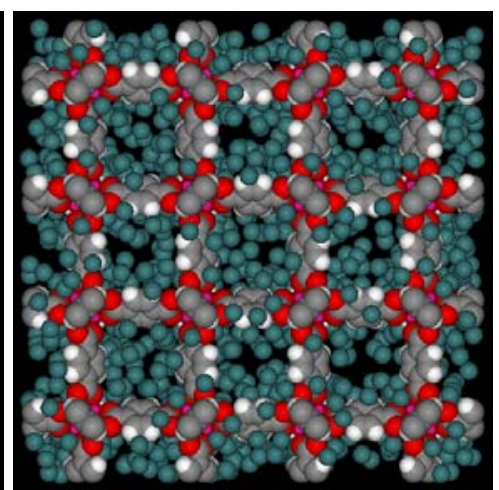

2 Unit Cell

Figure 59: Snapshots for $\mathrm{H}_{2}$ Adsorption on IRMOF-1 at $77 \mathrm{~K}$ and (a) $\mathrm{p}=1$ bar; (b) $\mathrm{p}=2$ bar; (c) $\mathrm{p}=10$ bar. Red: oxygen atoms in solid; Gray: carbon atoms in solid; White: hydrogen atoms in solid; Magenta: metal (Zn) atoms in solid; Cyan: hydrogen molecules adsorbed in IRMOF-1. 
To improve the agreement with experiments, we can see from Fig. 58 that the lowpressure adsorption should be maintained (or increased a little bit) and high-pressure adsorption should be decreased. To achieve this target, with the information obtained from the snapshots, we can employ the approach that decreases $\mathrm{H}_{2}$-linker (carbon and hydrogen) interaction potentials and meanwhile increases $\mathrm{H}_{2}$-oxygen interaction potential. We have empirically adjusted the interaction parameters for $\mathrm{H}_{2}-\mathrm{C}, \mathrm{H}_{2}-\mathrm{H}$, and $\mathrm{H}_{2}-\mathrm{O}$ and two best fits are shown in Figure 60 and 61. For the first best fit, we have decreased the $\mathrm{H}_{2}-\mathrm{C}$ and $\mathrm{H}_{2}-\mathrm{H}$ interaction potentials by $60 \%$ and increased the $\mathrm{H}_{2}-\mathrm{O}$ interaction potential by $300 \%$ compared to the interaction potentials obtained by Lorentz-Berthelot (LB) mixing rules. For the second best fit, the $\mathrm{H}_{2}-\mathrm{C}$ and $\mathrm{H}_{2}-\mathrm{H}$ interaction potentials were decreased by $70 \%$ and $\mathrm{H}_{2}-\mathrm{O}$ interaction potential was increased by $350 \%$ compared to the interaction potentials obtained by LB mixing rules. Those empirically adjusted parameters are unrealistic compared with Sagara \& Ganz's ab initio data (Sagara \& Ganz, J. Chem. Phys., 121, 12543 (2004)).

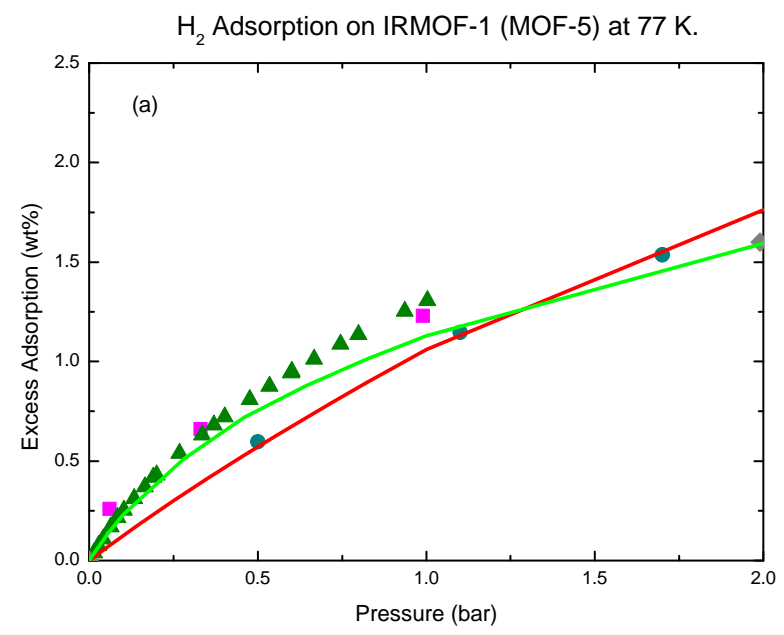




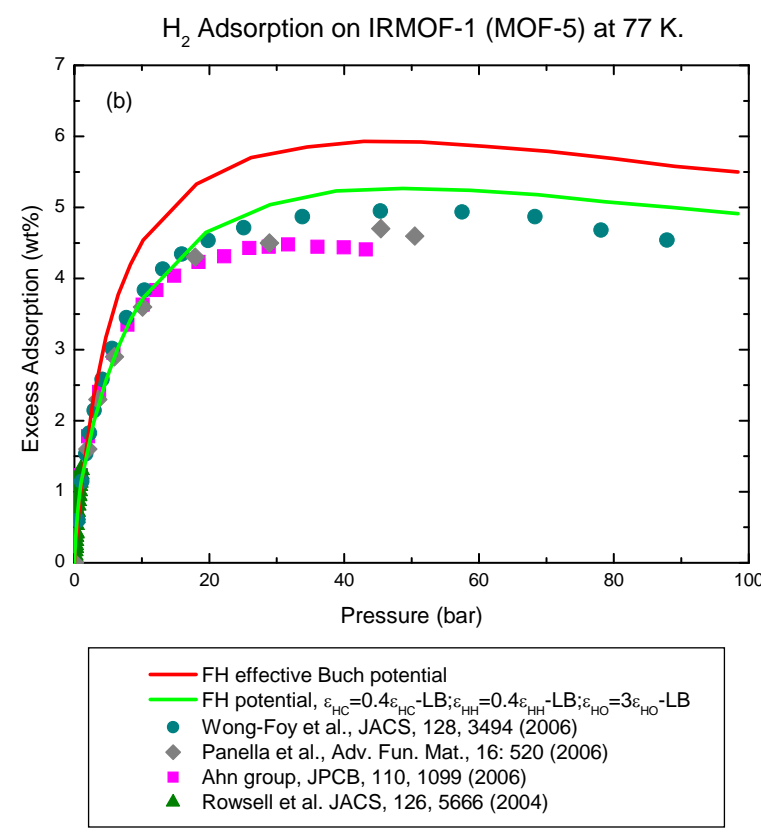

Figure 60: $\mathrm{H}_{2}$ Adsorption isotherms on IRMOF-1 at $77 \mathrm{~K}$ using empirically adjusted parameters: best fit-1 (green line). (A) $\mathrm{P}=0 \sim 2$ bar; (B) $\mathrm{P}=0 \sim 110$ bar.

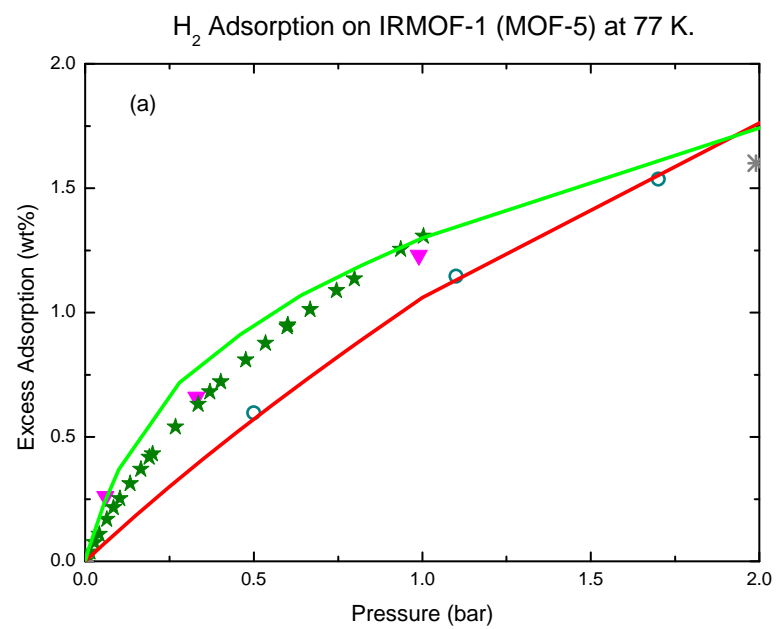




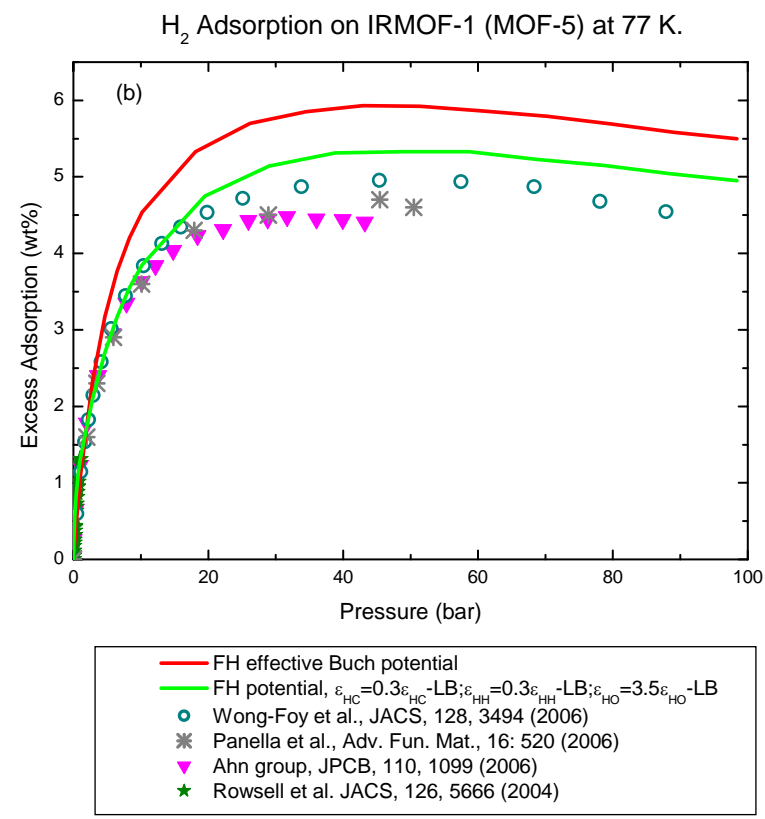

Figure 61: $\mathrm{H}_{2}$ adsorption isotherms on IRMOF-1 at $77 \mathrm{~K}$ using empirically adjusted parameters: best fit-2(Green line). (A) $\mathrm{P}=0 \sim 2$ bar; (B) $\mathrm{P}=0 \sim 110$ bar.

\subsection{Charge-charge interactions}

We have used the UFF model to account for atomic interactions between solid and fluid atoms. The UFF model is essentially a collection of Lennard-Jones potentials; electrostatic interactions between fluid molecules and framework are therefore ignored within the UFF model. However, the metal-oxide clusters and organic linkers in MOFs are partially charged. It is a good approximation to ignore the electrostatic interactions for simple nonpolar molecules, like Argon and methane. But molecules that have dipole or quadrupole moments may have substantial electrostatic interactions with the framework interactions that significantly affect the adsorption properties. In this part, we present our results for $\mathrm{H}_{2}$ and $\mathrm{N}_{2}$ adsorption in CuBTC by taking into account the charge-quadrupole interactions.

The interaction potential between a point charge and a point quadrupole is as given by ${ }^{1}$

$$
u_{q \theta}(r, \phi)=\frac{1}{8 \pi \varepsilon_{0}} \frac{q_{\text {solid }} \Theta\left(3 \cos ^{2}(\phi)-1\right)}{r^{3}}
$$

where $q_{\text {solid }}$ is the charge on the framework atoms (in units of coulomb, C), $\Theta$ is the quadrupole moment of the adsorbate $\left(\mathrm{C} \cdot \mathrm{m}^{2}\right), \phi$ is the angle between the adsorbate molecule symmetry axis and the line connecting it with a solid atom, $r$ is the distance between a solid atom and center of mass of an adsorbate molecule $(\mathrm{m})$, and $\varepsilon_{0}$ is the vacuum permittivity $\left(=8.8541878176 \times 10^{-12}\right.$ 
$\left.\mathrm{C}^{2} /(\mathrm{J} \mathrm{m})\right)$. The charges on the solid atoms of CuBTC are listed in Table 2-1, and the quadrupole moments of $\mathrm{H}_{2}$ and $\mathrm{N}_{2}$ are listed in Table 2-2.

Table 2-1: The charge of solid atoms in $\mathrm{CuBTC}^{2}$

\begin{tabular}{|l|l|}
\hline Atoms & Charge (e) \\
\hline$C_{\text {benzene }}(\mathrm{C})$ & -0.092 \\
\hline$C_{\text {benzene }}(\mathrm{CH})$ & -0.014 \\
\hline $\mathrm{C}_{\text {carboxyl }}$ & 0.778 \\
\hline $\mathrm{Cu}$ & 1.098 \\
\hline $\mathrm{O}$ & -0.665 \\
\hline $\mathrm{H}$ & 0.109 \\
\hline
\end{tabular}

Table 2-2: The quadrupole moment of adsorbate molecules

\begin{tabular}{|l|l|}
\hline Adsorbate & Quadrupole moment $\left(\mathbf{C} \cdot \mathbf{m}^{2}\right)$ \\
\hline $\mathrm{H}_{2}{ }^{3}$ & $2.1 \times 10^{-40}$ \\
\hline $\mathrm{N}_{2}{ }^{4}$ & $4.89 \times 10^{-40}$ \\
\hline
\end{tabular}

The charge-quadrupole interaction is a function of $r^{-3}$, which is a long-range interaction compared with the LJ potential (which goes as $r^{-6}$ ). Thus, we need large potential truncation to accurately account the charge-quadrupole interactions. The summation of the charge-quadrupole interactions should be over entire unit cell of the MOF in order to maintain electrostatic neutrality. We have calculated the effects of truncation on the charge-quadrupole interaction potential and $\mathrm{H}_{2}$ adsorption isotherm. We have found that in terms of amount $\mathrm{H}_{2}$ adsorbed in CuBTC, summation over $2 \times 2 \times 2$ unit cells $(52 \times 52 \times 52 \AA)$ gives results that are numerically identical to summation over $4 \times 4 \times 4$ unit cells $(104 \times 104 \times 104 \AA)$, as can be seen in Figure 62 . This is due to (1) Charge-quadrupole interactions decay as $r^{-3}$, making interactions become very small at large distance (see Table 2-3) and (2) the cancellation of positive and negative chargequadrupole interactions. We have summed over $2 \times 2 \times 2$ unit cells for charge-quadrupole interactions in our simulations. 


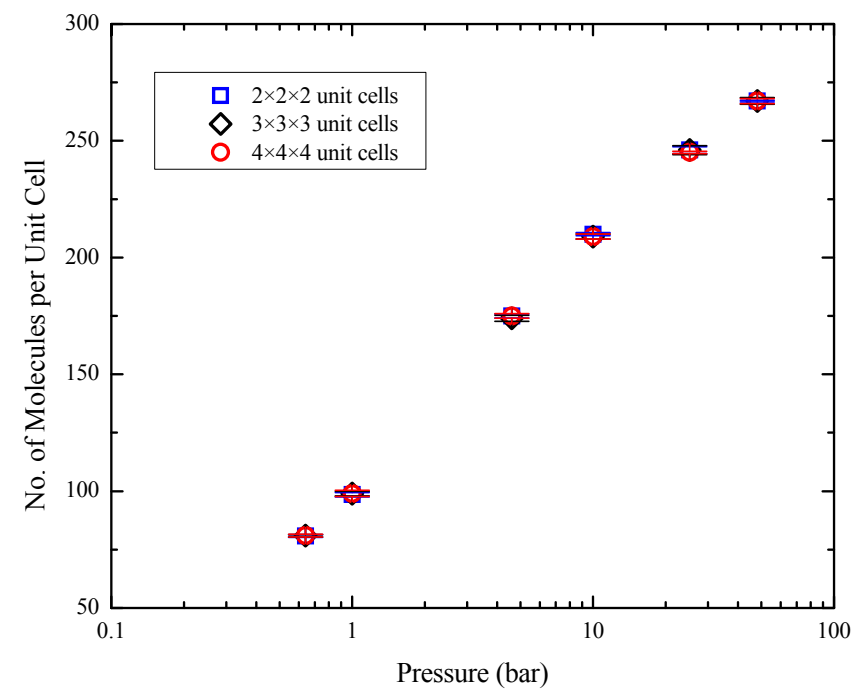

Figure 62: Comparison the effect of truncations for charge-quadrupole interactions on the amount adsorbed for $\mathrm{H}_{2}$ in $\mathrm{CuBTC}$ at $77 \mathrm{~K}$.

Table 2-3: Comparison of $\mathrm{H}_{2}-\mathrm{O}$ charge-quadrupole interaction at various distance $(\phi=0)$.

\begin{tabular}{|l|l|l|}
\hline Distance, $\AA$ & Energy, K & \% of the energy at $r=3.5 \AA$ \\
\hline 3.5 & -340 & 100 \\
\hline 26 (2 UCs) & -0.8 & 0.2 \\
\hline 39 (3 UCs) & -0.24 & 0.07 \\
\hline 52 (4 UCs) & -0.1 & 0.03 \\
\hline
\end{tabular}

We have compared the adsorption isotherms for $\mathrm{H}_{2}$ in $\mathrm{CuBTC}$ with or without chargequadrupole interaction, shown in Figures 63 and 64. The amount adsorbed is enhanced by about $30 \%$ when charge-quadrupole interactions are taken into account at low pressures, $P<1$ bar, as can be seen in Figure 63. This increase of the amount adsorbed improves the agreement with experiments, but the simulations still underpredict the amount adsorbed at low pressures. The amount adsorbed is enhanced by about $10 \%$ at the highest pressure (Figure 64). The overall agreement with experiments over the whole range of pressure is improved.

We have used spherical LJ and 2-center LJ model for $\mathrm{N}_{2}$. The comparison of the adsorption isotherms by taking into account the charge-quadrupole interactions with that without charge-quadrupole interactions are shown in Figures 65 and 66. The inclusion of chargequadrupole interactions increases the amount $\mathrm{N}_{2}$ adsorbed by about $6 \%$ for both LJ and 2-center LJ model at $253 \mathrm{~K}$ and $298 \mathrm{~K}$. This increase improves the agreement with experiments. 


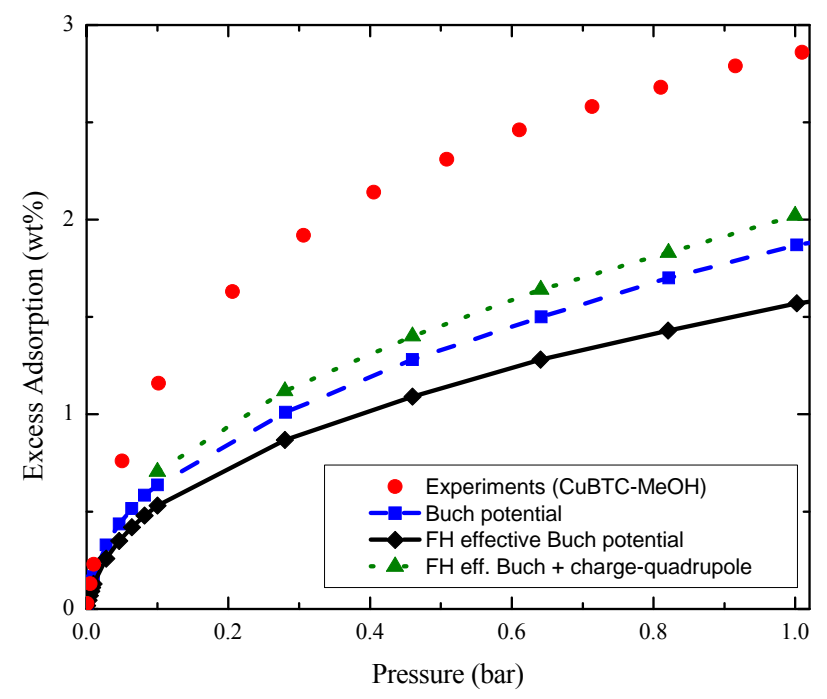

Figure 63: Effect of charge-quadrupole interactions on the adsorption isotherm for $\mathrm{H}_{2}$ in $\mathrm{CuBTC}$ at $77 \mathrm{~K}$-low pressure regime.

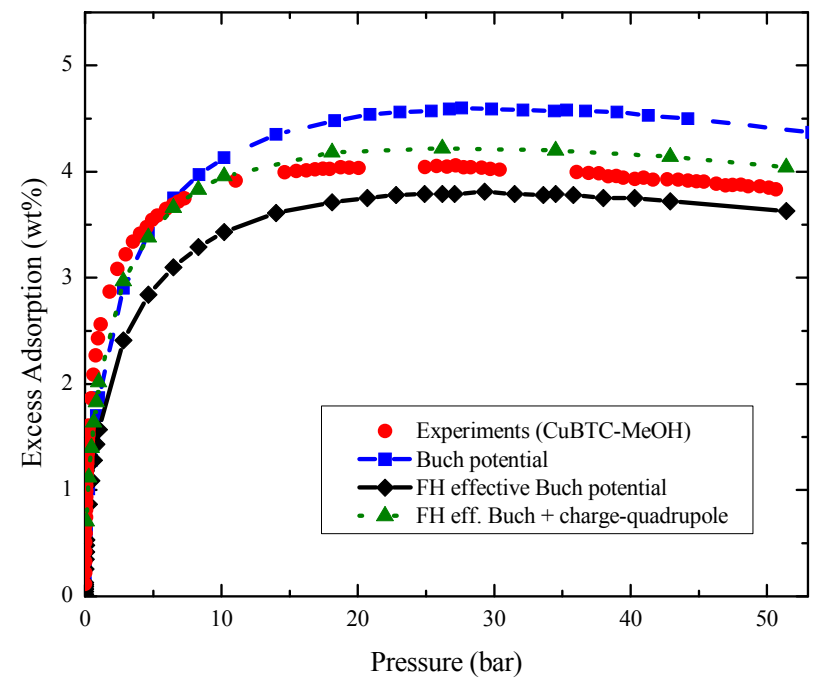

Figure 64: Effect of charge-quadrupole interactions on the adsorption isotherm for $\mathrm{H}_{2}$ in $\mathrm{CuBTC}$ at $77 \mathrm{~K}$ - high pressure regime. 


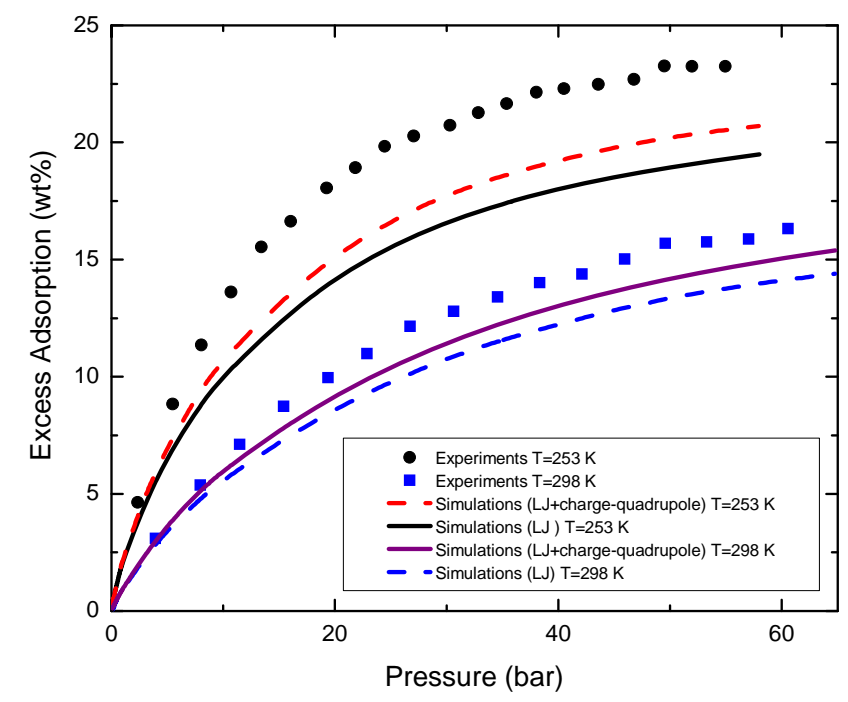

Figure 65: $\mathrm{N}_{2}$ (spherical LJ model) adsorption in CuBTC - effects of charge-quadrupole interactions on adsorption.

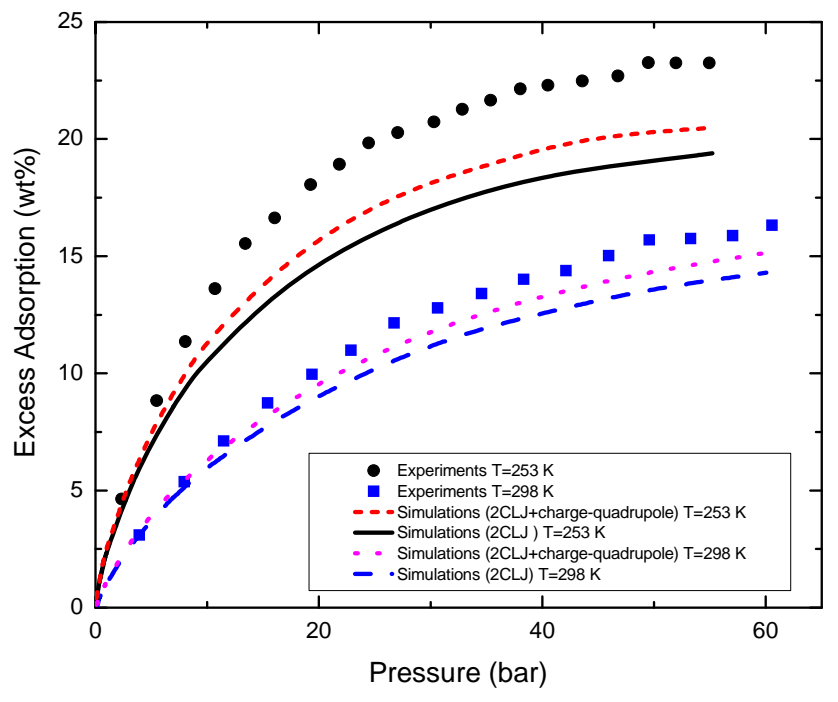

Figure 66: $\mathrm{N}_{2}$ (2-center LJ model) adsorption in CuBTC-effects of charge-quadrupole interactions on adsorption.

\subsection{Calculation of excess adsorption}

It is important to understand how experimental data are collected in order to make reasonable comparisons between simulations and experiments. We have investigated how to better compare adsorption isotherms computed from simulations with those measured in experiments. 


\subsubsection{Calculation of excess adsorption from simulations}

We have converted the total adsorption obtained from simulation to excess adsorption to compare with the experiments. We employed two commonly used methods to compute excess adsorption. The first method uses pore volume of the adsorbent and bulk adsorbate density to calculate the number of adsorbate molecules in the pore in the case of there is no adsorbent. This method is consistent with the treatment of experimental data. The excess adsorption, $N_{e x}$, is calculated by,

$$
N_{e x}=\frac{1000\left(N_{a d}-\rho_{b} V_{\text {free }}\right) m}{M}
$$

where $m$ is the molecular weight of the absorbate molecule $(\mathrm{g}), N_{a d}$ is the total number of molecules adsorbed in a unit cell, $\rho_{b}$ is the bulk gas density $\left(\mathrm{g} / \mathrm{cm}^{3}\right), M$ is the mass of a unit cell of the adsorbent $(\mathrm{g})$, and $V_{\text {free }}$ is the free volume in a unit cell of adsorbent $\left(\mathrm{cm}^{3}\right)$, which is calculated by the helium volume truncated at a helium-adsorbent interaction potential $1000 \mathrm{~K}$.

We have also computed the excess adsorption in a different way. We simulate adsorption of the gas in the porous material, but we truncate the solid-fluid potential, so that it is strictly repulsive, i.e., there are no attractive forces between the adsorbate and the adsorbent. The number of molecules in the system at a given temperature and pressure is a measure of the amount that would be present for a bulk gas in the free volume. The excess adsorption is calculated by,

$$
N_{e x}=\frac{1000\left(N_{a d}-N_{a d, U_{s f}=0}\right) m}{M}
$$

where $N_{a d, U_{s f}=0}$ is the number of adsorbate molecules in the pore at the same conditions of temperature and chemical potential as $N_{a d}$, but setting attractive potential equal to zero.

The comparison between the excess adsorption using Eq. (6) and Eq. (7) is shown in Figures 67 for $\mathrm{H}_{2}, \mathrm{CH}_{4}$, Ar and $\mathrm{N}_{2}$ adsorption in $\mathrm{CuBTC}$. We see that the excess adsorption calculated from Eq. (7) is always significantly greater than that computed from Eq. (6) at high pressures. The reason for this is that when the solid-fluid potential is truncated at zero the effective pore volume becomes much smaller than the helium pore volume. Note that the helium pore volume can be substantially larger than the pore volume measured by larger molecules, such as $\mathrm{CH}_{4}$. We believe that Eq. (6) should be more accurate for computing excess adsorption than Eq. (7). 
Simulated Adsorption Isotherms for $\mathrm{H}_{2}$ on HKUST-1 (CuBTC) at $77 \mathrm{~K}$.

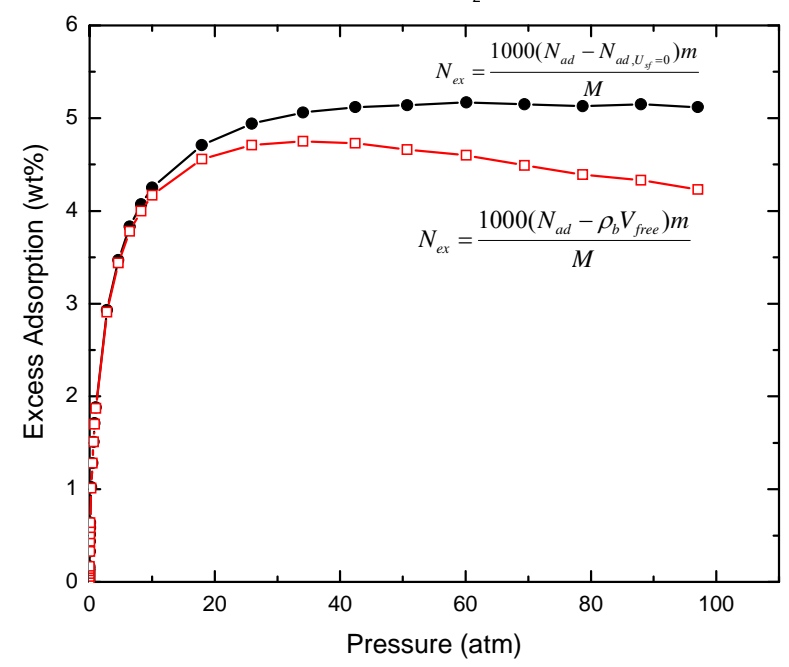

Simulated Adsorption Isotherms for $\mathrm{CH}_{4}$ on HKUST-1 (CuBTC) at $298 \mathrm{~K}$.

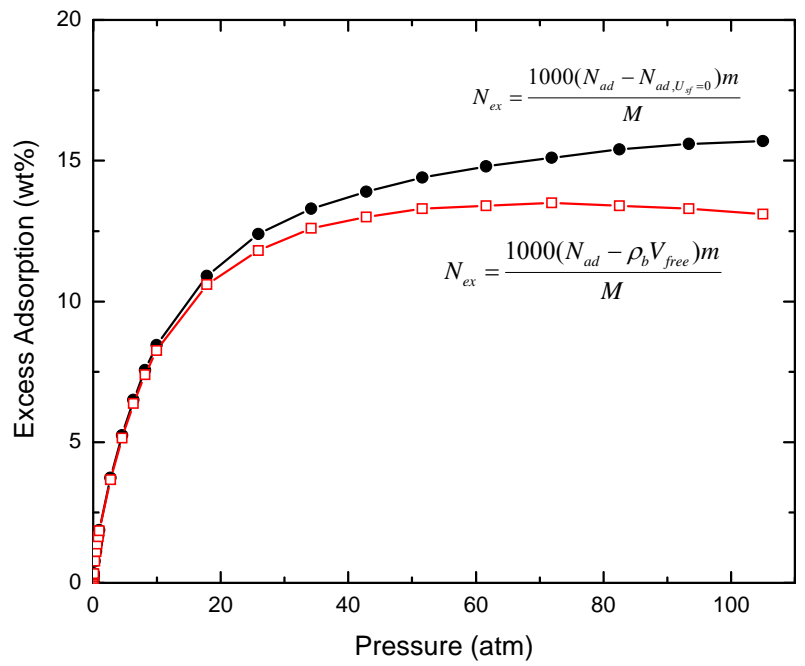


Simulated Adsorption Isotherms for Ar on HKUST-1 (CuBTC) at $298 \mathrm{~K}$.

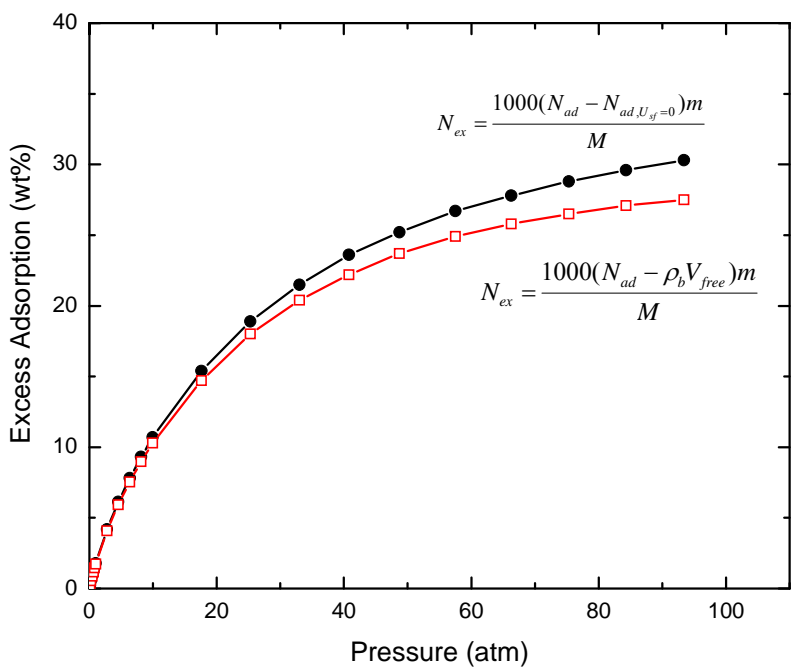

Simulated Adsorption Isotherms for $\mathrm{N}_{2}$ on HKUST-1 (CuBTC) at $298 \mathrm{~K}$.

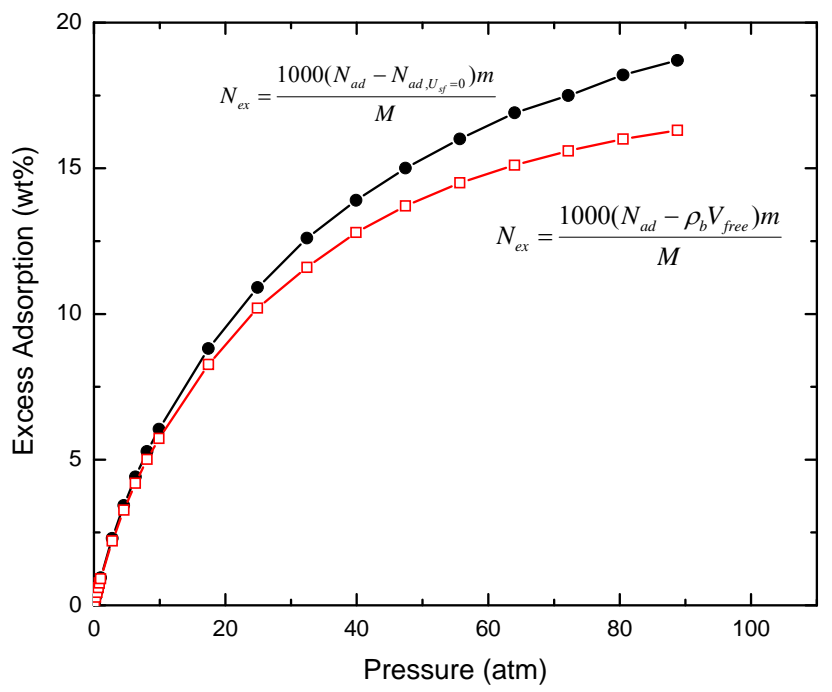

Figure 67: Comparison between the excess adsorption using two different methods for $\mathrm{H}_{2}, \mathrm{CH}_{4}$, Ar, $\mathrm{N}_{2}$ adsorption in $\mathrm{CuBTC}$ at $298 \mathrm{~K}$.

\subsubsection{Calculation of excess adsorption from experiments}

The crystal density of the MOF, $\rho_{\text {MOF }}\left(\mathrm{g} / \mathrm{cm}^{3}\right)$, is calculated by:

$$
\rho_{\text {MOF }}=\frac{m_{\text {solid }, U C}}{V_{U C}}
$$


where $m_{\text {solid,UC }}$ is the mass of all the atoms in one unit cell of the crystal $(\mathrm{g}), V_{U C}$ is the total volume of one unit cell $\left(\mathrm{cm}^{3}\right)$.

$$
\rho_{\text {ske,MOF }}=\frac{m_{\text {solid }, U C}}{V_{U C}(1-\phi)}=\frac{\rho_{\text {MOF }}}{(1-\phi)}
$$

where $\rho_{\text {ske,MOF }}$ is the skeletal density of the MOF $\left(\mathrm{g} / \mathrm{cm}^{3}\right), \phi$ is the porosity of the MOF, which is defined by,

$$
\phi=\frac{V_{\text {pore }, U C}}{V_{U C}}
$$

where $V_{\text {pore UC }}$ is the free volume in one unit cell of $\operatorname{MOF}\left(\mathrm{cm}^{3}\right)$.

If we know the skeletal density, we can calculate porosity, vice versa.

For a given mass of MOF sample, $m_{\text {sample }}$, the free pore volume of the sample, $V_{\text {free }}$, is,

$$
V_{\text {free }}=\frac{m_{\text {sample }}}{\rho_{\text {MOF }}} \phi
$$

If we know the total volume of the chamber, $V_{\text {cell }}$, we can calculate the total free volume of the chamber by,

$$
V_{\text {free }}^{\text {total }}=V_{\text {cell }}-V_{\text {solid }}=V_{\text {cell }}-\frac{m_{\text {sample }}}{\rho_{\text {MOF }}}(1-\phi)
$$

The best way to measure the free volume in experiments is to use helium with and without the MOF sample in the cell to determine $V_{\text {cell }}$ and $V_{\text {free }}^{\text {total }}$, assuming that helium does not adsorb.

In an experiment a given amount of gas is dosed to the cell. We call this amount $n_{\text {adsorbate }}$ (mole). If none of the gas adsorbed within the sorbent then the pressure in the cell would be $P_{\text {cell }}$, and this can be calculated from an EOS,

$$
P_{\text {cell }}=f\left(n_{\text {adsorbate }}, T, V_{\text {free }}^{\text {total }}\right)
$$

But because of adsorption, the pressure becomes, $P_{\text {cell }}^{a d}<P_{\text {cell }}$. We can calculate the corresponding amount of adsorbate in the free volume by an EOS,

$$
n_{\text {adsorbate }}^{\text {free }}=f\left(P_{\text {cell }}^{\text {ad }}, T, V_{\text {free }}^{\text {total }}\right)
$$

So, the excess adsorption, $n_{\text {excess }}(\mathrm{mole} / \mathrm{g})$, is,

$$
n_{\text {excess }}=\frac{\left(n_{\text {adsorbate }}-n_{\text {adsorbate }}^{\text {free }}\right)}{m_{\text {sample }}}
$$

In the adsorption experiments for $\mathrm{CuBTC}$, the porosity calculated from $\mathrm{N}_{2}$ adsorption at $77 \mathrm{~K}$ was used ( $\phi=0.7)$. However, the helium porosity, $\phi=0.6$, was used in the simulations to convert total adsorption to excess adsorption. We have shown the effects of the value of porosity on the amount adsorbed for $\mathrm{Ar}$ and $\mathrm{N}_{2}$ on $\mathrm{CuBTC}$ in Figure 68 . There is about $5 \%$ difference in 
the amount adsorbed. When we compare simulations with experiments, we should make sure both experiments and simulations use the same porosity to validate the comparison.

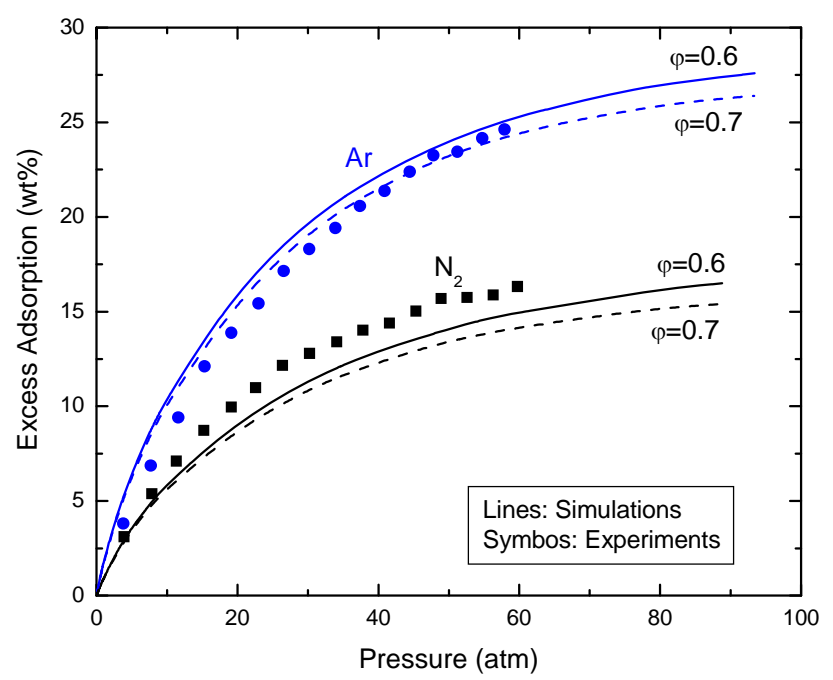

Figure 68: Comparison of Simulated and Experimental Ar and $\mathrm{N}_{2}$ Adsorption Isotherms on CuBTC at $298 \mathrm{~K}$.

To summarize this part, we have found that quantum effects are significant for $\mathrm{H}_{2}$ adsorption on MOFs at $77 \mathrm{~K}$, and Feynman-Hibbs effective potential approximates quantum effects with acceptable accuracy at $77 \mathrm{~K}$. The bulk equation of state for $\mathrm{H}_{2}$ is reproduced accurately by the $\mathrm{FH}-\mathrm{Buch}$ potential. $\mathrm{H}_{2}$-solid interaction potentials can be modified to improve the agreement between simulations and experiments. Empirically adjusted parameters for IRMOF-1 are unrealistic when compared to $a b$ initio calculations. The oxygen parameters were increased by $300-350 \%$, far too large to be "reasonable". The inclusion of charge-charge interactions increases the adsorption for polar adsorbates. When compare simulations with experiments, same porosity as used in experiments should be used to calculate the excess adsorption.

\section{VDOS Calculations for MOFs}

We have carried out a series of calculations on hypothetical MOF structures in order to identify adsorption potentials needed to facilitate uptake of large amounts of $\mathrm{H}_{2}$ in MOFs. We have focused on using two known structures, IRMOF-1 and IRMOF-14, and exploring the effect of changing the interaction potential between the sorbate $\left(\mathrm{H}_{2}\right)$ and the sorbent framework atoms. Our approach involves hypothetical changes to the chemical makeup of the framework, without changing the geometry of the framework. In the future we will explore more realistic changes to MOFs by modifying the chemical composition and geometric structure of the MOFs.

We have computed the volumetric density of states (VDOS) as a way to estimate the storage capacity of a material. The VDOS calculations are much more rapid to perform than 
adsorption isotherm calculations. An integral over the VDOS gives the amount of volume available for adsorption in a given range of adsorption energies. The VDOS for IRMOF-14 is given in Figure 69 below. A simple approximation states that the amount of $\mathrm{H}_{2}$ adsorbed at room temperature and moderate pressures is largely determined by the amount of volume available to the adsorbate where the potential is lower than about $-1000 \mathrm{~K}$. This volume can be found by integrating the VDOS from the lower limit (-2400 K in the graphs below) to an upper limit of $1000 \mathrm{~K}$. We see from Figure 69 that IRMOF-14 has zero volume available in this range. When the carbon potential is multiplied by a factor of 8 the volume is $1960 \AA^{3}$ per unit cell and when multiplied by a factor of 20 the volume is $6600 \AA^{3}$ per unit cell. The volume available increases by a factor of 3.4, while the adsorption isotherms at $298 \mathrm{~K}$, shown in Figure 70, indicate that the amount adsorbed at the highest pressure ( $46 \mathrm{bar}$ ) increases by a factor of 1.5. The increase in volume with solid-fluid potential less than $-1000 \mathrm{~K}$ does not quantitatively predict the increase in the amount adsorbed because much of the volume at higher potentials also contributes to adsorption. However, the qualitative features of adsorption are captured by this very simple rule. We also present the amount adsorbed at $77 \mathrm{~K}$ for comparison in Figure 71.

The VDOS for IRMOF-1 with various modified carbon parameters are plotted in Figure 72. The corresponding adsorption isotherms for modified IRMOF-1 at $298 \mathrm{~K}$ and $77 \mathrm{~K}$ are plotted in Figures 73 and 74, respectively. The same qualitative trends can be seen when starting with IRMOF-1 compared with IRMOF-14. The amount adsorbed is larger in IRMOF-14 for the same value of the perturbed potential because of the geometric structure of IRMOF-14, which has a larger available volume to begin with.

The changes to the potential and adsorption isotherms in Figures 69 to 74 were brought about by modifying the framework carbon potentials. We have also investigated the effect of changing other atoms. The VDOS curves for IRMOF-14 modified by changing the oxygen atom potentials are plotted in Figure 75. Note by comparison with Figure 3-1 that changing the oxygen potential parameter has a much smaller effect than changing the carbon atom potential. This is because there are far more carbon atoms in the framework than oxygen atoms. Similar tends were observed for IRMOF-1 (not shown). The adsorption isotherms at $298 \mathrm{~K}$ are plotted in Figure 76. Note that the maximum amount adsorbed is about $8.3 \mathrm{mg} / \mathrm{g}$ or about $0.83 \mathrm{wt} \%$ when the oxygen potential parameters are changed, compared with a maximum amount of about 53 $\mathrm{mg} / \mathrm{g}$ when the carbon parameters are changed (cf. Figures 76 and 70).

We have also changed the potential parameters for the $\mathrm{Zn}$ metal atoms at the corners of the IRMOF-14 structure. The corresponding VDOS curves are plotted in Figure 77. As could be expected, changing the $\mathrm{Zn}$ potential, while keeping the other potentials fixed has a small effect on both the VDOS (Figure 3-9) and the $298 \mathrm{~K}$ adsorption isotherms (Figure 78).

These model calculations suggest that the adsorption potential must be changed quite dramatically (by a factor of about 20) in order to achieve a very high uptake of hydrogen at room temperature. Mechanisms for increasing the adsorption potential by this amount are probably limited to weak chemisorption interactions, such as are present when $\mathrm{H}_{2}$ molecules interact with under coordinated metal atoms, including Ti and Sc. 


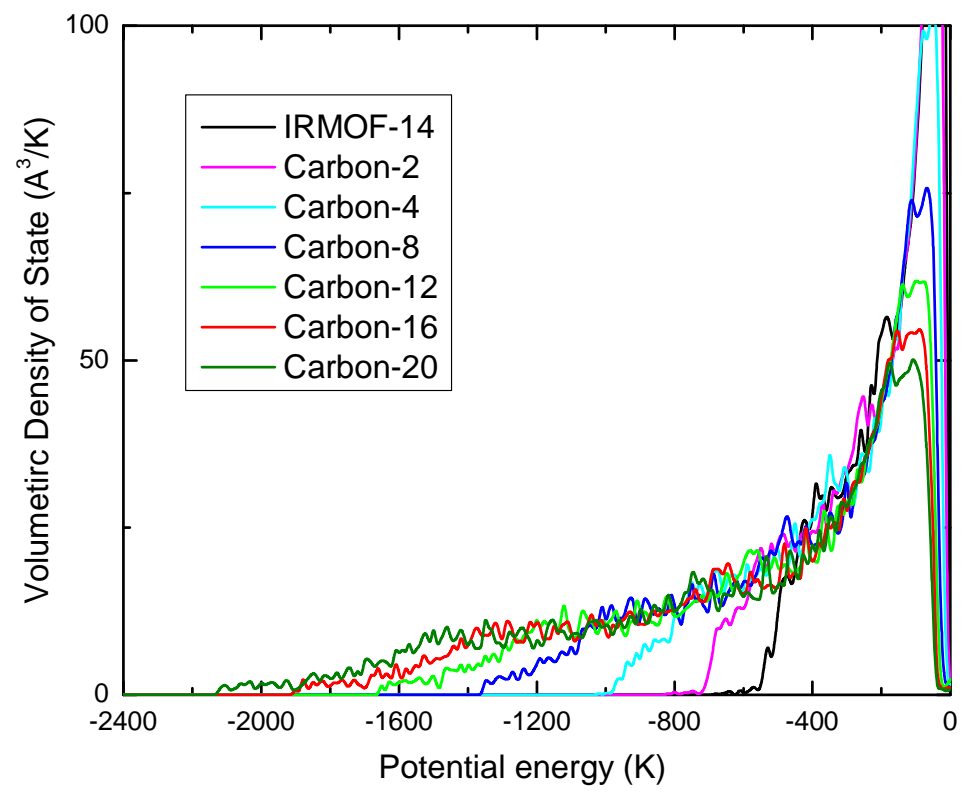

Figure 69. VDOS for IRMOF-14 with the standard potential parameters (black line) and with the potential for carbon changed by factors of $2,4,8,12,16$, and 20, as shown in the legend on the graph. 


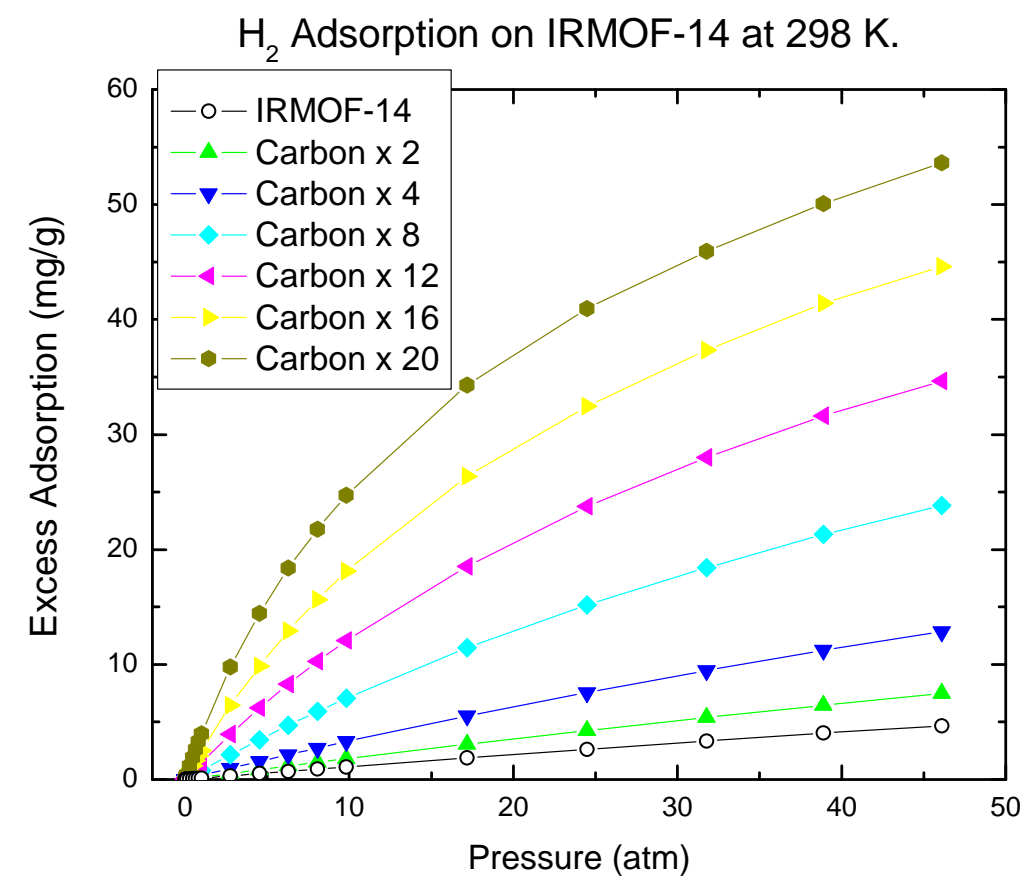

Figure 70. The adsorption isotherms for $\mathrm{H}_{2}$ on modified IRMOF-14 at $298 \mathrm{~K}$. The adsorption potential for the carbon atoms in IRMOF-14 have been increased by factors of 2, 4, 8, 12, 16, and 20, as indicated in the legend. See Figure 69. 


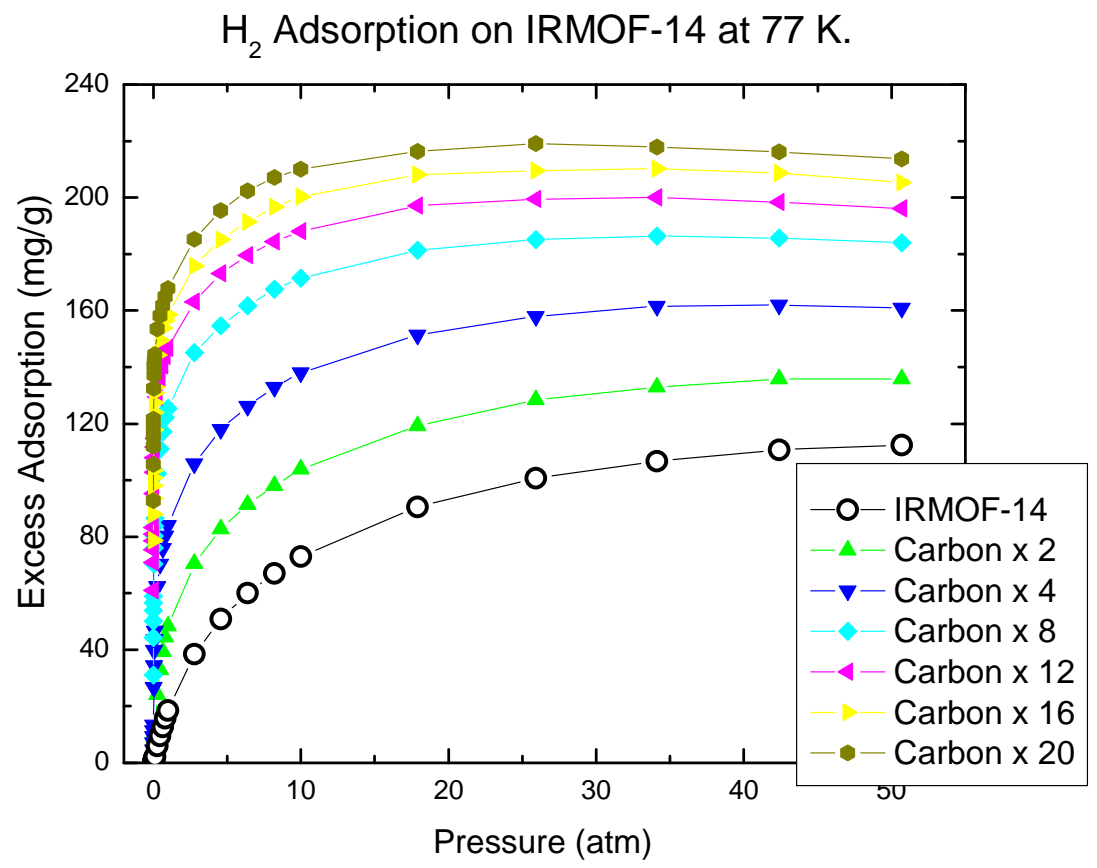

Figure 71. The adsorption isotherms for $\mathrm{H}_{2}$ on modified IRMOF-14 at $77 \mathrm{~K}$. The adsorption potential for the carbon atoms in IRMOF-14 have been increased by factors of 2, 4, 8, 12, 16, and 20, as indicated in the legend. See Figure 69. 


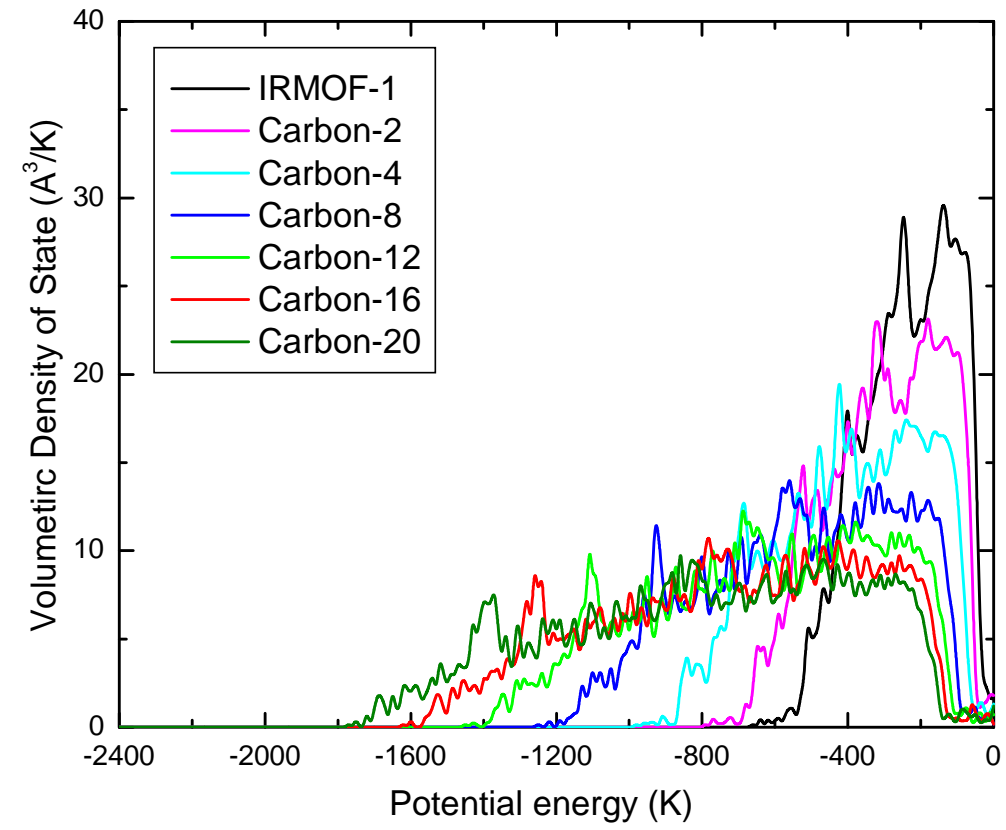

Figure 72. VDOS for IRMOF-1 with the standard potential parameters (black line) and with the potential for carbon changed by factors of $2,4,8,12,16$, and 20, as shown in the legend on the graph. 


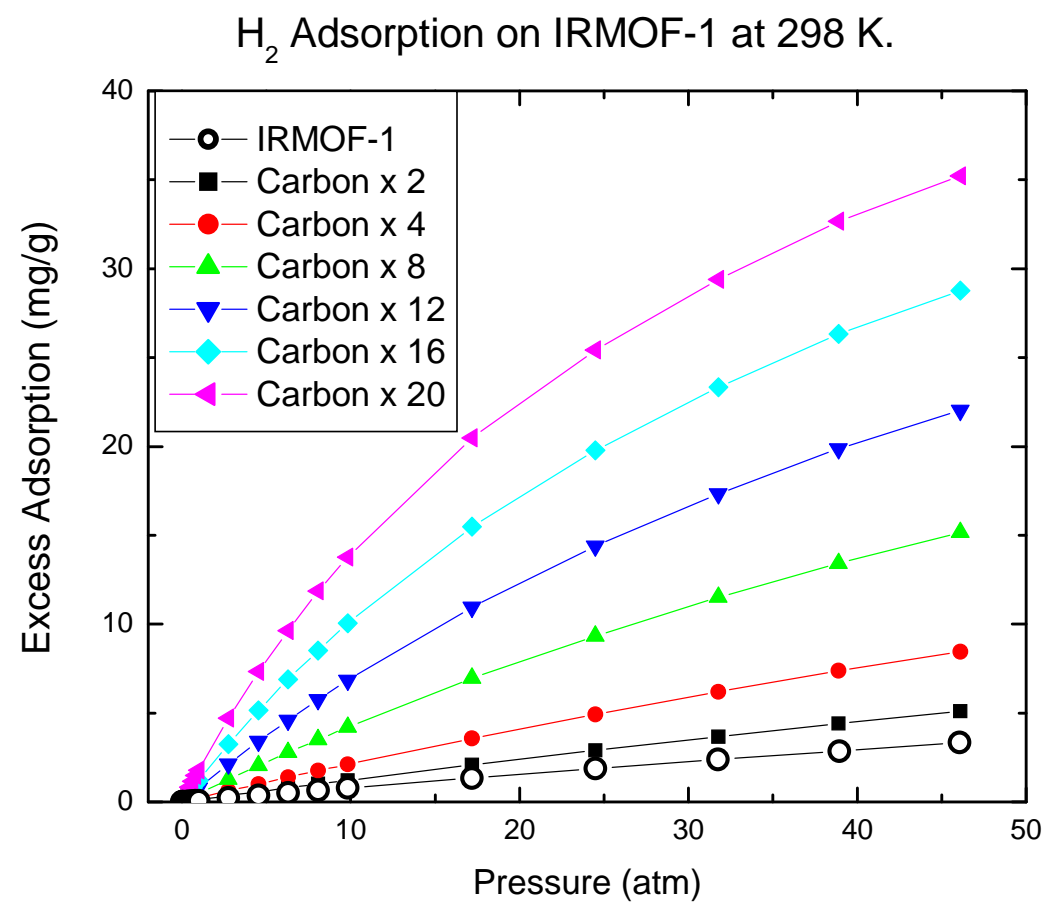

Figure 73. The adsorption isotherms for $\mathrm{H}_{2}$ on modified IRMOF-1 at $298 \mathrm{~K}$. The adsorption potential for the carbon atoms in IRMOF-14 have been increased by factors of 2, 4, 8, 12, 16, and 20, as indicated in the legend. See Figure 72. 
$\mathrm{H}_{2}$ Adsorption on IRMOF-1 at $77 \mathrm{~K}$.

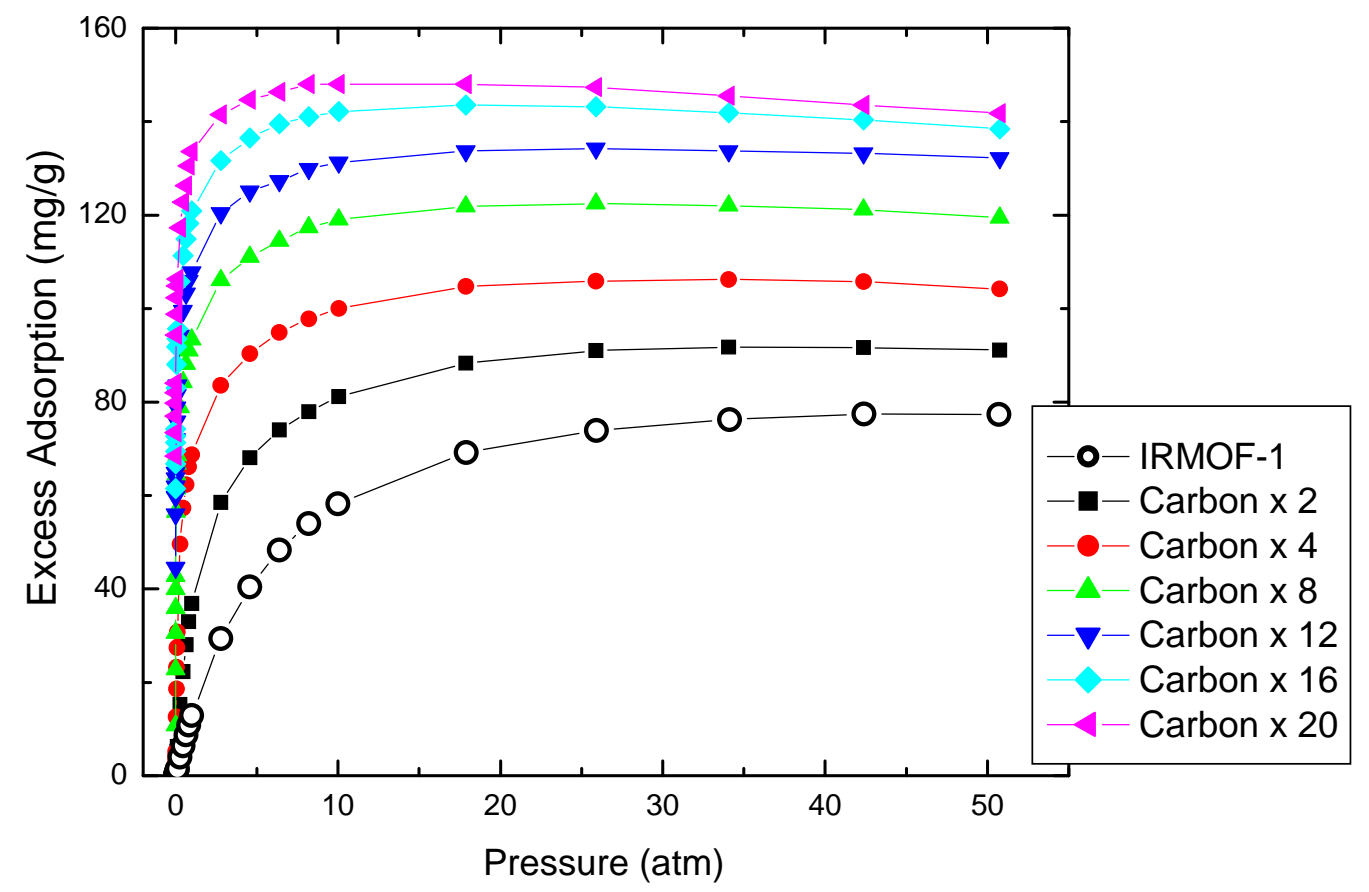

Figure 74. The adsorption isotherms for $\mathrm{H}_{2}$ on modified IRMOF-1 at $77 \mathrm{~K}$. The adsorption potential for the carbon atoms in IRMOF-14 have been increased by factors of 2, 4, 8, 12, 16, and 20, as indicated in the legend. See Figure 72. 


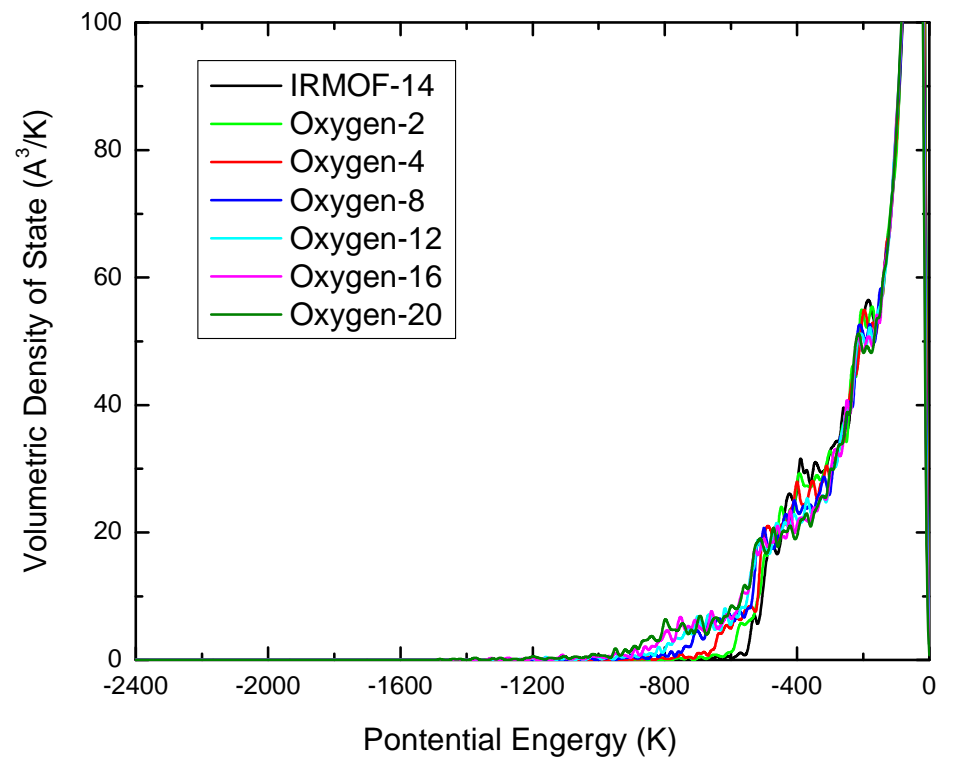

Figure 75. VDOS for IRMOF-14 with the standard potential parameters (black line) and with the potential for oxygen changed by factors of $2,4,8,12,16$, and 20 , as shown in the legend on the graph. 


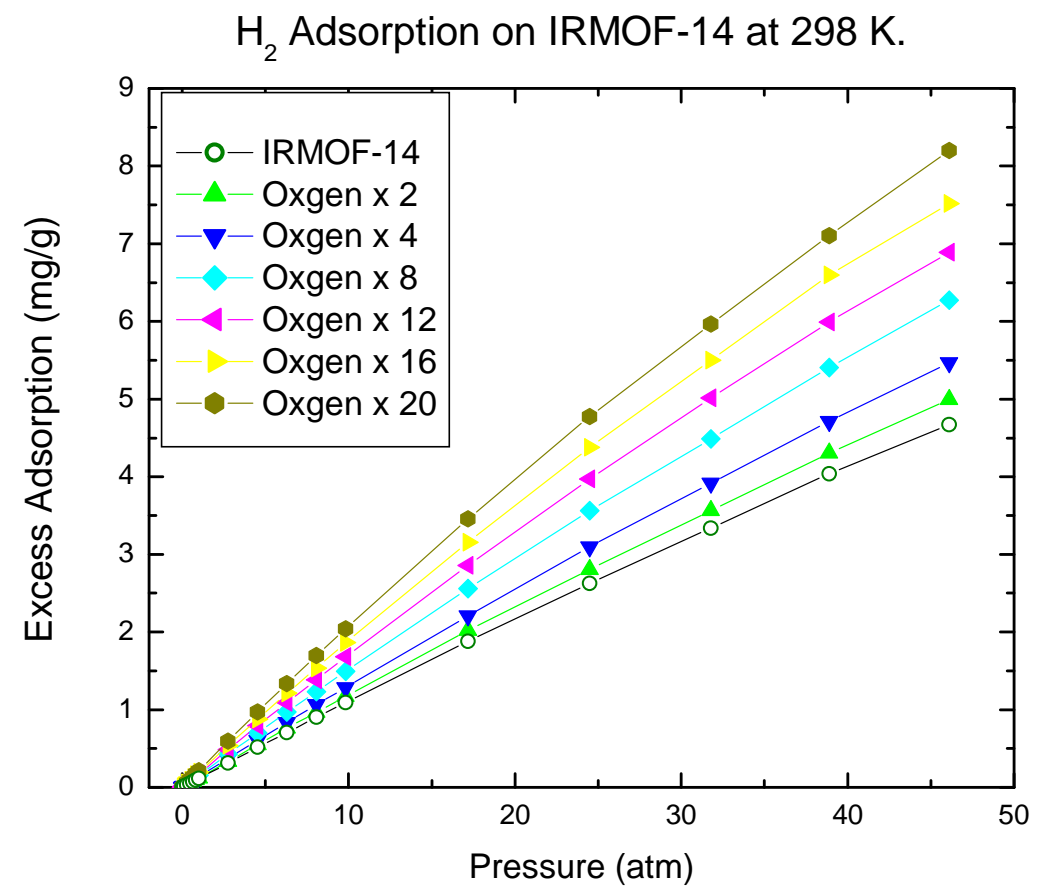

Figure 76. The adsorption isotherms for $\mathrm{H}_{2}$ on modified IRMOF-14 at $298 \mathrm{~K}$. The adsorption potential for the oxygen atoms in IRMOF-14 have been increased by factors of 2, 4, 8, 12, 16, and 20, as indicated in the legend. See Figure 75. 


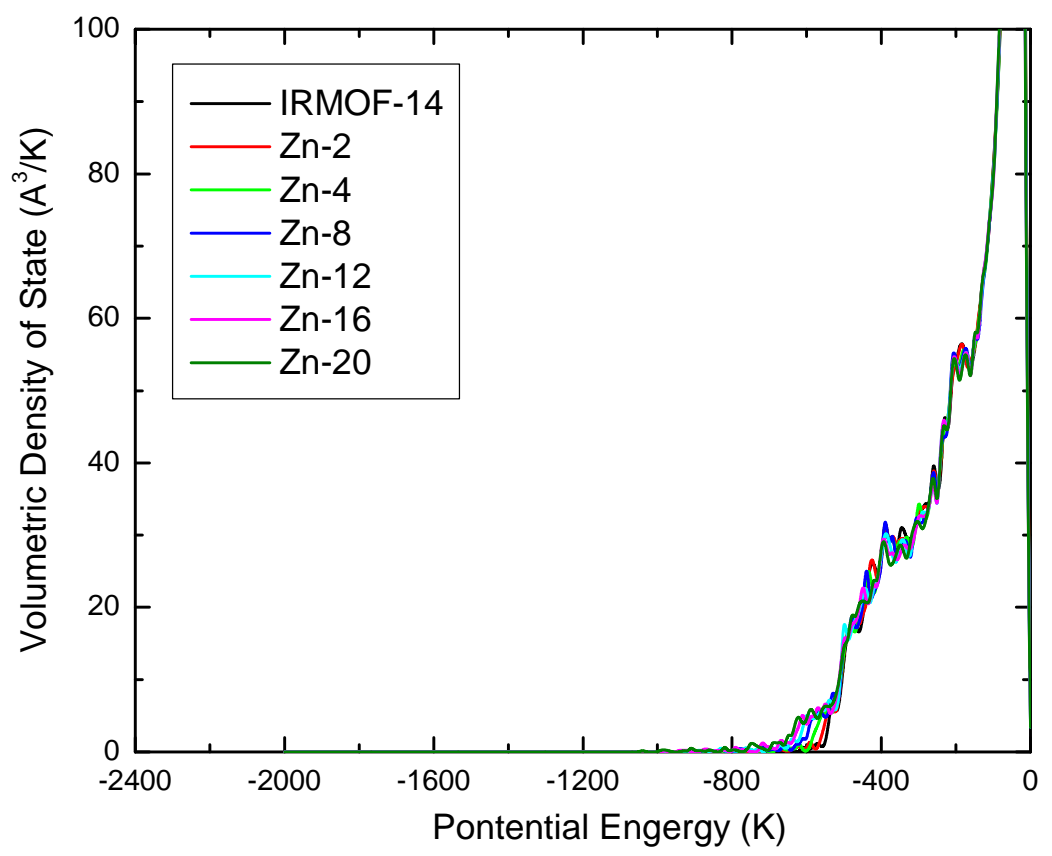

Figure 77. VDOS for IRMOF-14 with the standard potential parameters (black line) and with the potential for zinc changed by factors of $2,4,8,12,16$, and 20, as shown in the legend on the graph. 


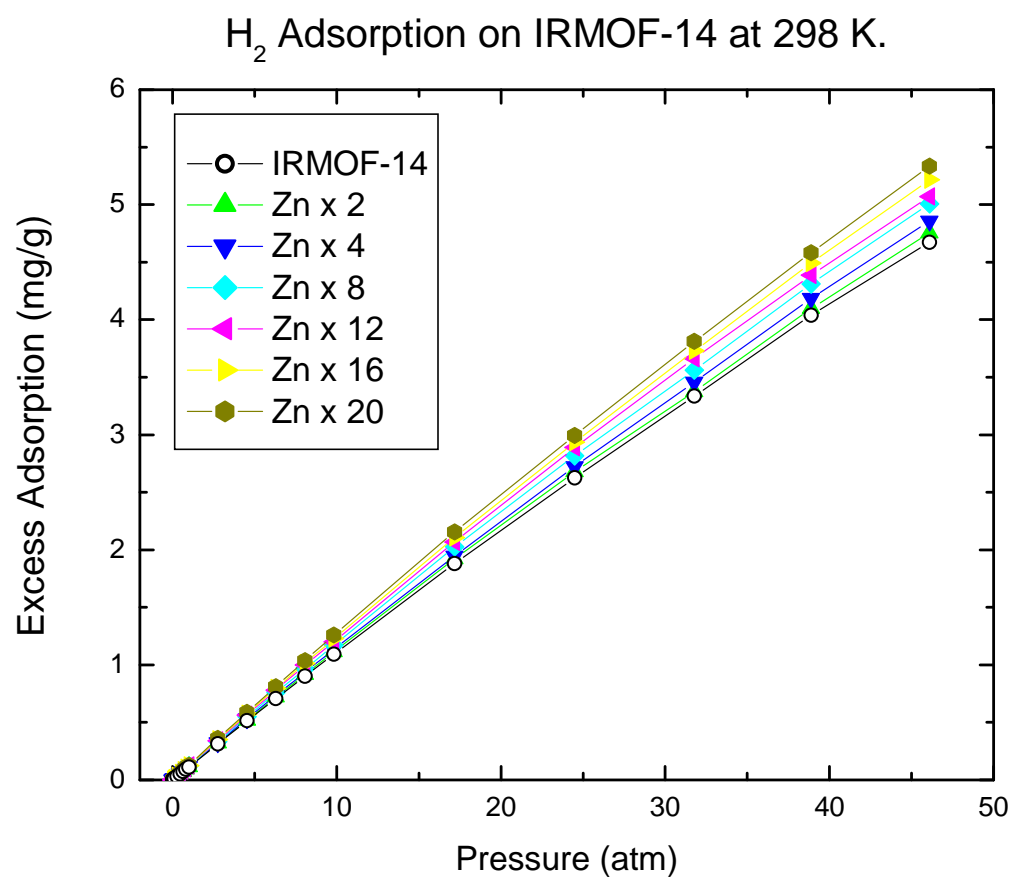

Figure 78. The adsorption isotherms for $\mathrm{H}_{2}$ on modified IRMOF-14 at $298 \mathrm{~K}$. The adsorption potential for the zinc atoms in IRMOF-14 have been increased by factors of 2, 4, 8, 12, 16, and 20, as indicated in the legend. See Figure 75.

\section{E. Pore-filling process for $\mathrm{H}_{2}$ in MOFs}

We have been studying the pore filling process for $\mathrm{H}_{2}$ adsorption in MOFs. We have used a histogram method for studying the pore filling process. We divided the simulation box into a number of small cubic bins (a total of 42,875 bins of which 21,050 are located in the pore void space), each with a volume of $0.405 \AA^{3}$. We have calculated the occupancy probability for $\mathrm{H}_{2}$ adsorption in each bin at a given pressure. We have sorted the bins in order of probability of occupancy. Summation over a fraction of sorted bins reveals the most probable location of adsorbate molecules within the sorbent at a given pressure and temperature. The number of bins that are required to give a specified value of the summation is a measure of how strongly localized the adsorbed atoms are. For example, a summation of 0.8 indicates that we are including the most probable locations for $80 \%$ of the adsorbed molecules. The fraction of bins that are summed over to reach 0.8 is a measure of the localization of the adsorption. We have plotted the summation of the probabilities as a function of the number of bins for pressures of $P=$ $0.1,1$, and 10 bar at $77 \mathrm{~K}$ for $\mathrm{H}_{2}$ adsorption in CuBTC in Figure 79. The number of bins needed to reach a given probability for low pressure is smaller than that needed for high-pressure adsorption, indicating that at low pressure the adsorption is more localized, as is expected. For example, from Figure 79 we see that at $P=0.1$ bar $80 \%$ of the molecules are adsorbed in $8.1 \%$ of the void space, while for $P=1,26 \%$ of the void space are required to hold $80 \%$ of the molecules 
and at 10 bar $47 \%$ of the void space are required. This clearly shows that at low pressure the adsorption is highly localized.

The spatial distribution of the bins in the MOFs with the highest occupancy probability reveals where adsorption is most likely to occur. For $\mathrm{H}_{2}$ adsorption in $\mathrm{CuBTC}$ at 0.1 bar, the distribution of bins are shown in Figure 80. For probability $=0.4$, the occupied bins are located in the corners of the tetrahedron structure or the pockets, which are close to the oxygen ligands binding the metal atoms. When probability increases to 0.7 , the other positions inside the pocket pore are also populated. The positions close to the linker in the main pore will be populated when the probability is increased to 0.8 as can be seen in Figure 80 (c). For $\mathrm{P}=1$ bar, the bins are distributed in four corner positions only up to probability $=20 \%$. When the probability increases to $30 \%$ and $40 \%$, the positions in the main pore are populated before the positions inside the pocket pore are fully populated. These are shown in Figure 81 (a)-(c). For a pressure of 10 bar, the filling process is: the four corner positions in the pocket pore are populated first for the probability up to $5 \%$ (Fig. 82 (a)), then the positions close to linker in the main pore are populated along with the population of the positions in the pocket pore, as can be seen in Figure 82 (b) and Fig. 82 (c).

The pore-filling processing shows that there are two adsorption regions for $\mathrm{H}_{2}$ adsorption in CuBTC: pocket pore and main pore. At low-pressure the adsorption is mainly in pocket pores, while with the increase of the pressure, the main pores begin to populate. The pocket pore is relatively small (about $5 \AA$ in diameter), thus the electrostatic interactions could be enhanced in this small region. This could be the major reason for simulations underestimate the experiments at low pressure regime. More sophisticated force field based on quantum mechanics calculations is needed to accurately account the low pressure adsorption.

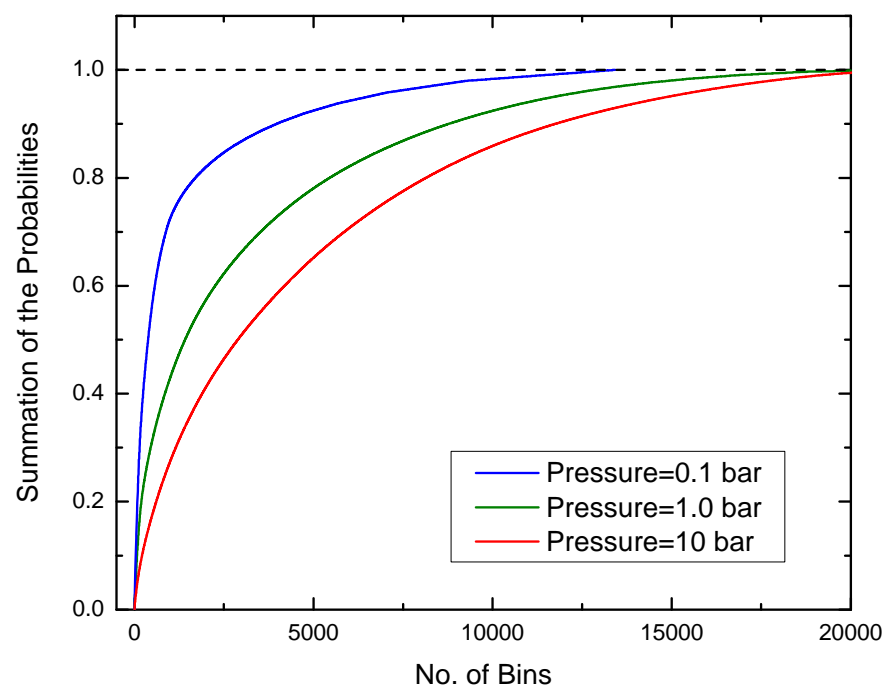

Figure 79: The Pore-filling Process for $\mathrm{H}_{2}$ Adsorption in $\mathrm{CuBTC}$ at $0.1,1.0$, and 10 bar and 77

$\mathrm{K}$. The size of the bin is $0.74 \times 0.74 \times 0.74 \AA$. 


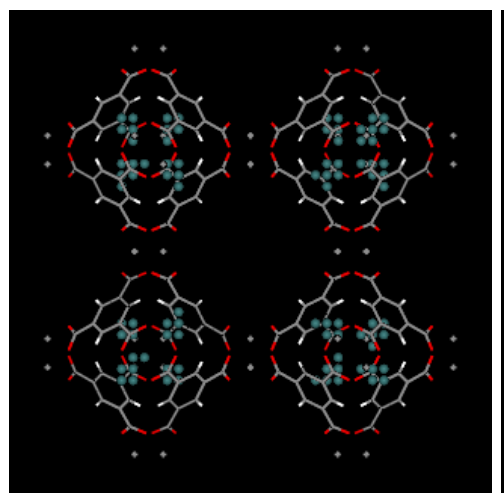

(a)

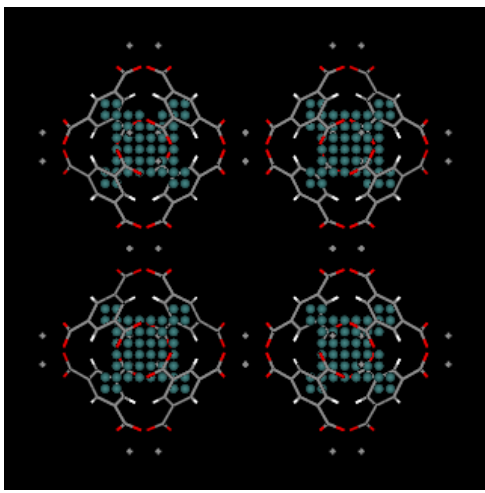

(b)

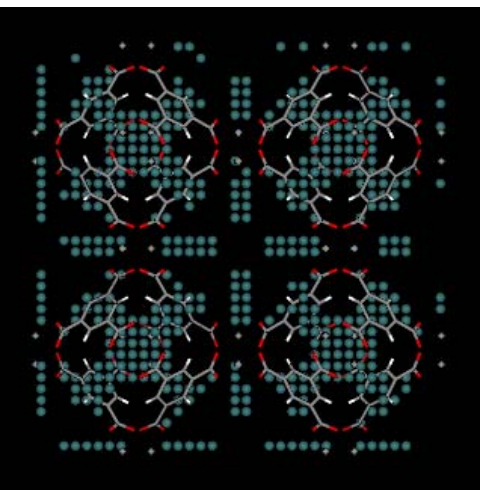

(c)

Figure 80: Distribution of bins for (a) probability $=40 \%$ (left figure) (b) probability $=70 \%$ (middle figure) (c) probability $=80 \%$ (right figure) at Pressure $=0.1 \mathrm{bar}$.

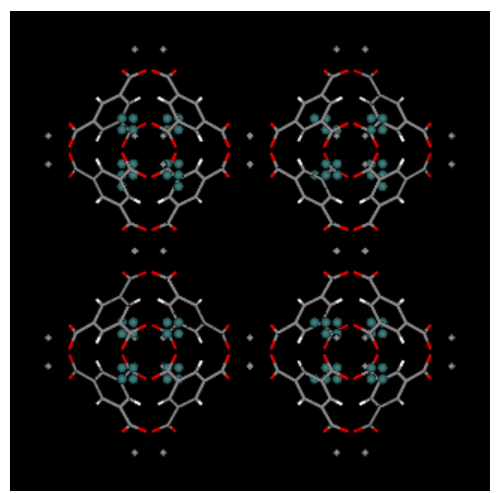

(a)

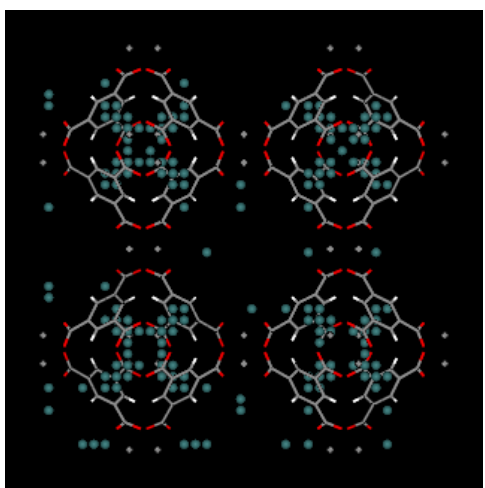

(b)

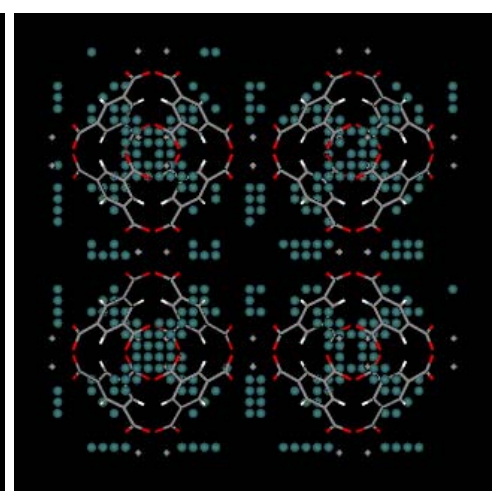

(c)

Figure 81: Distribution of bins for (a) probability $=20 \%$ (left figure) (b) probability $=30 \%$ (middle figure) (c) probability $=40 \%$ (right figure) at Pressure $=1$ bar.

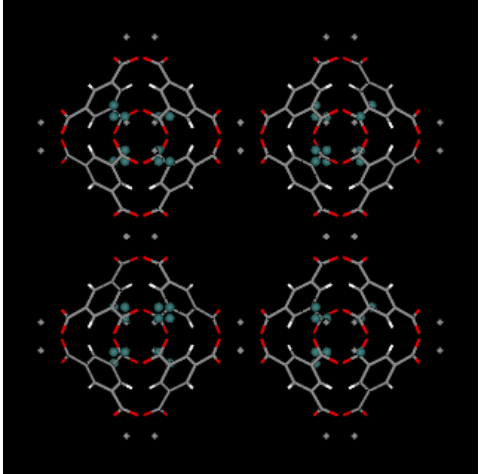

(a)

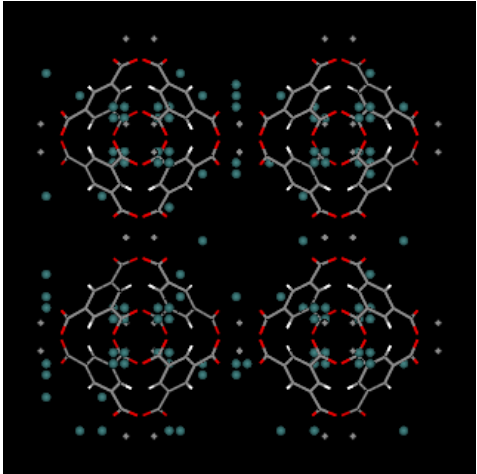

(b)

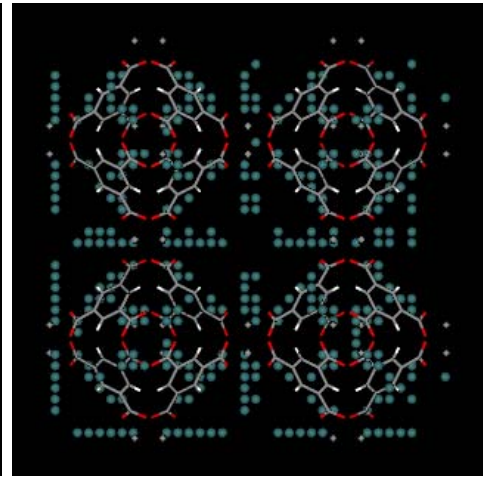

(c)

Figure 82: Distribution of bins for (a) probability $=5 \%$ (left figure) (b) probability $=10 \%$ (middle figure) (c) probability $=20 \%$ (right figure) at Pressure $=10 \mathrm{bar}$. 


\section{F. Diffusion properties for $\mathrm{H}_{2}$ in MOFs}

Apart from the equilibrium properties, the kinetic properties of gases in porous materials are also important for their practical applications. We have studied the diffusion coefficients for gases in MOFs.

\section{(1) Ar in CuBTC}

We have tested our calculations for argon diffusion in CuBTC. The self diffusivity for Ar in CuBTC at several loadings and temperatures are shown in Fig. 83. These results agree with Skoulidas' results (JACS, 126, 1356 (2004)) very well, indicating that our calculations are correct.

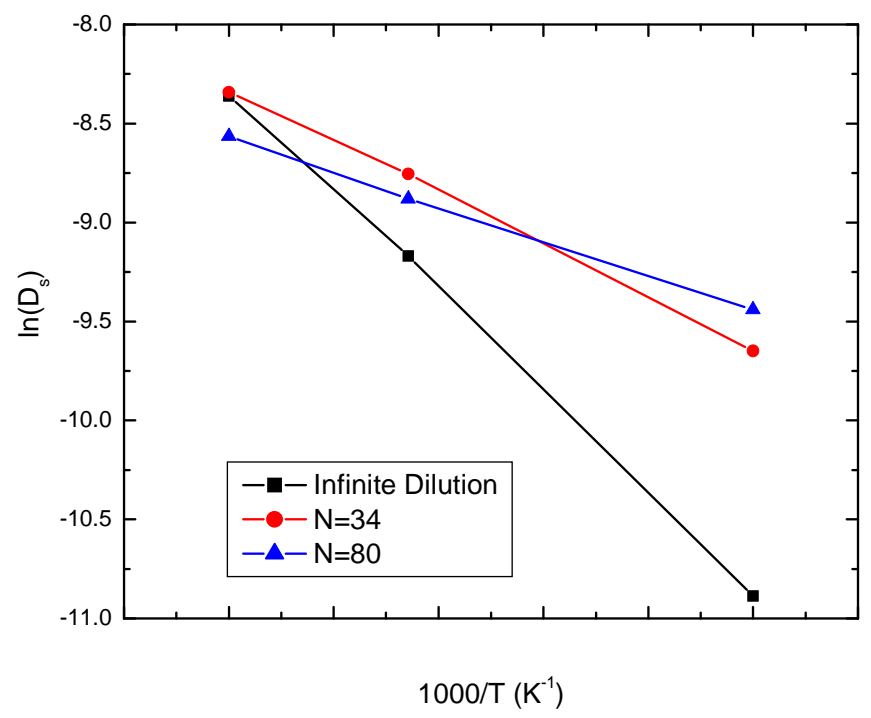

Figure 83. Arrhenius plot of $\mathrm{D}_{\mathrm{s}}$ for $\mathrm{Ar}$ in $\mathrm{CuBTC}$ at infinite dilution, 34, and 80 atoms per unit cell, at 200,298 , and $400 \mathrm{~K}$. The units of $\mathrm{D}_{\mathrm{s}}$ are $\mathrm{cm}^{2} / \mathrm{s}$.

\section{(2) $\mathrm{H}_{2}$ in Zn-BDC-TED}

We have studied the diffusivities for hydrogen in MOFs using Molecular Dynamics (MD) simulations. We have shown in our previous report that quantum effects are very important for hydrogen adsorption in MOFs at low temperature $77 \mathrm{~K}$; lead a decrease of about $30 \%$ in the amount of adsorbed at high pressures. We have incorporated Feynman-Hibbs effective Buch potential in the MD simulations to study the impact of quantum effects on the diffusion properties of hydrogen in MOFs. We have compared the self diffusivity and corrected diffusivity for hydrogen in Zn-BDC-TED at $77 \mathrm{~K}$ using classical Buch potential and FH effective Buch potential, as shown in Figs. 84 and 85. At the same loading, we can see that the self and corrected diffusivities decrease when quantum effects are taking into account, lead to a decrease of about 100\% at highest loading, as shown in Fig. 84 (a) and 85 (a). However, when we consider the diffusivity in terms of pressure, we see that the differences in self and corrected diffusivities become less for classical and FH effective potential, and the self diffusivity is actually greater when quantum effects are included, as can be seen in Fig. 84 (b). The reason for 
this is that the quantum fluid requires a significantly higher pressure to achieve a given loading than that for a classical fluid. The FH effective potential overcompensates for quantum effects at $298 \mathrm{~K}$ for adsorption; the classical Buch potential is a better approximation for $\mathrm{H}_{2}$ adsorption at room temperature. Thus we only show the results using the Buch potential in Fig. 86 and 87.

Practically, the transport diffusivity, $D_{t}(c)$, is more important and it is directly related to the macroscopic flux by Fick's Law

$$
J=-D_{t} \nabla c
$$

where $c$ is concentration. The transport diffusivity can be calculated via corrected diffusivity and thermodynamic correction factor,

$$
D_{t}(c)=D_{0}(c) \times\left(\frac{\partial \ln f}{\partial \ln c}\right)_{T}
$$

where $D_{0}(c)$ is the corrected diffusivity, $\left(\frac{\partial \ln f}{\partial \ln c}\right)_{T}$ is the thermodynamic correction factor, which can be calculated from adsorption isotherms.

We have calculated transport diffusivities for $\mathrm{H}_{2}$ in Zn-BDC-TED at 77 and $298 \mathrm{~K}$, shown in Figure 88 and 89. We have compared the transport diffusivities using the Buch potential and Feynman-Hibbs $(\mathrm{FH})$ effective Buch potential for $\mathrm{H}_{2}$ at $77 \mathrm{~K}$. Similar to the selfand corrected diffusivities, quantum effects on the transport diffusivity is very small, as can be seen from Figure 88. We also show the results at room temperature using the Buch potential. The transport diffusivities of hydrogen in Zn-BDC-TED at room temperature are the same order of magnitude as in IRMOF-1. Thus, we predict that adsorption of $\mathrm{H}_{2}$ in $\mathrm{Zn}$-BDC-TED is not kinetically limited.

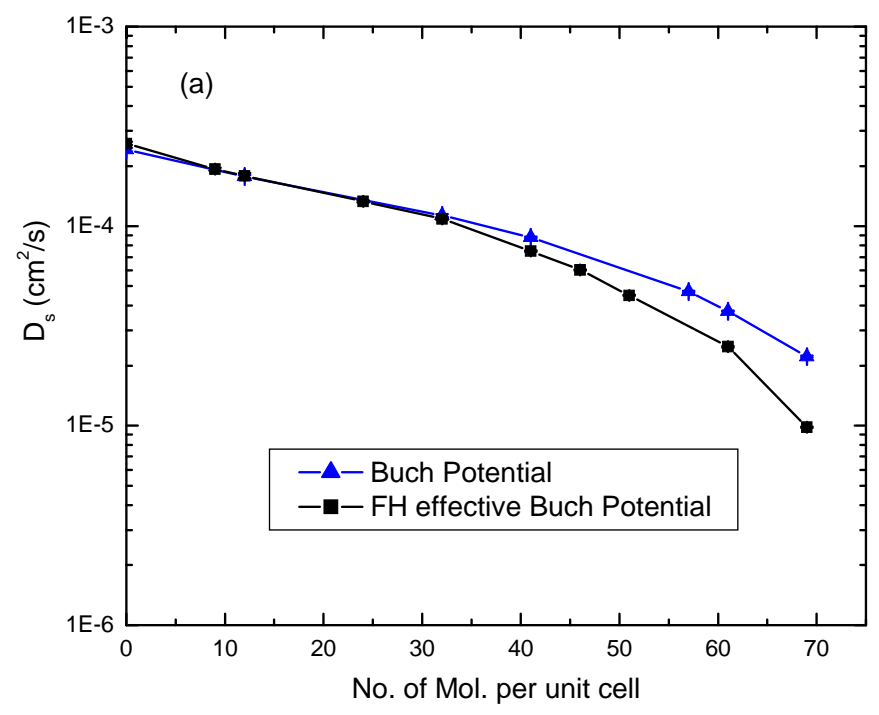




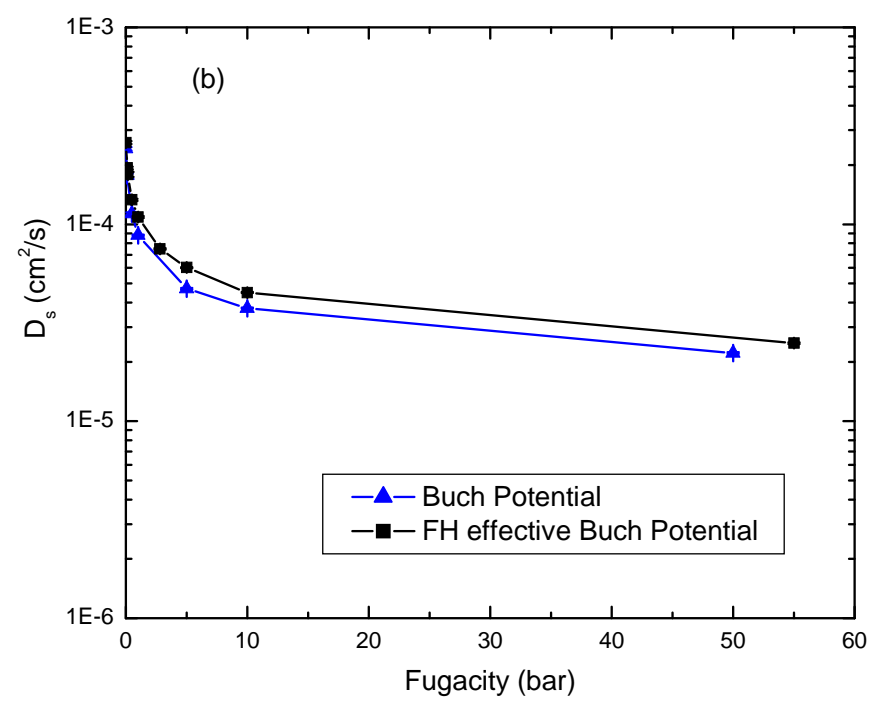

Figure 84: Self diffusivities of $\mathrm{H}_{2}$ in $\mathrm{Zn-BDC-TED}$ at $77 \mathrm{~K}$, (a) as a function of loading and (b) as a function of external fugacity (pressure).

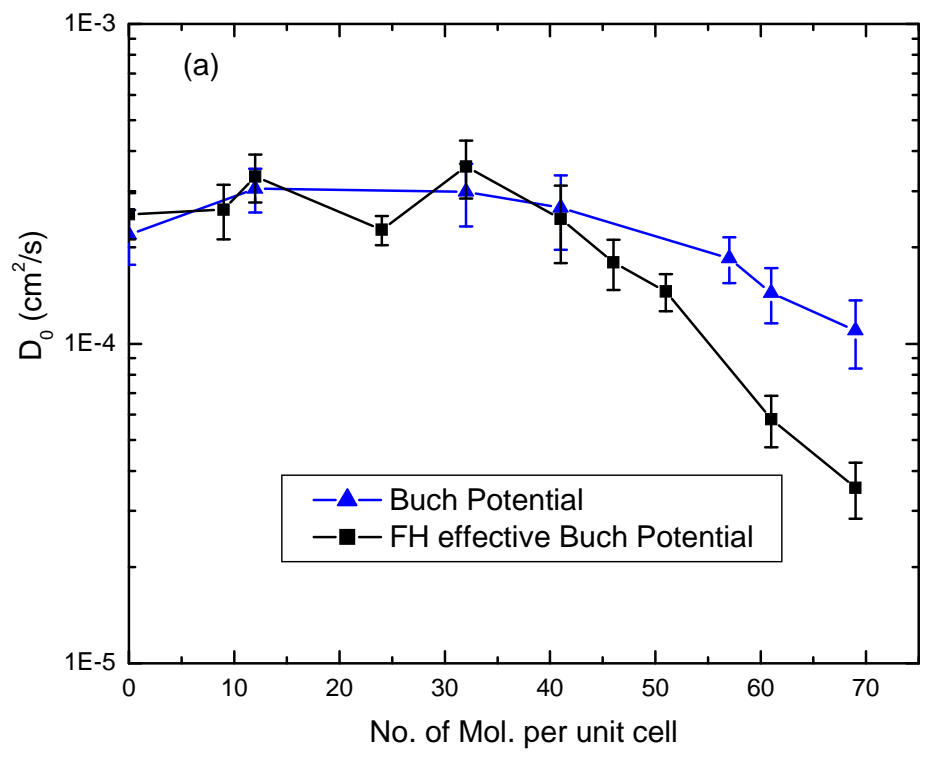




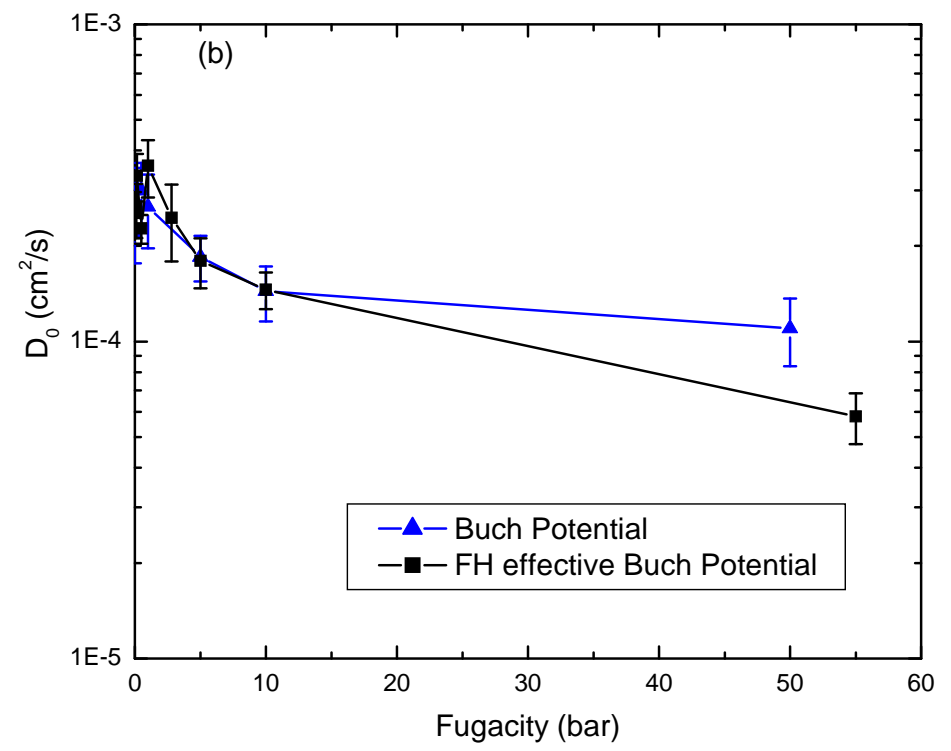

Figure 85: Corrected diffusivities of $\mathrm{H}_{2}$ in $\mathrm{Zn-BDC-TED} \mathrm{at} 77 \mathrm{~K}$, a) as a function of loading and (b) as a function of external fugacity (pressure).

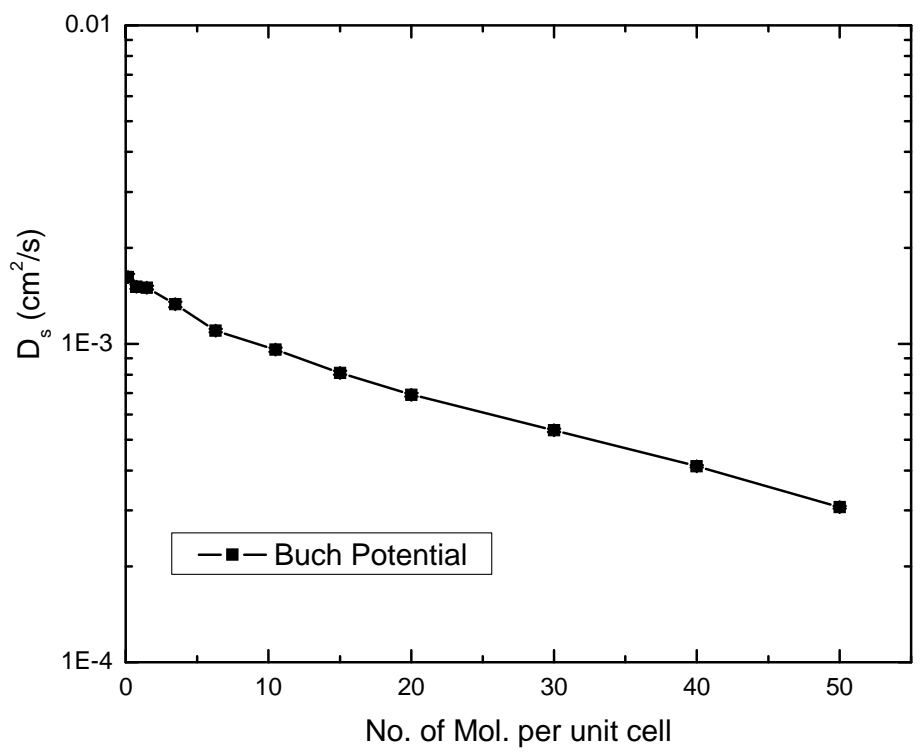

Figure 86: Self diffusivities of $\mathrm{H}_{2}$ in $\mathrm{Zn-BDC-TED} \mathrm{at} 298 \mathrm{~K}$. 


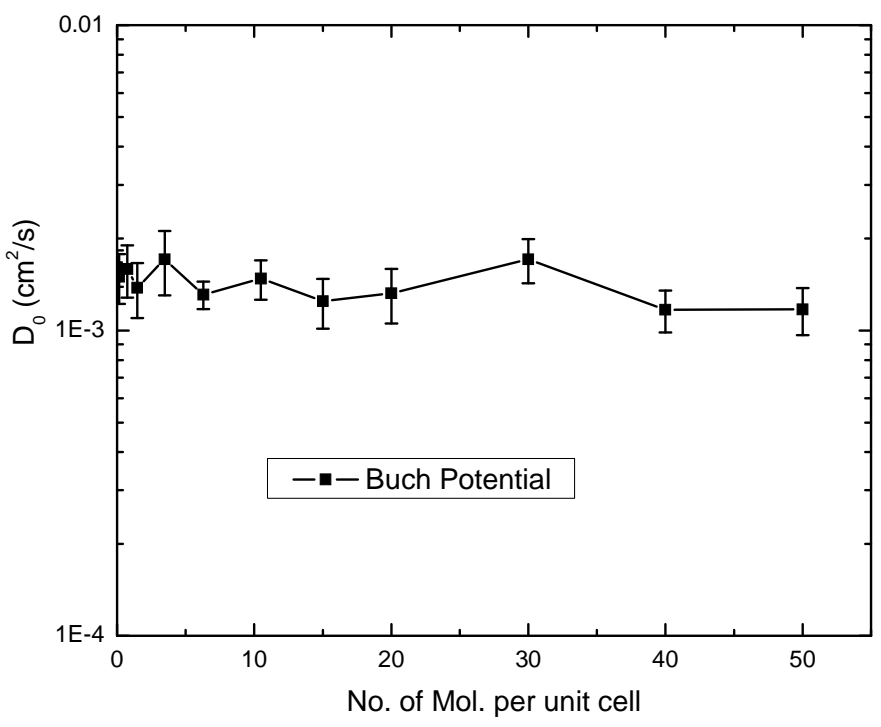

Figure 87: Corrected diffusivities of $\mathrm{H}_{2}$ in Zn-BDC-TED at $298 \mathrm{~K}$.

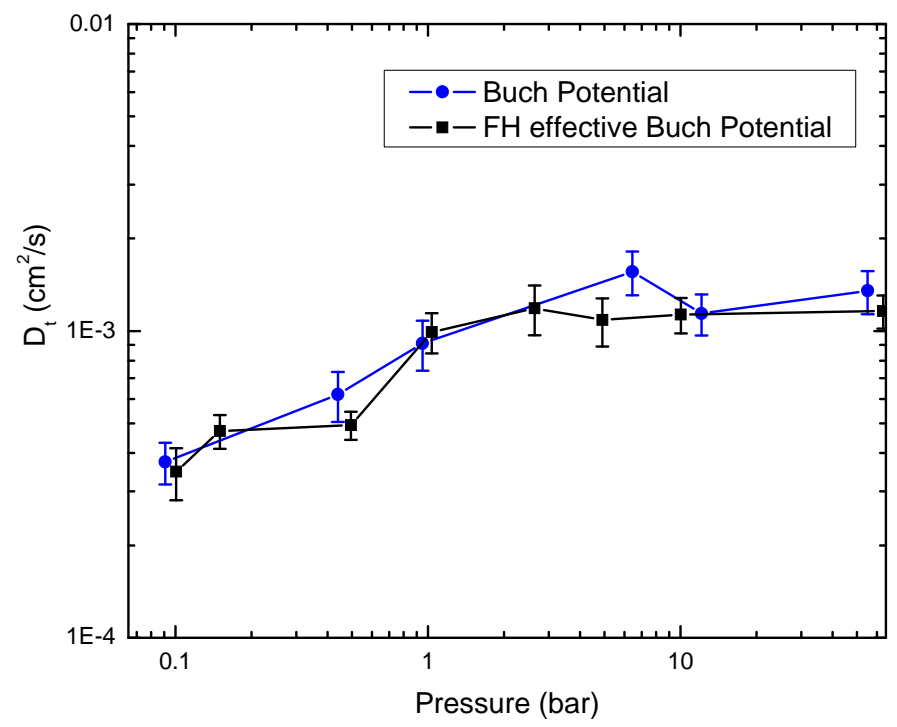

Figure 88: Transport diffusivities of $\mathrm{H}_{2}$ in Zn-BDC-TED at $77 \mathrm{~K}$. 


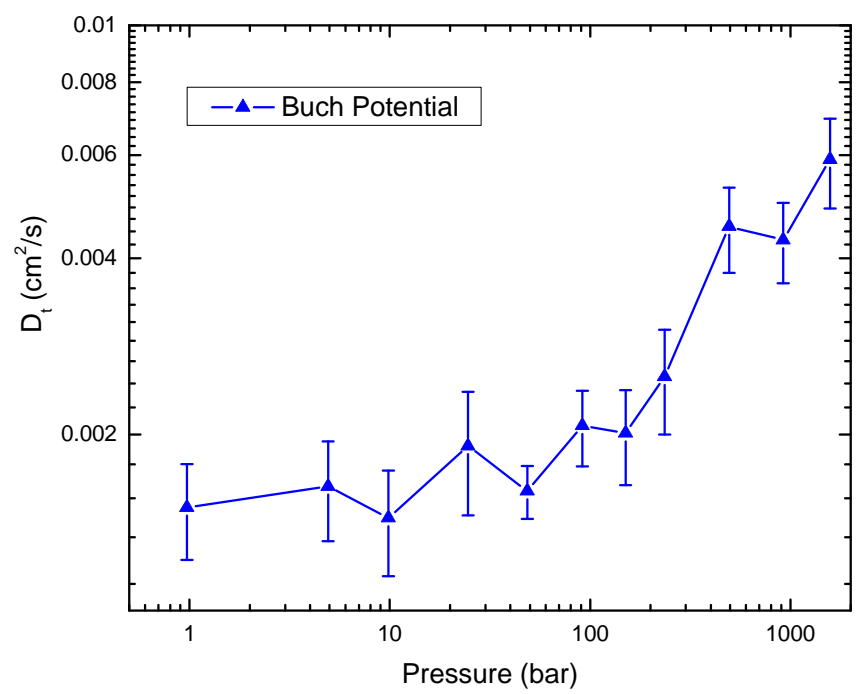

Figure 89: Transport diffusivity of $\mathrm{H}_{2}$ in Zn-BDC-TED at $298 \mathrm{~K}$.

\section{(3) $\mathrm{H}_{2}$ in $\mathrm{Zn}-\mathrm{TBIP}$}

[Zn(tbip)] has 3D network structure containing 1D open channels in $c$-axis ( $z$ direction), as shown in Figure 90. We have simulated the adsorption isotherms for $\mathrm{H}_{2}$ in [Zn(tbip)] and compared with experiments (Figure 32). The experimental adsorption and desorption isotherms have a big hysteresis, however the simulated adsorption and desorption isotherms show no hysteresis. One possible reason for the big hysteresis in experimental isotherms is that the diffusivities of $\mathrm{H}_{2}$ in [ $\mathrm{Zn}$ (tbip)] is very slow, and the equilibrium time in the experiments is not long enough to allow the adsorbate to diffuse into the material. We have calculated the diffusivities for $\mathrm{H}_{2}$ in [ $\mathrm{Zn}$ (tbip)] and compared with the diffusivities in [ $\mathrm{Zn}$ (bdc)(ted) $)_{0.5}$ ], shown in Figure 5-9. The diffusivities of $\mathrm{H}_{2}$ in [ $\mathrm{Zn}$ (tbip)] in $\mathrm{x}$ and y directions are about two order of magnitude smaller than in $\mathrm{z}$ directions, this indicates that the pores in [ $\mathrm{Zn}$ (tbip)] are primarily one dimension in $\mathrm{z}$ direction, coincides with what we can see from Figure 90. The selfdiffusivities of $\mathrm{H}_{2}$ in [ $\mathrm{Zn}$ (tbip)] at $77 \mathrm{~K}$ is about two order of magnitude smaller than in $\left[\mathrm{Zn}(\mathrm{bdc})(\mathrm{ted})_{0.5}\right]$, as can be seen in Figure 91 . The very slow diffusivity is one of the possible reasons for the great hysteresis in experimental adsorption/desorption isotherms. We have suggested doing adsorption/ desorption experiments using longer equilibrium time to verify if the slow diffusivity is the major reason for the hysteresis.

We have also shown the corrected diffusivities for $\mathrm{H}_{2}$ in [ $\mathrm{Zn}$ (tbip)] at $77 \mathrm{~K}$ in Figure 92. The self-diffusivities increase with the loading smoothly, but the corrected diffusivities have large fluctuation with the increase of loading when we used 40 trajectories and 8 ns for each trajectory in the MD simulations. We have studied the effect of the length of the simulation time on the corrected diffusivities. When longer simulation time (40 ns) was used, the corrected diffusivities become smooth with the increase of loading. This indicates that longer simulation time is needed to get reliable results for this material. Another interesting phenomenon is that the self-diffusivity increases with the increase of loading, this is different from the properties of 
gases diffusion in the other porous materials, in which the self-diffusivity decreases with the increase of loading.

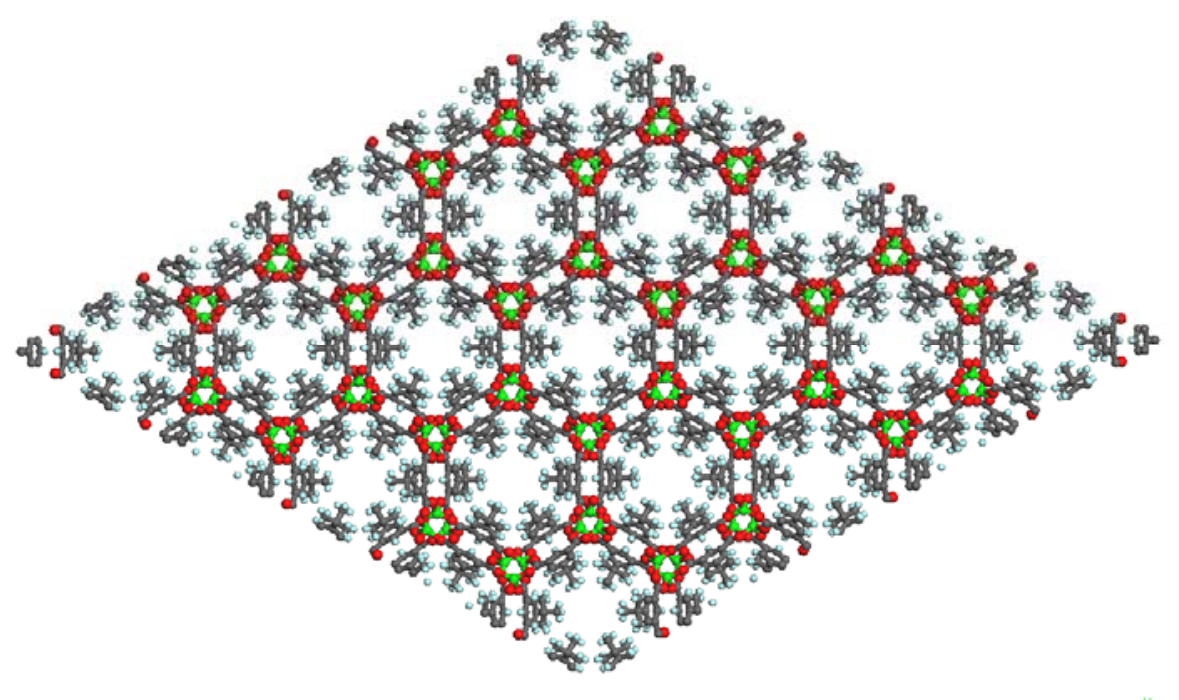

Figure 90:View of the crystal structure [Zn(tbip)] along the $c$-axis. Zn (green), O (red), C (dark gray), $\mathrm{H}$ (light gray).

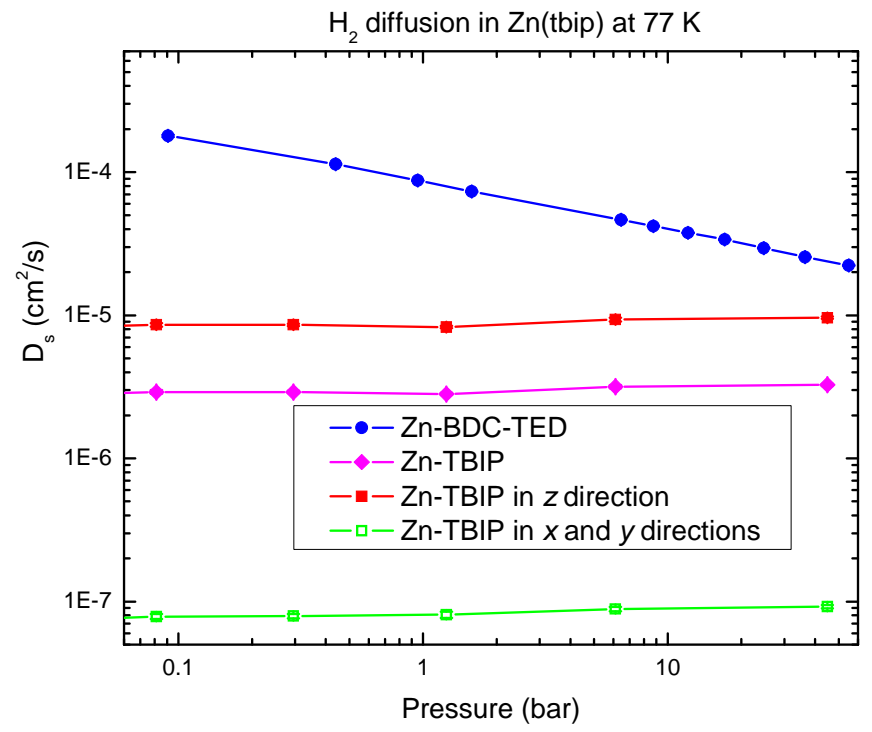

Figure 91: Comparison of self-diffusivity for $\mathrm{H}_{2}$ in $\left[\mathrm{Zn}(\right.$ tbip) $]$ and $\left[\mathrm{Zn}(\mathrm{bdc})(\text { ted })_{0.5}\right]$ at $77 \mathrm{~K}$. 


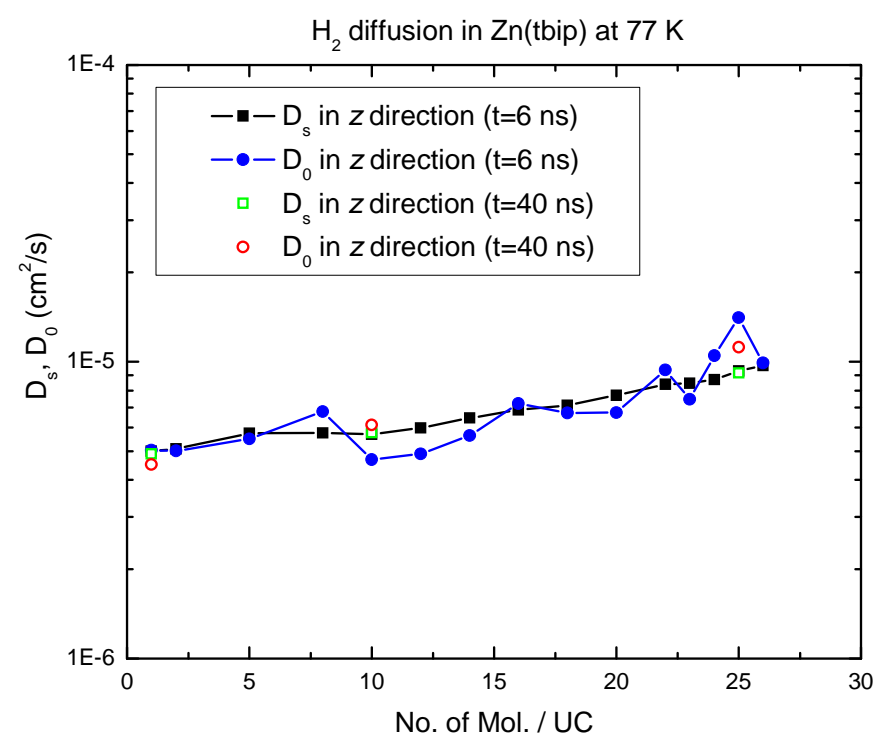

Figure 92: Self- and corrected diffusivities in z direction of the crystal for $\mathrm{H}_{2}$ in [ $\mathrm{Zn}$ (tbip)] at 77 K. (The diffusivities in $\mathrm{x}$ and $\mathrm{y}$ directions are about two order of magnitude smaller than in $\mathrm{z}$ direction, not shown in the figure.)

\section{CONFERENCE PRESENTATIONS, INVITED TALKS AND PUBLICATIONS}

1. Karl Johnson, Giovanni Garberoglio "Hydrogen Storage in Metal Organic Frameworks: Predictions from Computer Simulations", Symposium on Materials for the Hydrogen Economy, Materials Science \& Technology 2005 Pittsburgh, Pennsylvania, September 25-28, 2005.

2. J. Karl Johnson1, Sudhakar V. Alapati, Bing Dai, Giovanni Garberglio, David S. Sholl, "Computational Studies of Hydrogen Storage: Metal Organic Frameworks and Destabilized Metal Hydrides", W. E. Heraeus Seminar on Hydrogen Storage with Novel Nanomaterials, Bad Honnef, Germany, 23-27 October, 2005.

3. Jinchen Liu, Bing Dai, J. Karl Johnson, R.T. Obermyer, S.G. Sankar, Long Pan, Jing Li, and Giovanni Garberoglio. "Modeling Hydrogen Adsorption in Microporous MetalOrganic Frameworks", AIChE Annual Meeting, San Francisco, CA, 12-17 November 2006.

4. Jinchen Liu, Jeffrey T. Culp, Sittichai Natesakhawat, Bradley C. Bockrath, Brian Zande, S. G. Sankar, Giovanni Garberoglio, and J. Karl Johnson. "Experimental and Theoretical Studies of Gas Adsorption in $\mathrm{Cu}_{3}(\mathrm{BTC})_{2}$ : An Effective Activation Procedure". J. Phys. Chem. C., 2007, 111, 9305. 
5. Jinchen Liu, Jeong Yong Lee, Long Pan, Richard T. Obermyer, Satoru Simizu, Brian Zande, Jing Li, S.G. Sankar, J. Karl Johnson ,"Adsorption and Diffusion of Hydrogen in a New Metal-Organic Framework Material: [Zn(bdc)(ted)..5]", J. Phys. Chem. C., 2008, 112, 2911.

6. Xu, D. J.; Pan, L.; Emge, T. J.; Huang, X. -Y.; Li, J. Acta Cryst., 2006, C62, m150

7. $\quad$ Park, H. S.; Britten, J. F.; Mueller, U.; Lee, J. Y.; Li, J.; Parise, J. B. Chem. Mater., 2007, 19, 1302-1308.

8. Yuen, T.; Danilovic, D.; Li, K.-H.; Li, J. J. Appl. Phys., 103, $07 \mathrm{~B} 725$ (2008).

9. Pan, Y.; Li, K.-H.; Bi, W.-H.; Li, J. Acta Cryst. C, Submitted.

10. Li, J. "Microporous Metal Organic Frameworks: New Materials for Gas Separation and Storage”, ExxonMobil Research \& Engineering Co., Annandale, NJ, September 20, 2005.

11. Li, J. "New Materials for Hydrogen Storage: Recent Development on Microporous Metal Organic Frameworks (MMOFs)", 9th Conference on Solid State Chemistry and Inorganic Synthesis, Beijing, China, October 9-11, 2005.

12. Li, J. "Microporous Metal Organic Frameworks: New Materials for Gas Separation and Hydrogen Storage", Fujian Institute of Research on the Structure of Matter, Chinese Academy of Sciences, Fuzhou, Fujian, China, October 12, 2005.

13. Li, J. "New Sorbent Materials: Recent Development on Microporous Metal Organic Frameworks (MMOFs)", Shanghai JiaoTong University, Shanghai, China, October 13, 2005.

14. Li, J. "Microporous Metal Organic Frameworks (MMOFs): New Materials Promising for Gas Separation and Storage", First International Symposium on Chemistry of Coordination Space, Okazaki, Nagoya, Japan, November 14-15, 2005.

15. Li, J. "Microporous Metal Organic Frameworks (MMOFs): New Sorbent Materials Promising for Gas Separation and Storage", Kyoto University, Kyoto, Japan, November $16,2005$.

16. Pan, L.; Lee, J.Y.; Huang, X.-Y.; Li, J. "New Materials for Hydrogen Storage: Recent Development on Microporous Metal Organic Frameworks (MMOFs)", Fall 2005 MRS Meeting, Boston, MA, November 28 - December 2, 2005.

17. Li, J. "Recent Development on Microporous Metal Organic Frameworks (MMOFs): New Materials Promising for Gas Separation and Storage", University of Science and Technology, Hefei, China, July 6, 2006.

18. Pan, L.; Lee, J. Y.; Li, J. "Design, Synthesis, Structure Characterization and Low Temperature Hydrogen Sorption of Microporous Metal Organic Frameworks (MMOFs)", Fall 2006 MRS Meeting, Boston, MA, November 27 - December 1, 2006. 
19. Li, J. "New Materials for Hydrogen Storage: Current Development on Microporous Metal Organic Frameworks", National Institute of Advanced Industrial Science and Technology (AIST), Osaka, Japan, January 22, 2007.

20. Li, J. "Microporous Metal Organic Frameworks: New Sorbent Materials for Hydrogen Storage”, Energy Day, Rutgers University, May 24, 2007.

21. Li, J. "Developing Multifunctional Microporous MOF Based Materials”, Organic Magnetism Symposium, Oak Ridge National Lab, Oak Ridge, TN, July 16-17, 2007.

22. Li, J. "A New Family of Sorbent Materials: Porosity and Possible Applications in Gas Storage and Separation”, Nankai University, Tianjin, P.R. China, August 17, 2007.

23. Li, J. "Developing Multifunctional Microporous Metal-Organic Framework Materials for Gas Storage and Separation”, Haverford College, Haverford, PA, September 14, 2007.

24. Li, J. "Microporous Metal Organic Frameworks as Functional Materials for Gas Storage and Separation", $5^{\text {th }}$ National Symposium on Structural Chemistry, Fuzhou, P.R. China, October 25-31, 2007.

25. Li, J. "MMOFs: Porosity and Potential Applications", South China University of Technology, Guangzhou, P. R. China, October 30, 2007. 